九州大学学術情報リポジトリ

Kyushu University Institutional Repository

\title{
Size Of Farm Observed Through The Law Of Decreasing Returns
}

Ishigame, Toshizo

Department of Agriculture, Kyushu Imperial University

https://doi.org/10.5109/22565

出版情報 : 九州大学大学院農学研究院紀要. 3 (8)，pp.179-250，1933-02. Kyushu Imperial University バージョン：

権利関係 : 
Journal of the Department of Agriculture, Kyushu Imperial University, Vol. 3, No. 8

February 25, 1933

\title{
SIZE OF FARM OBSERVED THROUGH THE, LAW OF DECREASING RETURNS
}

\author{
Toshizo Ishigame
}

(With Fifty-four Iïgures and Eirght I'lates)

\section{CONTENIS}

\section{Introduction}

A. Method of investigation.

B. Principal terms used.

C. Iaw of decreasing returns.

I). Intensity of culture.

F. Goals considered.

F. Conditions adhered to.

II. Properties of decreasing return curves

I. Relations between product curves and intensities of culture.

A. Case where area of land is given.

B. Case where area of land is not fixed.

I) Case where, as 1 (land) increases, both $P$ (quantities of product) and $\mathbf{I}$. (substances combined to compose production elements except land) increase in proportion with 1.

2) Case where $I$, to obtain $P$ proportional to 1 increases, as 1 increases, not in proportion with 1 .

3) Other cases.

II. Relations between price curves and intensities of culture.

A. Case where prices of products and of all production elements are fixed.

A) Case where area of land is given.

(I) Case of fixed tenancy by money.

(2) Case of share tenancy by money.

(3) Case of tenancy by substance.

13) Case where area of land is not fixed.

I) Case where, as 1 increases, both $p$ (costs of products) and $\mathrm{L}$ increase in proportion with 1 .

2) Case where $I$, to obtain p proportional to 1 increases, as 1 increases, not in proportion with $\mathrm{I}$.

3) Other cases.

B. Case where prices of products and of all production elements are not fixed. 
III. Proper combinations of production elements

I. Proper combinations of two elements to win the goals when all other elements are kept fixed.

II. Proper combinations of all elements to win the goals.

A. Case of the utmost profitable combination.

B. Cases to win other goals.

III. Extent of application.

A. When the production elements are fixed or limited in quantities.

13. Carses to win mixed goals.

C. The production elements which are not economic goods.

I). Determination of size of farm.

E. Application to other enterprises and industries.

(I) Animal husbandry.

(2) Others.

IV. Discussion and conclusion

Literature.

\section{INTRODUCTION}

As is widely known, in connection with the agricultural production, there are stated several kinds of laws of decreasing returns on profit, and most of them are concerned either with the amount of the products and the cost of the production elements or with the amount of the products and the substantial quantities of the individual production elements, while that stated by $\mathrm{H}$. C. Taylor about the crop farming on a certain land is concerned with the amount of the products and the substantial quantities of the combined production elements in combination. According to my investigation of his explanation, if the data are sufficiently obtained, the problem of the proper size of the farm can fairly be solved by the law, so far as observed from the stand-point of the combinations of the production elements. This essay contains the essential points of the investigation.

\section{A. METHOD OF INVESTIGATION}

In this investigation a graphical method applied to the curves is adopted, the reasons being:-

(I) On treating the groups of the continuous numerals, it is most convenient and essential to adopt graphical method, because by treating in this way it is possible to know easily the general features of the groups and the exact values and positions of the maxima and minima. 
(2) The numerals on the agricultural concerns are too much complicated to be treated by the algebraical formulae. There may be some cases where they answer the purpose, but such cases are limited by the several conditions and accordingly the circles of their applications are unavoidably narrow. The only suitable way of fully. treating such numerals is, I believe, the graphical method applied to the curves.

(3) The graphical method, if once fully understood, is easy to apply in almost all cases and is quite clear and convenient to compare the quantities of the several production elements and to investigate the relations existing among them.

(4) By using the curves, we can absolutely avoid such mistakes that are apt to lead to disregard the continuity existing among the numerals or to confuse the increments and the totals.

\section{B. PRINCIPAL TERMS USED}

The conventional meanings of the principal terms used in this investigation are as follows :-

Manual power $=($ family-labour $)+($ hired labour $)=M^{*}$

Price of manual power $=$ (estimated wages of family-labour $)+$ (wages payed for hired labour $)=\mathrm{m}$.

Equipment $=$ (buildings $)+($ machinery and tools $)+($ working animals $)$ $+($ fodder for working animals $)=\mathrm{F}^{*}$

Cost of equipment $=($ cost of buildings $)+(\operatorname{cost}$ of machinery and tools $)+($ cost of working animals $)=$ (building depreciation $)+($ expense of maintaining buildings) + (expense of working, repairing and substituting machinery and tools $)+($ expense of maintaining working animals $)=e$

Nourishing material $=$ (manures and fertilizers $)+($ irrigation water $)$ $=\mathrm{N}^{*}$

Price of nourishing material $=$ cost of manures and fertilizers and of irrigation water $=n$

Seed $=\mathrm{S}$

Price of seed $=\mathrm{s}$

Economic substances combined to compose the production elements, except land $=\mathrm{M}+\mathrm{E}+\mathrm{N}+\mathrm{S}=\mathrm{I}^{*}$

Price of the said substances $=m+e+n+s=l c$

* In the formulae, the sign + does not mean the addition in mathematics lut it means the combinations. 
Taxes and the other charges on $M=t_{m}$.

Taxes and the other charges on $\mathrm{E}=\mathrm{t}_{e}$

Taxes and the other charges on $\mathrm{N}=\mathrm{t}_{n}$

Taxes and the other charges on $\mathrm{S}=\mathrm{t}_{s}$

Taxes and the other charges except those imposed on land $=$ $\mathrm{t}_{m}+\mathrm{t}_{e}+\mathrm{t}_{n}+\mathrm{t}_{s}=\mathrm{t}$

Land $=1$

Price for using land=r. This is different in qualities in the case of renting and in the case where the land is owned. In the latter case, however, the price will be commonly estimated by the land rent prevailing; so in this investigation it is assumed to be the same as the land rent in which the taxes and all other charges imposed on land are included, and the discussions on the latter case are entirely omitted. In the former case, there being the several kinds of the tenancy, some typical ones are selected for consideration and abbreviated as follows :-

\begin{tabular}{l|c|c}
\hline \hline Land rent & Fixed & Share \\
\hline Money & $\mathrm{rl}$ & $\mathrm{rs}$ \\
\hline Substance & $\mathrm{r}$ \\
\hline
\end{tabular}

Quantities of products $=P$

Price of products $=$ gross return $=p$

Total $\cos t=l c+t+r$

Total cost excluding price for using land $=1 \mathrm{c}+\mathrm{t}$

Gross profit $=($ gross return $)-($ total cost excluding price for using land $)=\mathrm{p}-(\mathrm{lc}+\mathrm{t})=\mathrm{Gp}$

Net profit $=($ gross return $)-($ total cost $)=p-(l c+t+r)=N p$.

\section{LAW OF DECREASING RETURNS}

\section{Meaning}

So called law of decreasing returns on profit can be classified into three, one being concerned with the amount of the products and the cost of the production elements, another with the amount of the products and the substantial quantities of the individual elements and the other with the amount of the products and the substantial quantities of the 
production elements in combination. In this investigation the last case is taken for discussion and can be divided into three kinds, namely

(I) that which expresses the state of production due to the physiological properties of the crop in connection with the production elements,

(2) that which includes, besides (I), all artificial means to carry on and complete the production as the industry, such as operations for land preparation, process of sowing and harvesting, treatments after harvesting, etc., and

(3) that which is intermediate of (I) and (2).

( I) may be called the physiological law of decreasing returns and does not form the direct object of the investigation with regard to the size of farm. To discuss the size of farm, we must take (2) as the object of investigation and it may be called the technical law of decreasing returns. What is called the law of decreasing returns in this investigation is this technical one concerned with the amount of the products and the substantial quantities of the production elements in combination, unless otherwise specified.

\section{Limits}

In this investigation, two kinds of the farming limits are granted to exist technically i.e. (1) that owing to the limit of I, applicable on a given 1 and (2) that owing to the limit of 1 available under a given $\mathrm{L}$, because the farming must be realized to accomplish its object by utilizing 1 and L.

\section{Treatment}

In Fig. I, if $\mathrm{P}^{\prime}$ curve is the curve of decreasing increments of returns, the $\mathrm{P}$ curve, which is plotted by integrating the curve $\mathrm{P}^{\prime}$ along the axis $O X$, is the curve of the total products and its realization is nothing but the result of the existence of those properties which are shown by the curve $\mathrm{P}^{\prime}$. Hence, in this investigation we take the $\mathrm{P}$ curve instead of $\mathrm{P}^{\prime}$ curve as the object of discussion.

For the sake of reference are shown below some relations between the $\mathrm{P}$ curve and the $\mathrm{P}^{\prime}$ curve.

(I) The point on $\mathrm{P}$ curve, which has the same $\mathrm{L}$ as the highest point of $\mathrm{P}^{\prime}$ curve, is the point of inflexion of $\mathrm{P}^{\prime}$ curve i.e. the portion of $\mathrm{P}$ curve which lies between the origin and the point is concaved to 
the upward and the portion which lies on the right hand side of the point is convexed to the upward.

(2) The point on $\mathrm{P}$ curve, which has the same $\mathrm{L}$ as the point where $\mathrm{P}^{\prime}$ curve comes to cross the axis $\mathrm{OX}$ as it decreases, is the highest point of $\mathrm{P}$ curve above $\mathrm{OX}$.

(3) The point on $P$ curve, which has the same $I$, as the point of $\mathrm{P}^{\prime}$ curve where the curve $\mathrm{P}^{\prime}$ intersects with the curve of $\mathrm{P} / \mathrm{L}$ or the curve of the quotients of the areas of $\mathrm{P}^{\prime}$ curve divided by the corresponding $L$, is the tangent point of the tangent line drawn from the origin to the $\mathrm{P}$ curve.

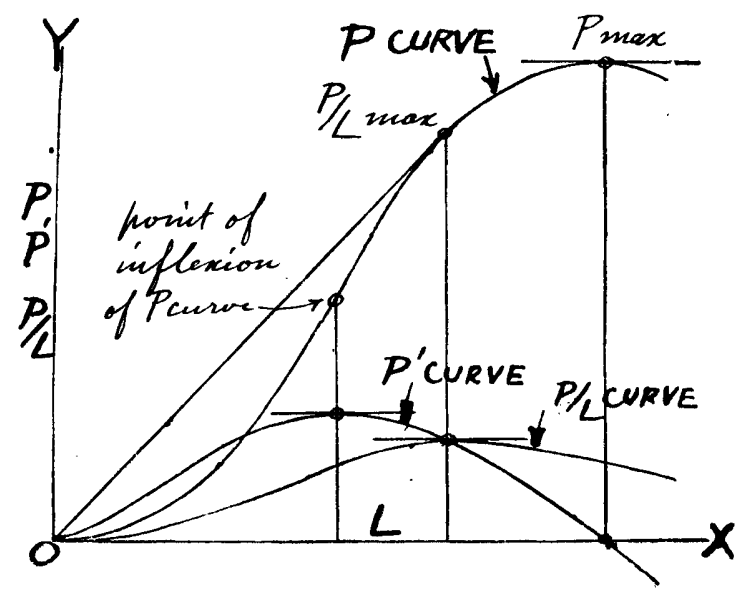

Fig. I. $P^{\prime \prime}$ and $P / L$ set on a scale different to that of $P$.

\section{INTENSI'TY OF CULTURE}

It is L/l. Fig. 2 is to explain its meaning. In the figure, the amount of 1 is set on $O Z$ axis and that of $L$ on $O X$. The point (OX, $O Z$ ) denotes the combination of the elements $I$ and $L$ and its intensity of culture is $\mathrm{OX} / \mathrm{OZ}$ or $\mathrm{L} / \mathrm{l}$. Thus, the intensity of culture of the point $\left(L_{1} l_{1}\right)$ is $L_{1} / l_{r}$ and that of the point $\left(L_{2} l_{2}\right)$ is $L_{2} / l_{2}$. Generally, the intensity of culture of the combination denoted by a point in the first quadrant of the figure is the ratio of its abscissa $O X$ divided by its ordinate $\mathrm{OZ}$. Now, comparing $\mathrm{I}_{1} / \mathrm{l}_{1}$ and $\mathrm{L}_{2} / \mathrm{I}_{2}$ on the figure, evidently $\mathrm{L}_{\mathrm{x}} / \mathrm{l}_{\mathrm{r}}<\mathrm{L}_{2} / \mathrm{I}_{2}$. In general, when the point thus set to show the combination of 1 and $L$ is connected with the origin by a straight line, the nearer is the straight line to $\mathrm{OX}$ axis or the smaller is the angle be- 
tween the straight line and $\mathrm{OX}$ axis the greater is the intensity of culture of the point i.e. the combination is more intensive, and the nearer it is to $\mathrm{OZ}$ axis or the smaller is the angle between the straight line and $O Z$ axis the smaller is the intensity of culture of the point i.e. the combination is more extensive.

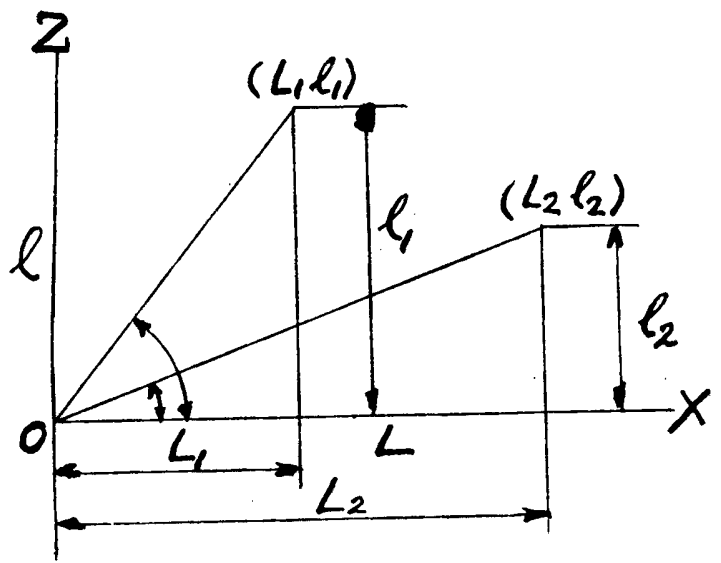

Fig. 2.

\section{E. GOALS CONSIDERED}

On enterprising a farm, there may be several objects of farming, each of which gives us the special kind of goal to win. So, on investigating the sizes of farm, we must take several goals for consideration.

In this investigation the following are considered :$\mathrm{P} / \mathrm{L} M A X, \mathrm{p} / \mathrm{L} M A X, \mathrm{Gp} / \mathrm{L} M A X,(\mathrm{p}-\mathrm{r}) / \mathrm{L} M A X, \mathrm{~Np} / \mathrm{L} M A X$, $\mathrm{P} M A X, \mathrm{p} M A X, \mathrm{Gp} M A X,(\mathrm{p}-\mathrm{r}) M A X, \mathrm{~Np} M A X$, $\mathrm{p} /(\mathrm{lc}+\mathrm{t}) M A X$ or $\mathrm{Gp} /(\mathrm{lc}+\mathrm{t}) M A X, \mathrm{p} / \mathrm{rl} M A X$ or $(\mathrm{p}-\mathrm{rl}) / \mathrm{r} 1 M A X$, $\mathrm{p} /(\mathrm{lc}+\mathrm{t}+\mathrm{r}) M A X$ or $\mathrm{Np} /(\mathrm{lc}+\mathrm{t}+\mathrm{r}) M A X$, and when it is loss, $\{(\mathrm{lc}+\mathrm{t})-\mathrm{p}\} \min ,\{(\mathrm{lc}+\mathrm{t}+\mathrm{r})-\mathrm{p}\} \min ,\{(\mathrm{lc}+\mathrm{t})-\mathrm{p}\}$ $/(\mathrm{lc}+\mathrm{t}) \min ,\{(\mathrm{lc}+\mathrm{t}+\mathrm{r})-\mathrm{p}\} /(\mathrm{lc}+\mathrm{t}+\mathrm{r}) \min$.

Here we must notice that

(I) In the treatment of curves, the word " maximum" or "minimum" of the quantity denoted by the ordinate is used to mean the greatest or smallest amount of the quantity not in the whole system but in its vicinity only, as usual in the theory of equations. 
(2) Suffixes " $M A X$ " and "max" or " $M I N$ " and " min" are used to express the different meanings, " $M I A X$ " or " $M I N$ " being used for the greatest or smallest one of "max" or "min" values, which will be fully understood later on.

\section{F. CONDITIONS ADHERED TO}

In this investigation, the following conditions are adhered to :-

( I) In a certain system of comparison of production, the state of land, the varieties of crop, the state of seed and the process of technic are to remain always the same. The cases where they differ are to be considered in separate system of comparison.

(2) The amounts of the products are known for all combinations of the production elements necessary to realize the curves of decreasing returns for the desired kinds and proportions of the production elements combined.

(3) In chapter II, the curve of decreasing returns is assumed to be continuous and to have not more than one maximum point, as shown on Fig. I.

(4) In chapter II, L is assumed to be possible to set on a line, as by H. C. Taylor.

II. PROPERTIES OF DECREASING RETURN CURVES

I. RELATIONS BETWEEN PRODUCT CURVES AND INTENSITIES OF CULTURE

A. Case where area of land is given

Here the product curves are the plane curves and we can notice (Fig. 3):-

(I) If $L_{1}$ is the abscissa of the point where $P$ curve is highest, $\mathrm{L}_{\mathrm{r}} / 1$ is the intensity of culture to give $\mathrm{P} \max$ on the land 1 .

(2) If $\mathrm{L}_{2}$ is the abscissa of the tangent point of the tangent line drawn from the origin to $\mathrm{P}$ curve, $\mathrm{L}_{2} / \mathrm{l}$ is the intensity of culture to give $\mathrm{P} / \mathrm{L}$ max on the land 1 .

(3) On the same land $I$, the intensity of culture at $P$ max is greater than that at $\mathrm{P} / \mathrm{L} \max$ i.e. the 1 and $\mathrm{L}$ combination at $\mathrm{P}$ max is intensive in comparison with that at $\mathrm{P} / \mathrm{L}$ max or the combination at $\mathrm{P} / \mathrm{L}$ max is extensive in comparison with that at $\mathrm{P}$ max. 


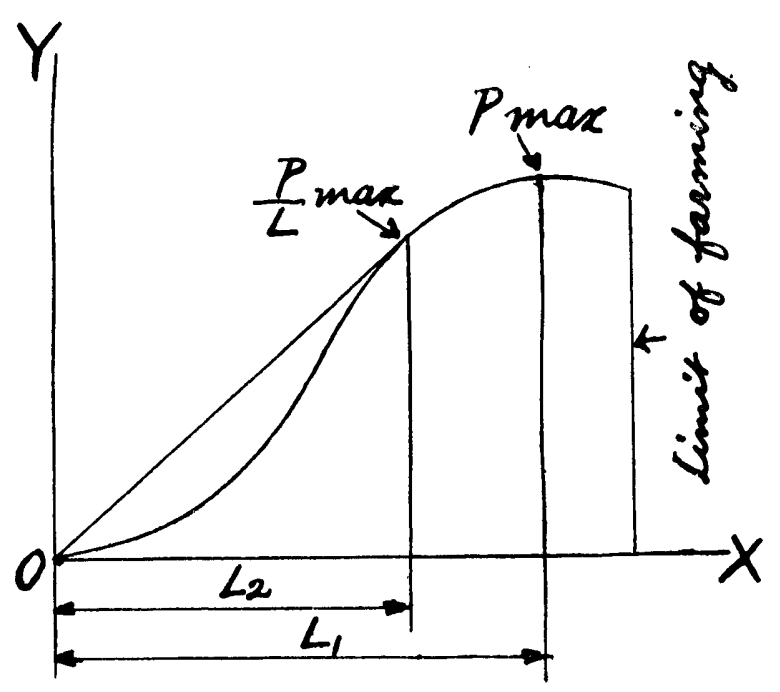

Fig. 3. (1 given.)

B. Case where area of land is not fixed.

Here the product curves form a solid, 1 being set on the third axis.

1) Case where, as 1 increases, both $P$ and $L$ incscase in proportion with 1 (Fig. 4)

(a) If the point $\left(\mathrm{L}_{1} 1_{\mathrm{r}}\right)$ represents the 1 and $\mathrm{L}$ combination which gives $\mathrm{P}$ max on $\mathrm{l}_{\mathrm{r}}$ land and the point $\left(\mathrm{L}_{2} \mathrm{l}_{2}\right)$ that which gives $\mathrm{P}$ max. on $l_{2}$ land, these two points are situated on a straight line radiating from the origin on the $\mathrm{XZ}$ plane.

(b) The points $\mathrm{P} \max$ on the $\mathrm{P}$ curves set on $\mathrm{l}_{\mathrm{r}}$ and $\mathrm{l}_{2}$ are situated on a straight line which radiates from the origin along the solid surface generated by the $\mathrm{P}$ curves and which projects on the $\mathrm{XZ}$ plane the said radiating straight line containing the points $\left(\mathrm{L}_{1} \mathrm{l}_{\mathrm{r}}\right)$ and $\left(\mathrm{L}_{2} \mathrm{l}_{2}\right)$.

(c) Exactly similar properties to $(a)$ and $(b)$ are noticed about the $\mathrm{P} / \mathrm{L}$ max points.

(d) The solid surface generated by the radiating straight lines connecting the points of the same meaning on $\mathrm{P}$ curves at different 1 , is identical with the solid surface generated by the $\mathrm{P}$ curves. 


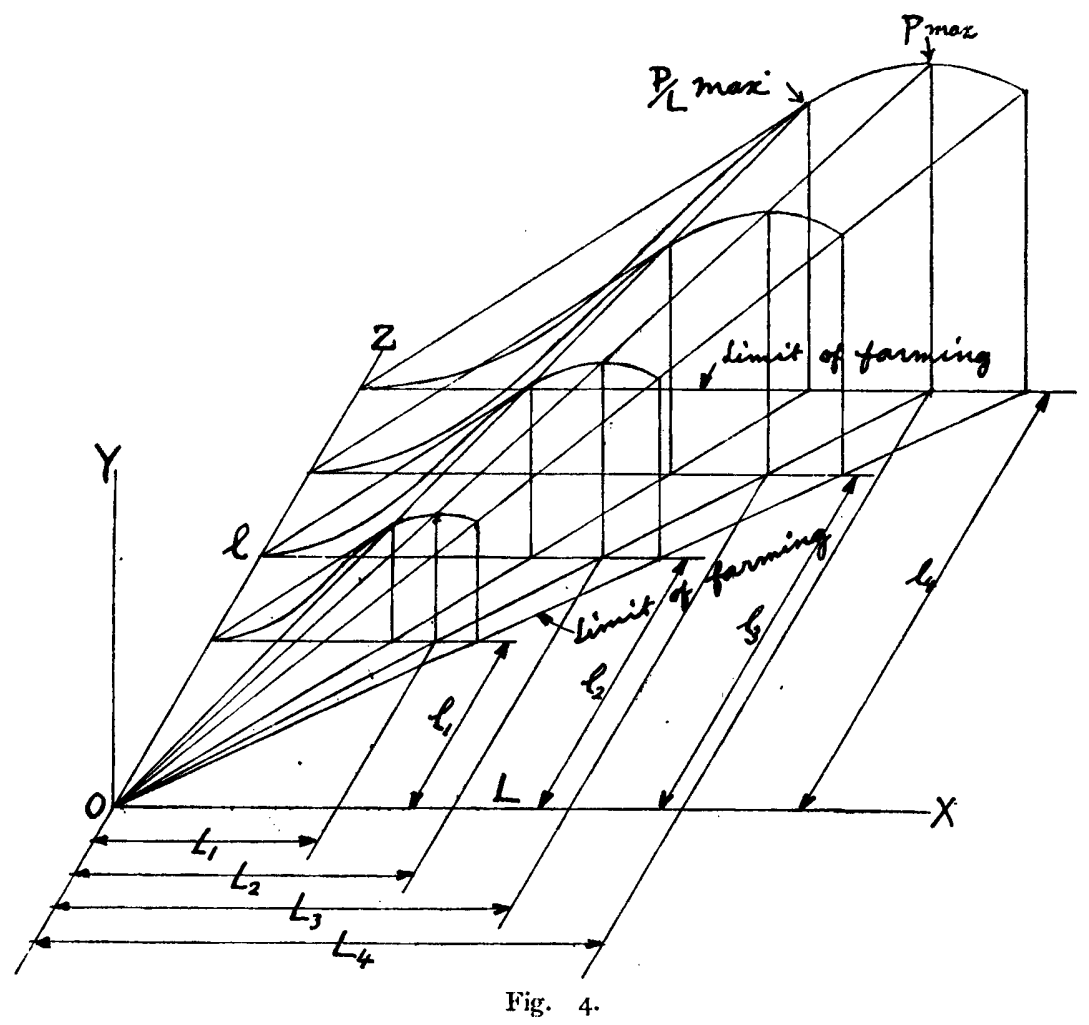

Thus we can deduce the following:-

(I) The 1 and $\mathrm{L}$ combinations corresponding to those points on $P$ curves which have the same meaning on the respective 1 , have the same intensities of culture.

(2) Ditto at the respective $L$, have the same intensities of culture.

(3) The intensity of culture, where any certain 1 combines with I, so as to give $P$ max on 1 , is the intensity of culture where the $P / l$ is max at the $\mathrm{L}$.

Proof:- $\ln$ Fig. 5, $\mathrm{A}$ is any point, near $\mathrm{P} m a x$, on $\mathrm{P}$ curve at a certain land 1 . The point $B$, which is situated on the straight line connecting $A$ and the origin and which has the same $\mathrm{L}$ as $\mathrm{P}$ max on 1 , is on the solid surface of $\mathrm{P}$ curves. Name $\mathrm{I}_{1}, \mathrm{P}, \mathrm{P}_{1}$ and $\mathrm{P}_{2}$ as shown on the figure.
Now,
$\mathrm{P}>\mathrm{P}_{2} \quad \therefore \mathrm{P} / \mathrm{l}>\mathrm{P}_{2} / \mathrm{l}$
and
$\mathrm{P}_{\mathrm{x}} / \mathrm{l}_{\mathrm{x}}=\mathrm{P}_{2} / \mathrm{l}$
$\therefore$
$\mathrm{P} / \mathrm{l}>\mathrm{P}_{\mathrm{I}} / 1_{\mathrm{I}}$, the proposition. 


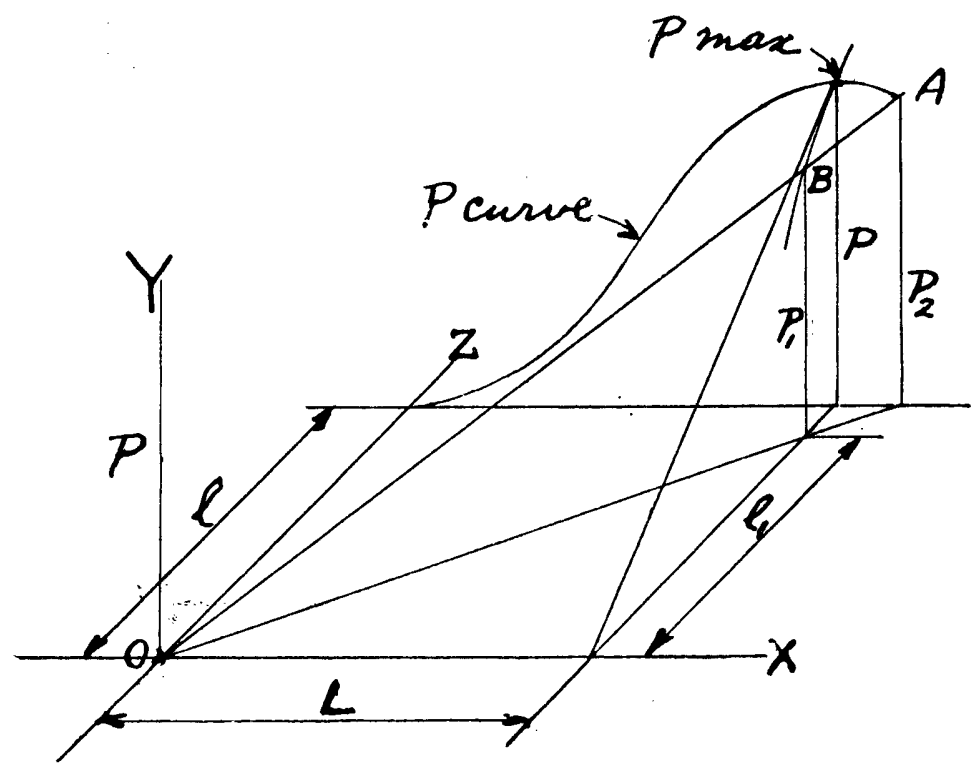

Fig. 5 .

(4) The intensity of culture, where any certain L combines with 1 so as to give $\mathrm{P} / \mathrm{I} \max$ at $\mathrm{L}$, is the intensity of culture where the $\mathrm{P}$ is max on the 1 .

(5) The intensity of culture to give $P$ max on a certain 1 is the same as that to give $\mathrm{P} / 1$ max at a certain $\mathrm{L}$.

(6) The intensity of culture, where any certain 1 combines with I. so as to give $\mathrm{P} / \mathrm{L}$ max on 1 , is the intensity of culture where the $\mathrm{P}$ is max at the $\mathrm{L}$.

Proof:-In Fig. 6, $\mathrm{A}$ is any point, near $\mathrm{P} / \mathrm{L}$ max, on $\mathrm{P}$ curve at a certain land 1 . The point $B$, which is situated on the straight line comnecting $A$ and the origin and which has the same $\mathrm{L}$ as $\mathrm{P} / \mathrm{L}$ max on 1 , is on the solid surface of $\mathrm{P}^{\prime}$ curves. Name $\mathrm{P}, \mathrm{P}_{1}, \mathrm{P}_{2}$ and $\mathrm{I}_{2}$ as shown on the figure.

$$
\begin{array}{lc}
\text { Now, } & \mathrm{P} / \mathrm{L}>\mathrm{P}_{2} / \mathrm{L}_{12} \text { and } \mathrm{P}_{2} / \mathrm{L}_{2}=\mathrm{P}_{1} / \mathrm{I} \\
\therefore & \mathrm{P} / \mathrm{L}>\mathrm{P}_{1} / \mathrm{L} \\
\text { or } & \mathrm{P}>\mathrm{P}_{1}, \text { the proposition. }
\end{array}
$$

(7) The intensity of culture, where any certain $\mathrm{L}$ combines with 1 so as to give $\mathrm{P} \max$ at $\mathrm{L}$, is the intensity of culture where $\mathrm{P} / \mathrm{L}$ is max on the 1 . 


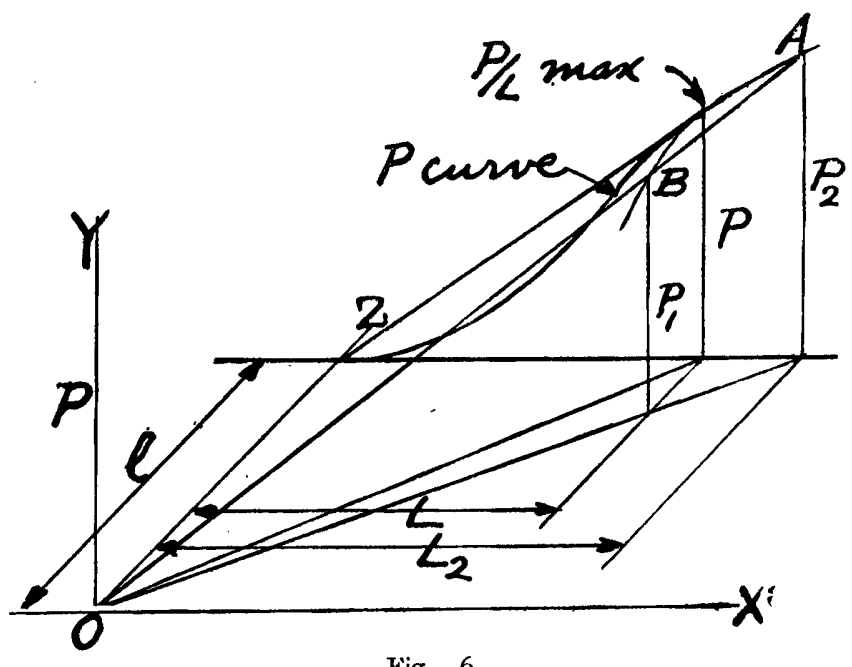

Fig. 6 .

(8) The intensity of culture to give $\mathrm{P} / \mathrm{L}$ max on a certain 1 is the same as that to give $\mathrm{P} \max$ at a certain $\mathrm{L}$.

(9) Comparing $P$ on different 1 at the intensity of culture where $\mathrm{P}$ is max on 1 , the greater is 1 the greater is the amount of $\mathrm{P}$ max.

(IO) Comparing $\mathrm{P} / \mathrm{L}$ on different 1 at the intensity of culture where $\mathrm{P} / \mathrm{L}$ is max on 1 , they are always the same in amount throughout the whole system with no concern with the amount of 1 .

( I I) Comparing $\mathrm{P}$ at different $\mathrm{L}$ at the intensity of culture where $\mathrm{P}$ is $\max$ at $\mathrm{L}$, the greater is $\mathrm{L}$ the greater is the amount of $\mathrm{P}$ max.

(12) Comparing $P / 1$ at different $L$ at the intensity of culture where $\mathrm{P} / \mathrm{I}$ is $\max$ at $\mathrm{L}$, they are always the same in amount throughout the whole system with no concern with the amount of $\mathrm{L}$.

(13) The intensity of culture at $\mathrm{P}$ max is always greater than that at $\mathrm{P} / \mathrm{L} \max$ i.e. the $\mathrm{l}$ and $\mathrm{L}$ combination at $\mathrm{P} \max$ is intensive in comparison with that at $\mathrm{P} / \mathrm{L}$, max or the latter is extensive in comparison with the former.

(14) The feature of the product curve solid surface in case 1) is as shown on Plate $37(\mathrm{~A})$ and that of the corresponding chart of the intensities of culture on Plate $37(\mathrm{~B})$.

Notice:-As evident from the above,the $\mathrm{P} \max$ or $\mathrm{P} / \mathrm{L}$ max exists in two cases i.e. when 1 is given and when $L$ is given, and has the different intensities of culture in the two cases. To avoid the confusion, in this investigation $\mathrm{P} \max$ or $\mathrm{P} / \mathrm{L} \max$ is said on 1 except where 
otherwise specified. Similarly Gp max, Gp/L max, $\mathrm{Np}$ max, $\mathrm{Np} / \mathrm{L}$ max, $\mathrm{p} /(\mathrm{l} \mathrm{c}+\mathrm{t})$ max, $\mathrm{p} /(\mathrm{l} \mathrm{c}+\mathrm{t}+\mathrm{r}) \max$, etc. are all used in the same senses, except where otherwise specified.

2) Case where $L$ to obtain $P$ proportional to 1 increases, as 1 increases, not in proportion with 1

Here observe the actual state of affairs in the crop farming. Owing to the properties of 1 and $\mathrm{I}$, in connection with the farming, the amount of $\mathrm{L}$, necessary to obtain $\mathrm{l}$ proportional to 1 , as 1 increases,

(a) is smaller than $L$ proportional to 1 , when 1 is of medium size,

(b) is larger than that, when 1 is beyond some extent and

(c) continues to accelerate as 1 increases and at last the farming reaches the limit.

Fig. 7 is to give, the idea of these changes of state. Thus, in this 2) case the following are noticed:-

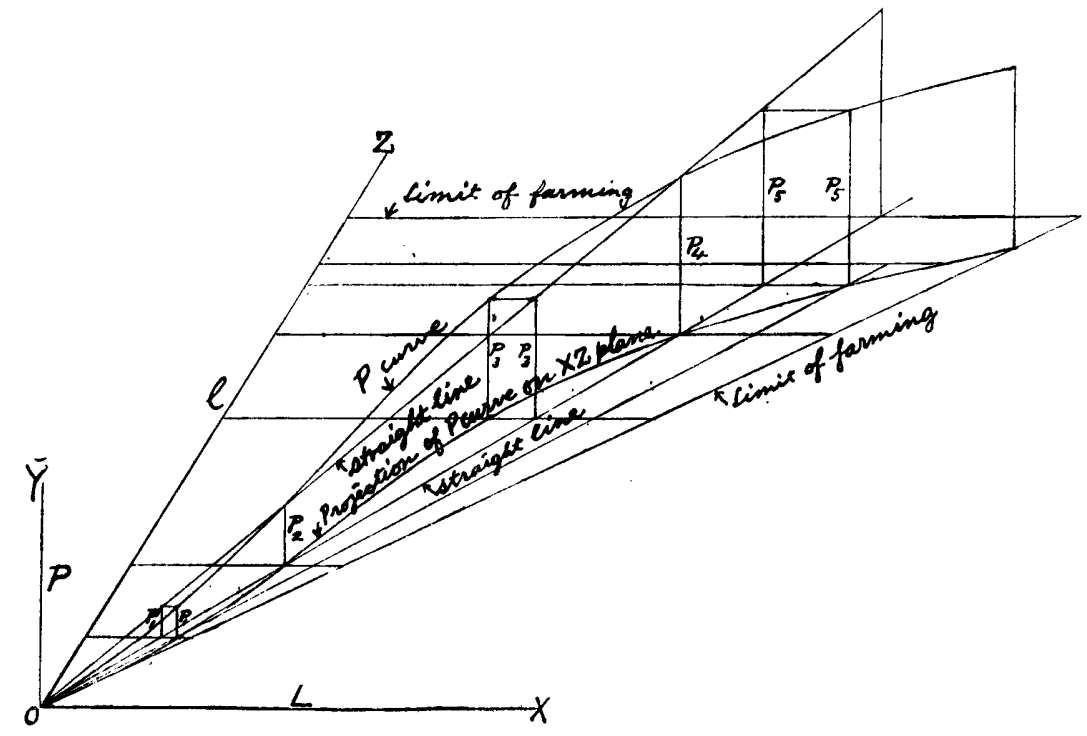

Fig. 7 .

(I) The intensity of culture, where any certain 1 combines with $\mathrm{L}$ so as to give $\mathrm{P} \max$ on 1 , is the intensity of culture where $\mathrm{P} / \mathrm{l}$ is max at the $\mathrm{L}$. 
Proof:-In Fig. 8, the point $A$ (LIP) is any point on $P$ max curve (locus of $\mathrm{P}$ max on $\mathrm{P}$ surface) and the point $\mathrm{B}\left(\mathrm{Ll}_{0} \mathrm{P}_{\mathrm{I}}\right)$ is another point on the surface near to $A$ and with the same $L$ as $A$. Then $P_{j} / I_{0}<$ $\mathrm{P} / 1$ is to be proved. Let $\mathrm{P}_{0}$ be the product at $\mathrm{P} \max$ on $\mathrm{J}_{0}$, then

and

$$
\mathrm{P} / \mathrm{l}=\mathrm{P}_{\mathrm{o}} / \mathrm{l}_{\circ}
$$

$\therefore$

$$
\begin{aligned}
& \mathrm{P}_{\mathrm{o}}>\mathrm{P}_{\mathrm{I}} \text { or } \mathrm{P}_{\mathrm{o}} / \mathrm{l}_{\mathrm{o}}>\mathrm{P}_{\mathrm{t}} / \mathrm{l}_{\mathrm{o}} \\
& \mathrm{P} / \mathrm{l}>\mathrm{P}_{\mathrm{l}} / \mathrm{l}_{\mathrm{o}}, \text { the proposition. }
\end{aligned}
$$

(2). The intensity of culture, where any certain $I$, combines with 1 so as to give $\mathrm{P} / \mathrm{l}$ max at $\mathrm{L}$, is the intensity of culture where $\mathrm{P}$ is max on the 1 .

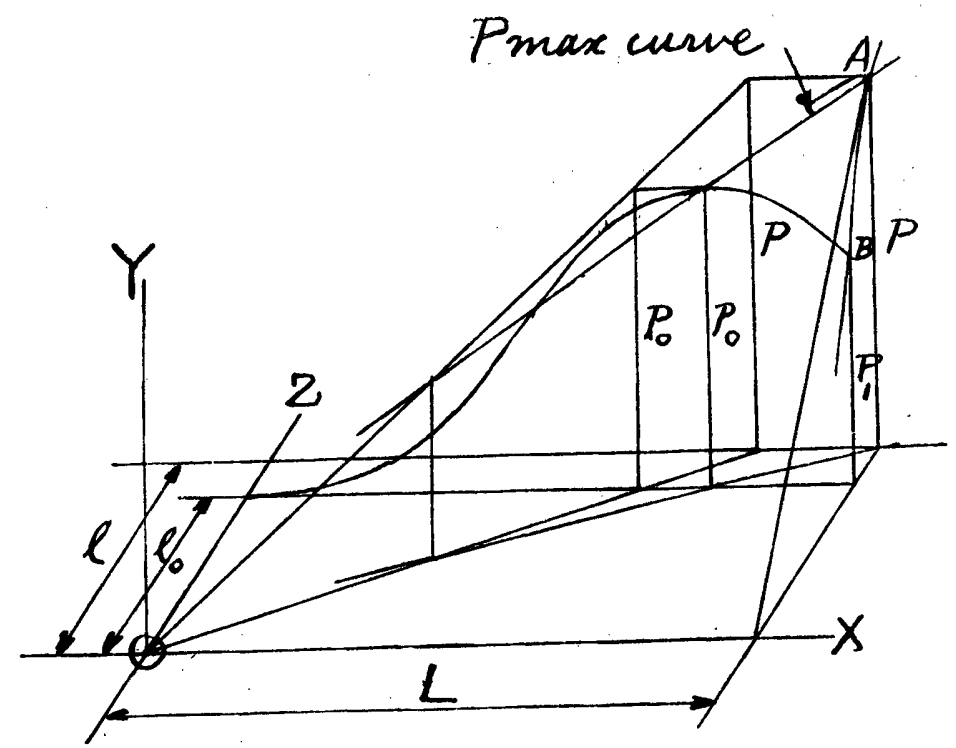

Fig. 8 .

(3) The combination to give $\mathrm{P} \max$ on an 1 has not generally the same intensity as that to give $\mathrm{P} / \mathrm{l} \max$ at an $\mathrm{L}$. The cases where they have the same intensity are only where the locus of the $P$ max curve projected on the $\mathrm{XZ}$ plane intersects witli the straight lines radiated from the origin in the $\mathrm{XZ}$ plane, the intensities along such a straight line being the same.

(4) The intensity of culture, where any certain I combines with $\mathrm{L}$ so as to give $\mathrm{P} / \mathrm{L} \max$ on 1 , is the intensity of culture where $\mathrm{P}$ is $\max$ at the $\mathrm{L}$. 
Proof when the intensity at $\mathrm{P} / \mathrm{L} \max$ on 1 is greater than that at $A$ point as on Fig. 9:- In the figure, the point $A\left(\mathrm{Ll}_{0} \mathrm{P}_{\mathrm{o}}\right)$ is any point on $\mathrm{P} / \mathrm{L}$ max curve (locus of $\mathrm{P} / \mathrm{L}$ max on $\mathrm{P}$ surface) and the point $\mathrm{B}\left(\mathrm{LIP}_{\mathrm{I}}\right)$ another point on the surface near to $\mathrm{A}$ and with the same $I$ as $\Lambda$. Then $P_{1}<P_{0}$ is to be proved. Let $P_{3}$ be the product at $P / L$, max on 1 and name $\mathrm{L}_{3}, \mathrm{~L}_{4}$ and $\mathrm{P}_{2}$ as shown on the figure, then

and

$$
\mathrm{P}_{\mathrm{o}} / \mathrm{P}_{3}=\mathrm{L} / \mathrm{L}_{4} \text { or } \mathrm{P}_{0}=\mathrm{L} / \mathrm{L}_{4} \times \mathrm{P}_{3}
$$

$\therefore$

$$
\mathrm{P}_{3} / \mathrm{P}_{2}=\mathrm{I}_{3} / \mathrm{I} \text {, or } \mathrm{P}_{3}=\mathrm{L}_{3} / \mathrm{L} \times \mathrm{P}_{2}
$$

now $\mathrm{L}_{3}>\mathrm{I}_{4}$ $\mathrm{P}_{10}=\mathrm{L} / \mathrm{L}_{4} \times \mathrm{L}_{3} / \mathrm{L} \times \mathrm{P}_{2}=\mathrm{L}_{3} / \mathrm{L}_{4} \times \mathrm{P}_{2}$

and $P_{2}>P_{1}$ $\therefore \mathrm{P}_{\mathrm{o}}>\mathrm{P}_{2}$ $\therefore \mathrm{P}_{\mathrm{o}}>\mathrm{P}_{1}$, the proposition.

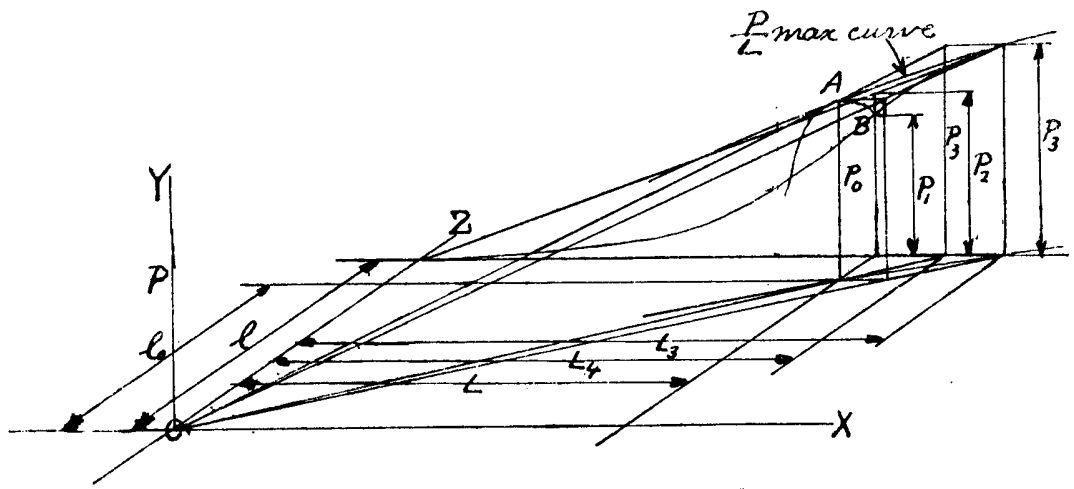

Fig. 9 .

Proofs for other cases are omitted.

(5) The intensity of culture, where any certain L combines with 1 so as to give $\mathrm{P} m a x$ at $\mathrm{I}$, is the intensity of culture where $\mathrm{P} / \mathrm{L}$ is max on the 1 .

(6) The combination to give $\mathrm{P} \max$ at an $\mathrm{L}$ has not generally the same intensity as that to give $\mathrm{P} / \mathrm{I}$, max on an 1 . The cases where they have the same intensity are only where the locus of $\mathrm{P} / \mathrm{L}$ max curve projected on the $\mathrm{XZ}$ plane intersects with the straight lines radiated from the origin in the $\mathrm{XZ}$ plane, the intensities along such a straight line being the same.

(7) Comparing $\mathrm{P}$ on different 1 at the intensity of culture where $\mathrm{P}$ is max on $\mathrm{l}$, the greater is 1 the greater is the amount of $\mathrm{P}$ max.

(8) Comparing $\mathrm{P} / \mathrm{L}$ on different 1 at the intensity of culture where $\mathrm{P} / \mathrm{L}$ is $\max$ on 1 , the amount of $\mathrm{P} / \mathrm{L} \max$ is max. at the 1 and $\mathrm{L}$ 
combination corresponding to the tangent point of the tangent line drawn from the origin to the curve projected on the $X Z$ plane by the curve generated by $\mathrm{P} / \mathrm{L}$ max on the $\mathrm{P}$ curve solid surface. Thus the $\mathrm{P} / \mathrm{L}$ at the tangent point is not only the $\mathrm{P} / \mathrm{L}$ max on the 1 but the greatest one among the several $\mathrm{P} / \mathrm{L}$ max throughout the whole system i.e. $\mathrm{P} /[, M A X$, and its intensity is denoted by $\mathrm{OX} / \mathrm{OZ}, \mathrm{OX}$ and $\mathrm{OZ}$ being the abscissa and ordinate of the tangent point in the $\mathrm{XZ}$ plane.

Proof:-(Fig. 10).

and $\mathrm{L}_{2}<\mathrm{L}_{2}^{\prime}$

$\therefore$

$$
\mathrm{P}_{1} / \mathrm{L}_{2}=\mathrm{P}_{2} / \mathrm{L}_{2}^{\prime}=\mathrm{P}_{3} / \mathrm{L}_{3}
$$

or $\mathrm{P}_{2} / \mathrm{L}_{2}>\mathrm{P}_{2} / \mathrm{L}_{2}^{\prime}$

$\mathrm{P}_{2} / \mathrm{L}_{2}>\mathrm{P}_{1} / \mathrm{L}_{\mathrm{I}}$ or $\mathrm{P}_{2} / \mathrm{L}_{3}$, the proposition.

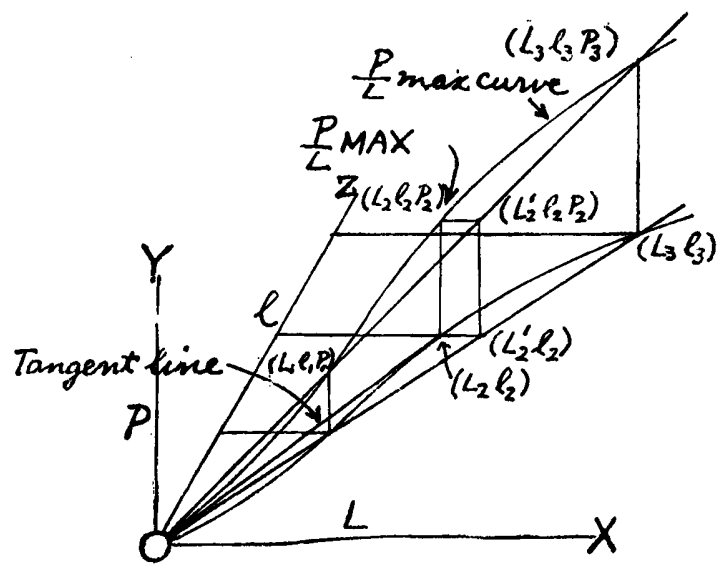

Fig 10.

(9) Comparing $P / 1$ on different 1 at the intensity of culture where $P / 1$ is max on 1, they are always the same in amount throughout the whole system with no concern with the amount of 1 .

(10) The intensity of culture at $\mathrm{P} \max$ is greater than that at $\mathrm{P} / \mathrm{L} \max$ on the same 1 i.e. on the same 1 , the 1 and $\mathrm{L}$ combination at $\mathrm{P} m a x$ is intensive in comparison with that at $\mathrm{P} / \mathrm{I}, \max$ or the latter is extensive in comparison with the former.

(I I) The feature of the product curve solid surface in case 2) is as shown on Plate 38 (A) and that of the corresponding chart of the intensities of culture on Plate $3 S$ (B). Here it must be noticed that, when the $\mathrm{P}$ max curve comes to end at the limit of farming owing to the limit of $\mathrm{L}$ applicable on a given 1 , the amount of $\mathrm{P}$ outside the range 
of 1 , where $\mathrm{P} \max$ exists to be compared mathematically, may be greater than the $\mathrm{P} M A X$ indicated on the plates, according to the natures of $\mathrm{P}$ curves and of the limit of farming. (Outside the said range of $1, \mathrm{P}$ max may be got for each 1 along the limit of farming, but it is not $\mathrm{P}$ max in the sense mentioned in IE ( $\mathrm{I}$ ) or in the mathematical sense, because to be $\mathrm{P} m a x$ in this sense, $\mathrm{P}$ at a certain 1 must be such as to be greater than any $\mathrm{P}$ which is given on the same 1 by either greater or smaller value of $\mathrm{L}$ in the vicinity. Thus, in the sense mentioned in IE ( 1 ) or in the mathematical sense, $\mathrm{P} M A X$ must be on $\mathrm{P}$ max curve as indicated on the plates; but if $\mathrm{P} M A X$ is used to mean the biggest amount of $\mathrm{P}$, it may be at an 1 greater than the 1 at $\mathrm{P} M A X$ indicated on the plates.)

\section{3) Other cases}

Among these, we can notice those cases where I) and 2) are combined. It is impossible to treat these cases in general, but special or individual cases, where the state of variation of production is clear, may be discussed separately. In this investigation, these cases are omitted.

\section{RELATIONS BE'TWEEN PRICE CURVES AND INTENSITIES OF CULTURE}

In the product curves discussed in $\mathrm{I}$, by taking $\mathrm{p}$ instead of $\mathrm{P}$ we have $p$ curve. It will be noticed that the relations between $p$ and $\mathrm{p}^{\prime}$ curves are the same as those between $\mathrm{P}$ and $\mathrm{P}^{\prime}$ curves described in IC 3) (Fig. I I and I2). Now by offsetting $(\mathrm{lc}+\mathrm{t})$ on the corresponding $p$ ordinates in the figures we have $(l c+t)$ curves having the abscissae common with $p$ curve. As to the relations between $p$ and $(l c+t)$ curves on a given 1 , the following will be noticed:-

( I) At the intensities where $p / L$ curve intersects with $(l c+t) / L$ curve or $p$ curve intersects with $(l c+t)$ curve, $p=(l c+t)$ or $G p=0$.

(2) At the intensities in the range of $\mathrm{L}$ where the ordinates of $p$ curve are greater than those of $(l c+t)$ curve, the $G p$ are positive.

(3) At the intensities outside the said range of $\mathrm{L}$ or where the ordinates of $p$ curve are smaller than those of $(l c+t)$ curve, the Gp are negative. 


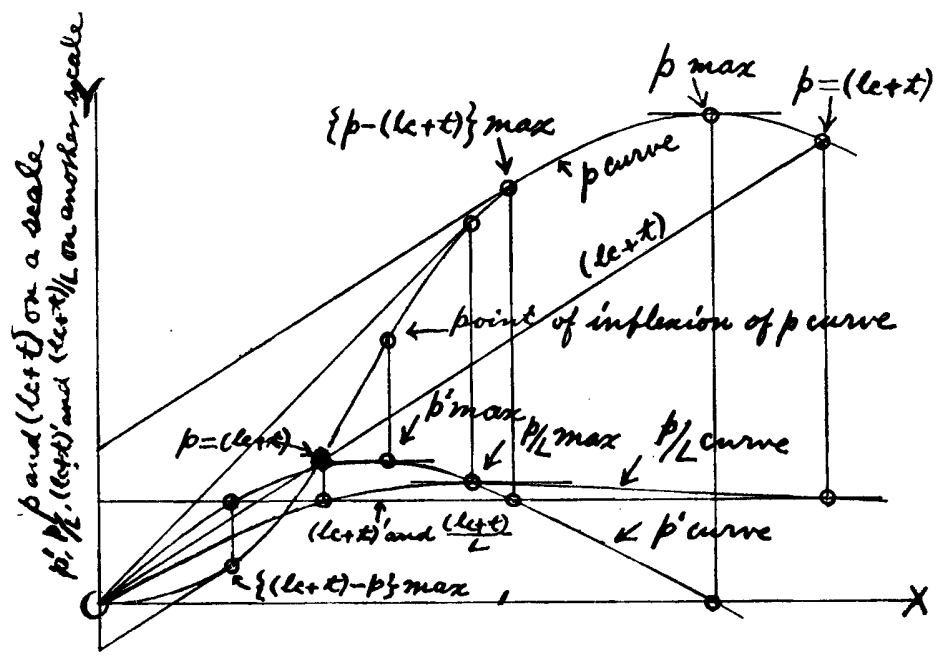

Fig. II. (l given)

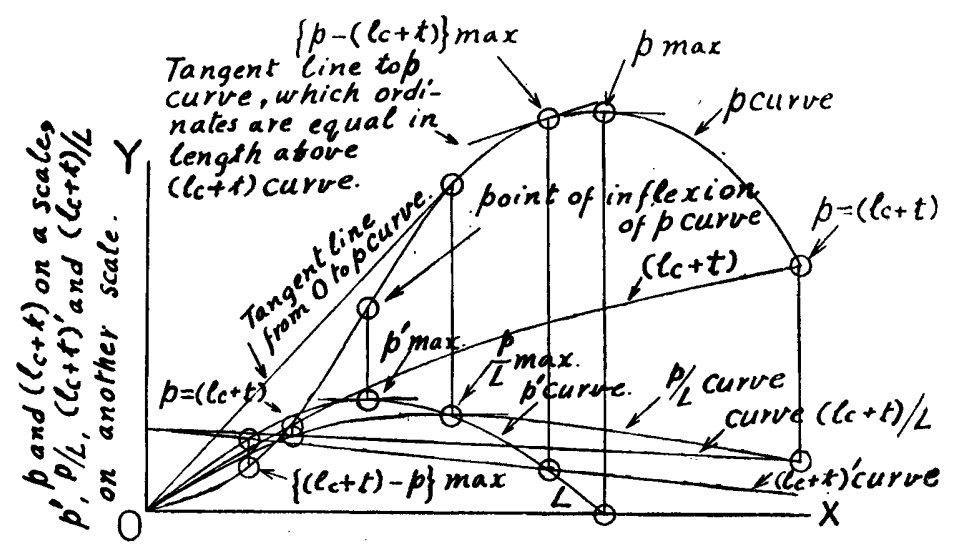

Fig. 12. (1 given)

(4) At those intensities where $p^{\prime}$ curve intersects with the curve of increments of $(\mathrm{lc}+\mathrm{t})$, or $(\mathrm{lc}+\mathrm{t})^{\prime}$ curve, $\{\mathrm{p}-(\mathrm{lc}+\mathrm{t})\}$ is $\max$ or $\{(\mathrm{l}+\mathrm{t})-\mathrm{p}\}$ is max according to the cases.

When $r$ is fixed for 1 given, by offsetting $(l c+t+r l)$ on the corresponding $p$ ordinates (Fig. 13 ), we have $(\mathrm{l}+\mathrm{t}+\mathrm{rl}$ ) curve having the abscissae common with $\mathrm{p}$ curve. As to the relations between $\mathrm{p}$ and $(\mathrm{l} c+\mathrm{t}+\mathrm{rl})$ curves on a given 1 , the following will be noticed:- 
$\left(5^{\prime}\right)$ At the intensities where $\mathrm{p}$ curve intersects with $(\mathrm{lc}+\mathrm{t}+\mathrm{rl})$ curve, $\mathrm{p}=(\mathrm{l} c+\mathrm{t}+\mathrm{rl})$ or $\mathrm{Np}=\mathrm{o}$.

$\left(6^{\prime}\right)$ At the intensities in the range of $\mathrm{L}$ where the ordinates of $\mathrm{p}$ curve are greater than those of $(\mathrm{l}+\mathrm{t}+\mathrm{rl})$ curve, the $\mathrm{Np}$ are positive.

$\left(7^{\prime}\right)$ At the intensities outside the said range of $\mathrm{L}$ or where the ordinates of $p$ curve are smaller than those of $(\mathrm{l}+\mathrm{t}+\mathrm{rl})$ curve, the $\mathrm{Np}$ are negative.

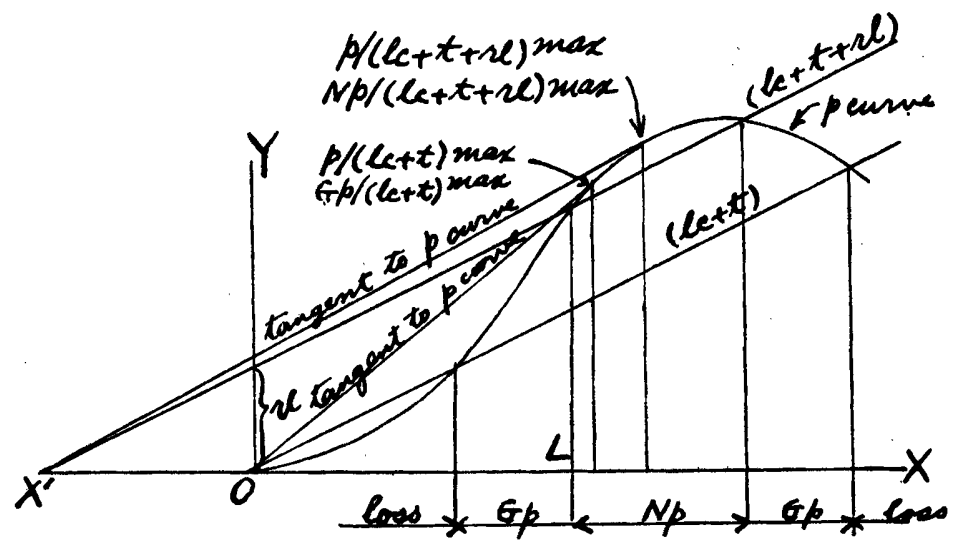

Fig. 13

When $r$ is proportional to $p$, by offsetting rs below the $p$ curve or setting $(p-r s)$ along the ordinates on the corresponding $p$ ordinates (Fig. 14), we have ( $\mathrm{p}-\mathrm{rs}$ ) curve having the abscissae common with $\mathrm{p}$ curve. As to the relations between $(p-r s)$ and $(l c+t)$ curves on a given 1 , the following will be noticed:-

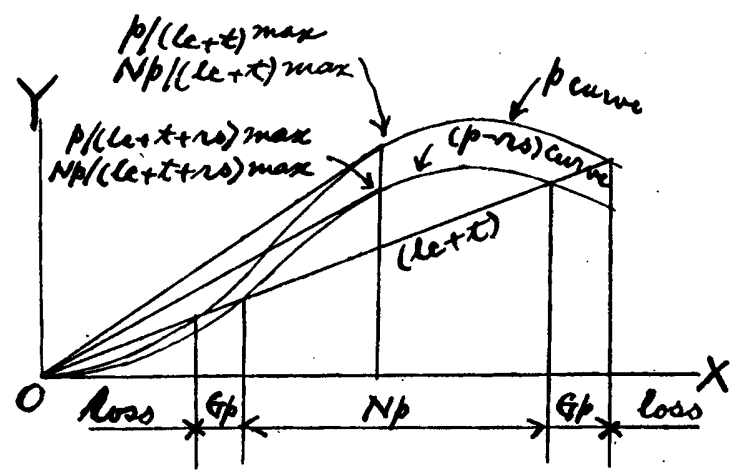

Fig. 14 
$\left(5^{\prime \prime}\right)$ At the intensities where $(\mathrm{p}-\mathrm{rs})$ curve intersects with $(\mathrm{lc}+\mathrm{t})$ curve, $\mathrm{p}=(\mathrm{l} c+\mathrm{t}+\mathrm{rs})$ or $\mathrm{Np}=\mathrm{O}$.

$\left(6^{\prime \prime}\right)$ At the intensities in the range of $\mathrm{L}$ where the ordinates of $(\mathrm{p}-\mathrm{rs})$ curve are greater than those of $(\mathrm{lc}+\mathrm{t})$ curve, the $\mathrm{Np}$ are positive.

$\left(7^{\prime \prime}\right)$ At the intensities outside the said range of $\mathrm{L}$ or where the ordinates of $(p-r s)$ curve are smaller than those of $(l c+t)$ curve, the $\mathrm{Np}$ are negative.

Investigations in II are done on these curves.

$\mathrm{L}$ to give $\mathrm{p} /(\mathrm{lc}+\mathrm{t}+\mathrm{r}) \max$ or $\mathrm{Np} /(\mathrm{lc}+\mathrm{t}+\mathrm{r}) \max$ on a given $\mathrm{l}$ can be found graphically as follows:-

(i) In the case of the fixed tenancy by money,

(a) When $(\mathrm{lc}+\mathrm{t}) / \mathrm{L}$ is constant (Fig. I3),

Prolong $(l c+t+r l)$ line to meet the $O X$ axis, prolonged, at $X^{\prime}$. From $\mathrm{X}^{\prime}$ draw the tangent to the $\mathrm{p}$ curve. The abscissa of the tangent point is the required $\mathrm{L}$.

(b) When $(\mathrm{lc}+\mathrm{t}) / \mathrm{L}$ is not constant (Fig. I 5),

Through (o, rl), draw a straight line $(\mathrm{lc}+\mathrm{t}+\mathrm{lr})_{t}$ in a direction convenient for the purpose. Take a point $A$ on $p$ curve and let the intersection of its ordinate with $(\mathrm{lc}+\mathrm{t}+\mathrm{rl})$ line be a. Through a draw the straight line parallel to $O X$ and let it intersect with the $(l c+t+r l)_{t}$ line at $a_{\mathrm{r}}$. Through $a_{\mathrm{r}}$ draw the straight line parallel to Oy and let it intersect with the straight line drawn through $A$ parallel to $O X$ at $A_{r}$. Connect several such $A_{\mathbf{r}}$ by a curve $\mathrm{p}_{\mathbf{r}}$. Prolong $(\mathrm{l}+\mathrm{t}+\mathrm{rl})_{t}$ and let it intersect with $\mathrm{OX}$, prolonged, at $\mathrm{X}^{\prime}$. Through $\mathrm{X}^{\prime}$ draw the tangent to $\mathrm{p}_{\mathrm{r}}$ curve. Through the tangent point $T_{\mathrm{I}}$ draw the straight line parallel to $O X$ and let it intersect with $p$ curve at $T$. $T$ is the point of $\mathrm{p} /(\mathrm{l} c+\mathrm{t}+\mathrm{rl}) \max$ and its abscissa is the required $\mathrm{L}$.

(ii) In the case of the share tenancy by money,

(a) When $(\mathrm{lc}+\mathrm{t}) / \mathrm{L}$ is constant,

From the origin draw the tangent to the $(p-r s)$ curve. The abscissa of the tangent point is the required L (Fig. I4).

(b) When $(\mathrm{l} c+\mathrm{t}) / \mathrm{L}$ is not constant,

The required $\mathrm{L}$ can be obtained graphically on the same principle of treatments as in (ii) (a) and (i) (b).

$\mathrm{L}$ to give $\mathrm{p} /(\mathrm{l} \mathrm{c}+\mathrm{t})$ max or $\mathrm{Gp} /(\mathrm{lc}+\mathrm{t})$ max on a given $\mathrm{l}$ can be found graphically on the same principle as for $L$ to give $p /(l c+t+r)$ $\max$ (Fig. I 5). 


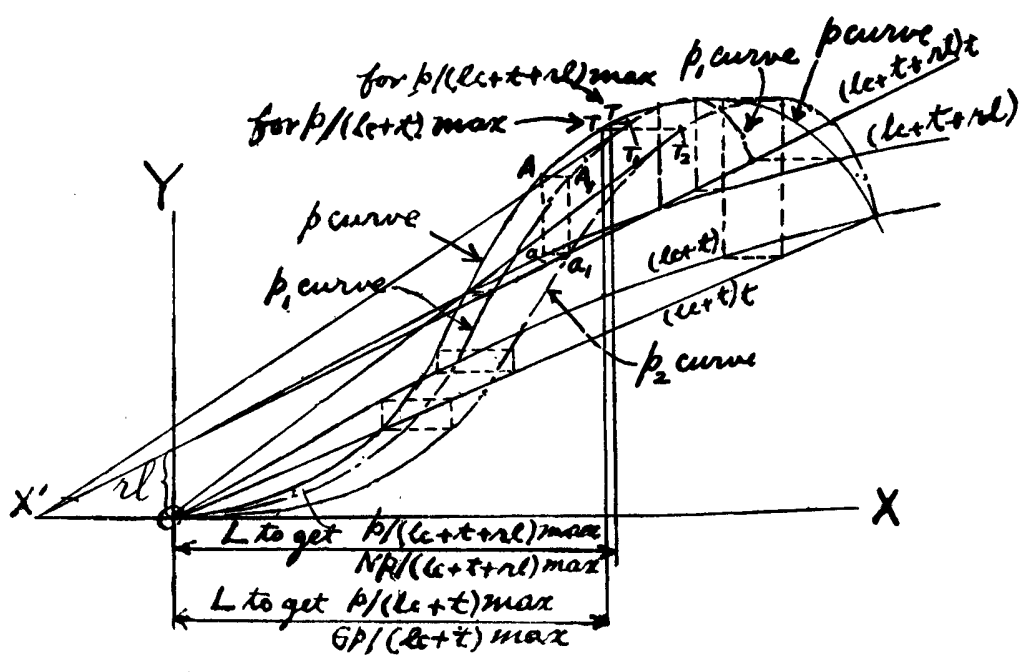

Fig. 15

A. CASE WHERE PRICES OF PRODUCTS AND OF ALL PRODUCTION ELEMENTS ARE FIXED

A). Case where area of land is given

Here the curves of the prices are the plane curves and the intensities of culture for several goals can be tabulated as follows :-

Notice. In the tables, those on the same lines have the same intensities and those on the upper lines are intensive in comparison with those on the lower lines.

(1) Case of fixed tenancy by money

( $t$ being assumed to be proportional to $\mathrm{L}$ )

(a) Where net profit exists

Table A (1) (a) (Fig. I6)

\begin{tabular}{l}
\hline $\mathrm{p}$ max, $(\mathrm{p}-\mathrm{rl}) \max , \mathrm{p} / \mathrm{rl} \max$ or $(\mathrm{p}-\mathrm{rl}) / \mathrm{rl} \max$ \\
\hline $\mathrm{Gp} \max , \mathrm{Np} \max$ \\
\hline $\mathrm{p} /(\mathrm{l} \mathrm{c}+\mathrm{t}+\mathrm{rl}) \max$ or $\mathrm{Np} /(\mathrm{lc}+\mathrm{t}+\mathrm{r}) \max$ \\
\hline$(\mathrm{p}-\mathrm{rl}) / \mathrm{L} \max , \mathrm{Np} / \mathrm{L} \max$ \\
\hline $\mathrm{p} / \mathrm{L} \max , \mathrm{Gp} / \mathrm{L} \max , \mathrm{p} /(\mathrm{lc}+\mathrm{t}) \max$ or $\mathrm{Gp} /(\mathrm{lc}+\mathrm{t}) \max$ \\
\hline$\{(\mathrm{lc}+\mathrm{t})-\mathrm{p}\} \max ,\{(\mathrm{lc}+\mathrm{t}+\mathrm{r} \mathrm{l})-\mathrm{p}\} \max$ \\
\hline
\end{tabular}




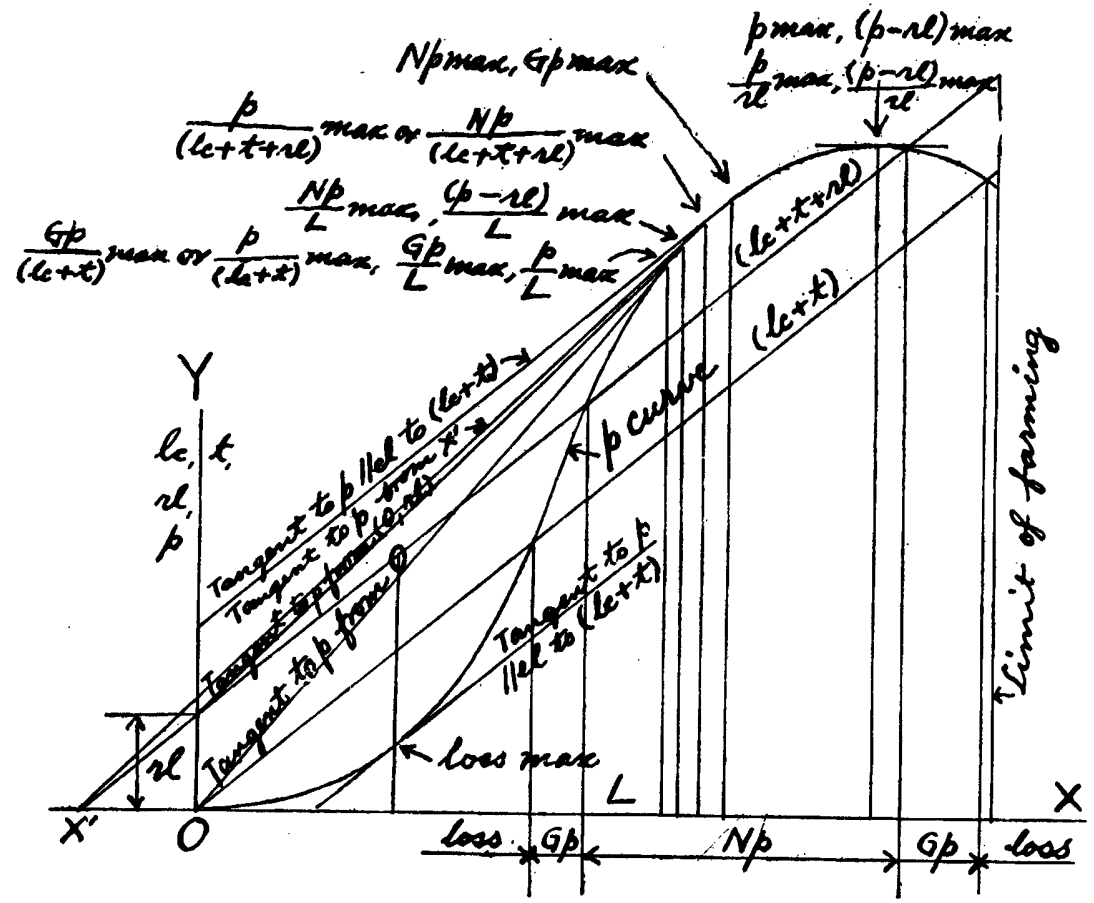

Fig. 16. (1 given)

It is interesting to note here that

( I) As the rate $(\mathrm{lc}+\mathrm{t}) / \mathrm{L}$ changes, Gp max moves between $\mathrm{p}$ max and $(\mathrm{p}-\mathrm{rl}) / \mathrm{L}$ max; and when $(\mathrm{lc}+\mathrm{t})=0, \mathrm{Gp} \max$ and $\mathrm{p} /(\mathrm{l} \mathrm{c}+\mathrm{t}+\mathrm{rl})$ max coincide with $\mathrm{p}$ max.

(2) As the rate $\mathrm{rl} / \mathrm{l}$ changes, $(\mathrm{p}-\mathrm{rl}) / \mathrm{L}$ moves between $\mathrm{p} / \mathrm{L}$ max and $\mathrm{Gp}$ max; and when $\mathrm{rl}=\mathrm{o},(\mathrm{p}-\mathrm{rl}) / \mathrm{L}$ max and $\mathrm{p} /(\mathrm{lc}+\mathrm{t}+\mathrm{rl})$ max coincide with $\mathrm{p} / \mathrm{L}$ max.

(3) The greatest allowable amount of $\mathrm{rl}$ is at Gp max.

(4) The greatest allowable amount of $(\mathrm{lc}+\mathrm{t}) / \mathrm{L}$ is at $(\mathrm{p}-\mathrm{rl}) / \mathrm{L}$ $\max$.

(b) Where net profit $=0$

Table A (I) (b). (Fig. I7)

$\mathrm{p} \max ,(\mathrm{p}-\mathrm{rl}) \max , \mathrm{p} / \mathrm{rl} \max$ or $(\mathrm{p}-\mathrm{rl}) / \mathrm{rl} \max$

Gp $\max ,(\mathrm{p}-\mathrm{rl}) / \mathrm{L}, \max , \mathrm{p} /(\mathrm{lc}+\mathrm{t}+\mathrm{rl}) \max$

$\mathrm{p} / \mathrm{L}, \max , \mathrm{Gp} / \mathrm{L} \max , \mathrm{p} /(\mathrm{lc}+\mathrm{t})=\max$ or $\mathrm{Gp} /(\mathrm{l} \mathrm{c}+\mathrm{t}) \max$

$\{(\mathrm{lc}+\mathrm{t})-\mathrm{p}\} \max ,\{\mathrm{lc}+\mathrm{t}+\mathrm{rl})-\mathrm{p}\} \max$ 


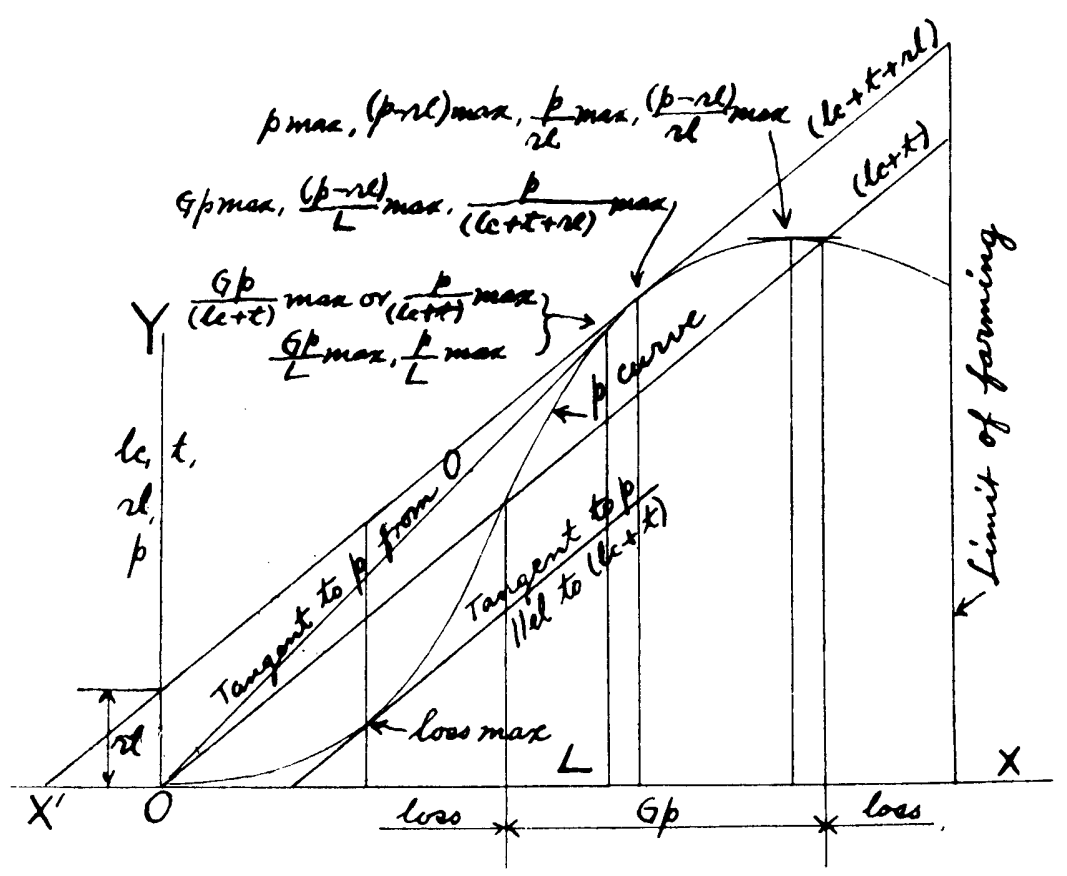

Fig. 17. (1 given)

(c) Where net profit is negative and gross profit is positive

(i) $\mathrm{p} \max >\mathrm{rl}$

Table A (I) (c) (i). (Fig. I 8 )

$\mathrm{p} \max ,(\mathrm{p}-\mathrm{rl}) \max , \mathrm{p} / \mathrm{rl} \max$ or $(\mathrm{p}-\mathrm{rl}) / \mathrm{rl} \max$

$(\mathrm{p}-\mathrm{rl}) / \mathrm{L} \max$

$\mathrm{p} /(\mathrm{l} \mathrm{c}+\mathrm{t}+\mathrm{rl}) \max$ or $\{(\mathrm{l} \mathrm{c}+\mathrm{t}+\mathrm{rl})-\mathrm{p}\} /(\mathrm{l} \mathrm{c}+\mathrm{t}+\mathrm{rl})$ min

Gp max, $\{(\mathrm{lc}+\mathrm{t}+\mathrm{rl})-\mathrm{p}\}$ min

$\mathrm{p} / \mathrm{L} \max , \mathrm{Gp} / \mathrm{L} \max , \mathrm{p} /(\mathrm{l} \mathrm{c}+\mathrm{t}) \max$ or $\mathrm{Gp} /(\mathrm{lc}+\mathrm{t}) \max$

$\{(\mathrm{lc}+\mathrm{t})-\mathrm{p}\} \max ,\{(\mathrm{lc}+\mathrm{t}+\mathrm{rl})-\mathrm{p}\} \max$ 


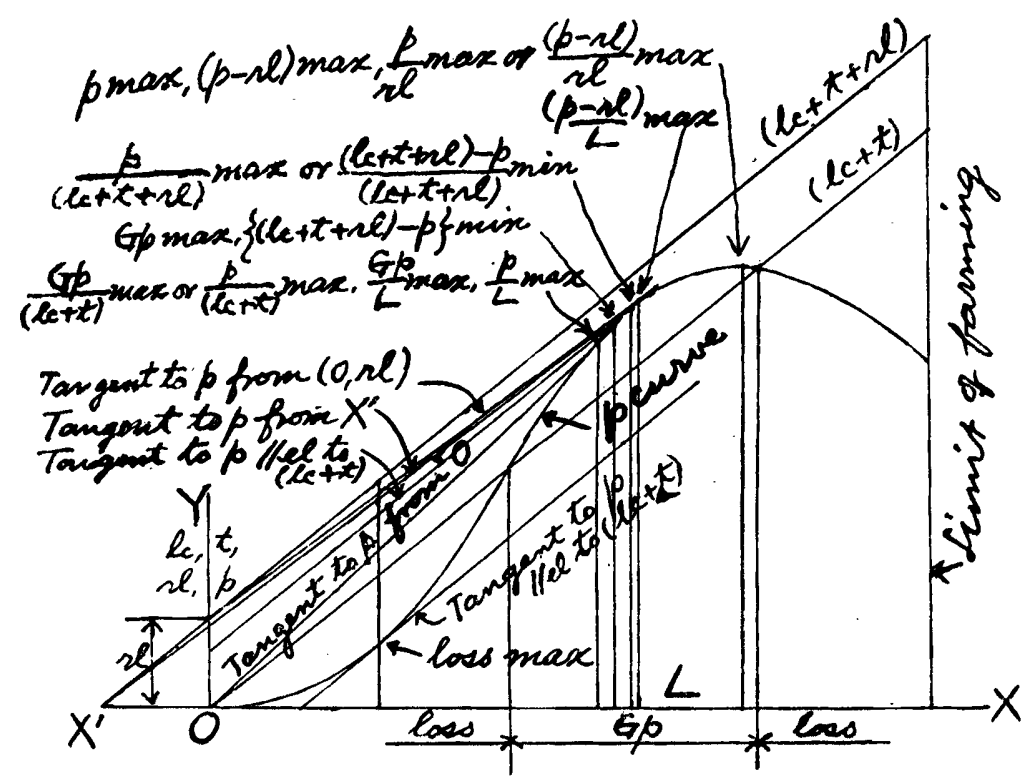

Fig. 18. (1 given)

(ii) $\mathrm{p} \max =\mathrm{r} 1$

Table A (I) (c) (ii). (Fig. 19)

$\mathrm{p} \max , \mathrm{p} / \mathrm{rl} \max$

$\mathrm{p} /(\mathrm{l} c+\mathrm{t}+\mathrm{rl})$ max or $\{(\mathrm{lc}+\mathrm{t}+\mathrm{rl})-\mathrm{p}\} /(\mathrm{l} \mathrm{c}+\mathrm{t}+\mathrm{rl})$ min

Gp max, $\{(\mathrm{lc}+\mathrm{t}+\mathrm{rl})-\mathrm{p}\}$ min

$\mathrm{p} / \mathrm{L}, \max , \mathrm{Gp} / \mathrm{L}, \max , \mathrm{p} /(\mathrm{l} \mathrm{c}+\mathrm{t}) \max$ or $\mathrm{Gp} /(\mathrm{lc}+\mathrm{t}) \max$

$\{(\mathrm{lc}+\mathrm{t})-\mathrm{p}\} \max ,\{(\mathrm{lc}+\mathrm{t}+\mathrm{rl})-\mathrm{p}\} \max$ 


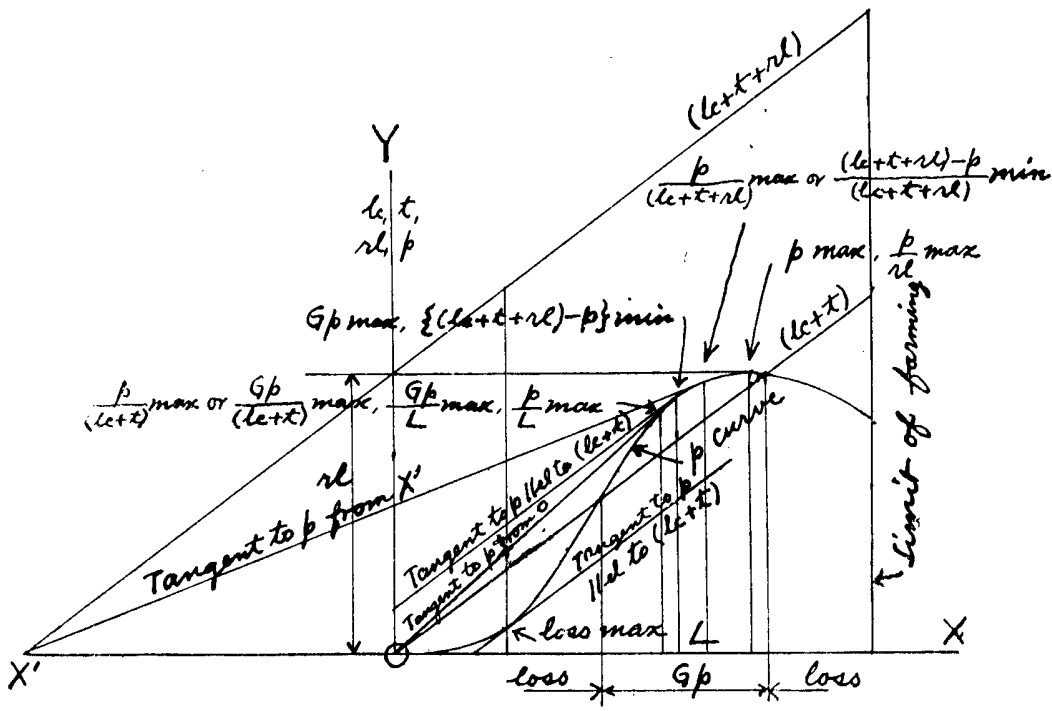

Fig. I9. (1 given)

(iii) $\mathrm{p} \max <\mathrm{rl}$

Table A (I) (c) (iii). (Fig. 20)

$(\mathrm{r} l-\mathrm{p}) / \mathrm{L}, \mathrm{min}$

$\mathrm{p} \max ,(\mathrm{rl}-\mathrm{p}) \min , \mathrm{p} / \mathrm{rl} \max$ or $(\mathrm{r} \mathrm{l}-\mathrm{p}) / \mathrm{rl} \min$

$\mathrm{p} /(\mathrm{lc}+\mathrm{t}+\mathrm{rl}) \max$ or $\{(\mathrm{lc}+\mathrm{t}+\mathrm{rl})-\mathrm{p}\} /(\mathrm{lc}+\mathrm{t}+\mathrm{rl}) \min$

Gp $\max ,\{(\mathrm{lc}+\mathrm{t}+\mathrm{rl})-\mathrm{p}\} \min$

$\mathrm{p} / \mathrm{I}, \max , \mathrm{Gp} / \mathrm{L}, \max , \mathrm{p} /(\mathrm{lc}+\mathrm{t}) \max$ or $\mathrm{Gp} /(\mathrm{lc}+\mathrm{t}) \max$

$\{(\mathrm{lc}+\mathrm{t})-\mathrm{p}\} \max ,\{\mathrm{lc}+\mathrm{t}+\mathrm{rl})-\mathrm{p}\} \max$ 


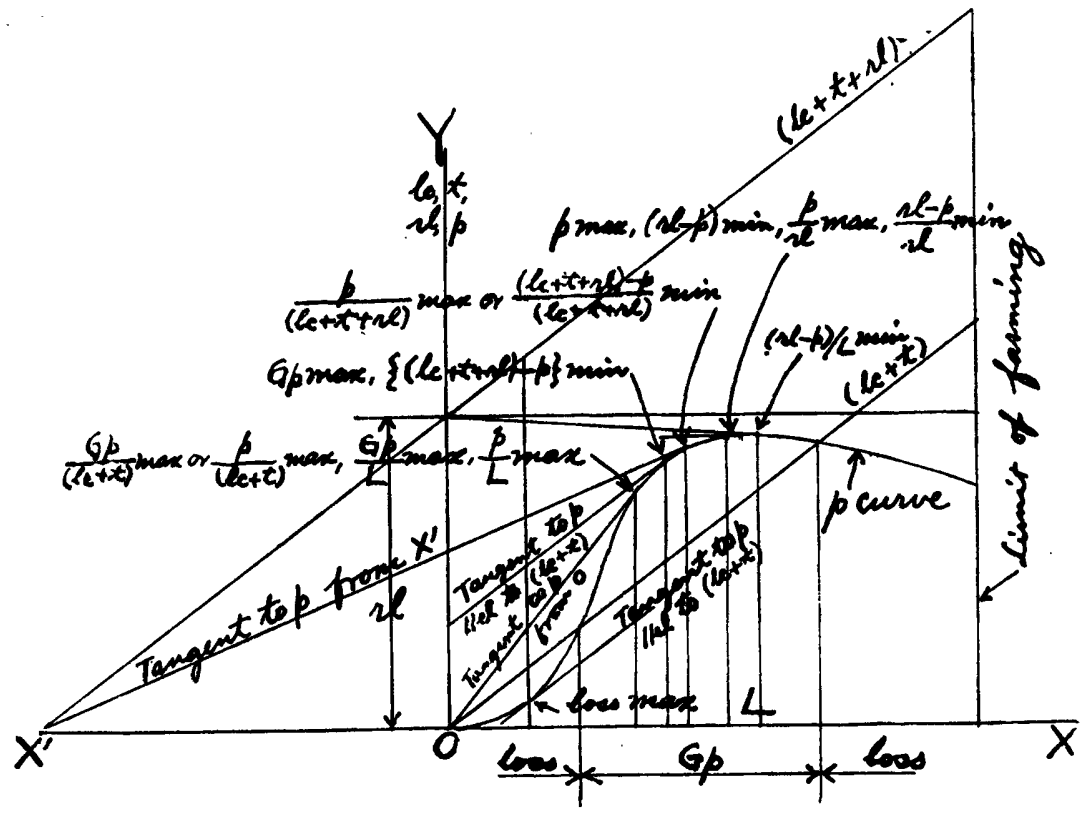

Fig. 20. (l given)

(d) Where gross profit $=0$

(i) $\mathrm{p} \max >\mathrm{rl}$

Table A (I) (d) (i). (Fig. 2I)

$\mathrm{p} \max ,(\mathrm{p}-\mathrm{rl}) \max , \mathrm{p} / \mathrm{rl} \max$ or $(\mathrm{p}-\mathrm{rl}) / \mathrm{rl} \max$

$(\mathrm{p}-\mathrm{rl}) / \mathrm{L} \max$

$\mathrm{p} /(\mathrm{lc}+\mathrm{t}+\mathrm{rl}) \max$ or $\{(\mathrm{lc}+\mathrm{t}+\mathrm{rl})-\mathrm{p}\} /(\mathrm{lc}+\mathrm{t}+\mathrm{rl}) \min$

$\mathrm{p} / \mathrm{L} \max ,\{(\mathrm{lc}+\mathrm{t}+\mathrm{rl})-\mathrm{p}\} \min , \mathrm{p} /(\mathrm{lc}+\mathrm{t}) \max$

$\{\mathrm{lc}+\mathrm{t})-\mathrm{p}\} \max ,\{(\mathrm{lc}+\mathrm{t}+\mathrm{rl})-\mathrm{p}\} \max$ 


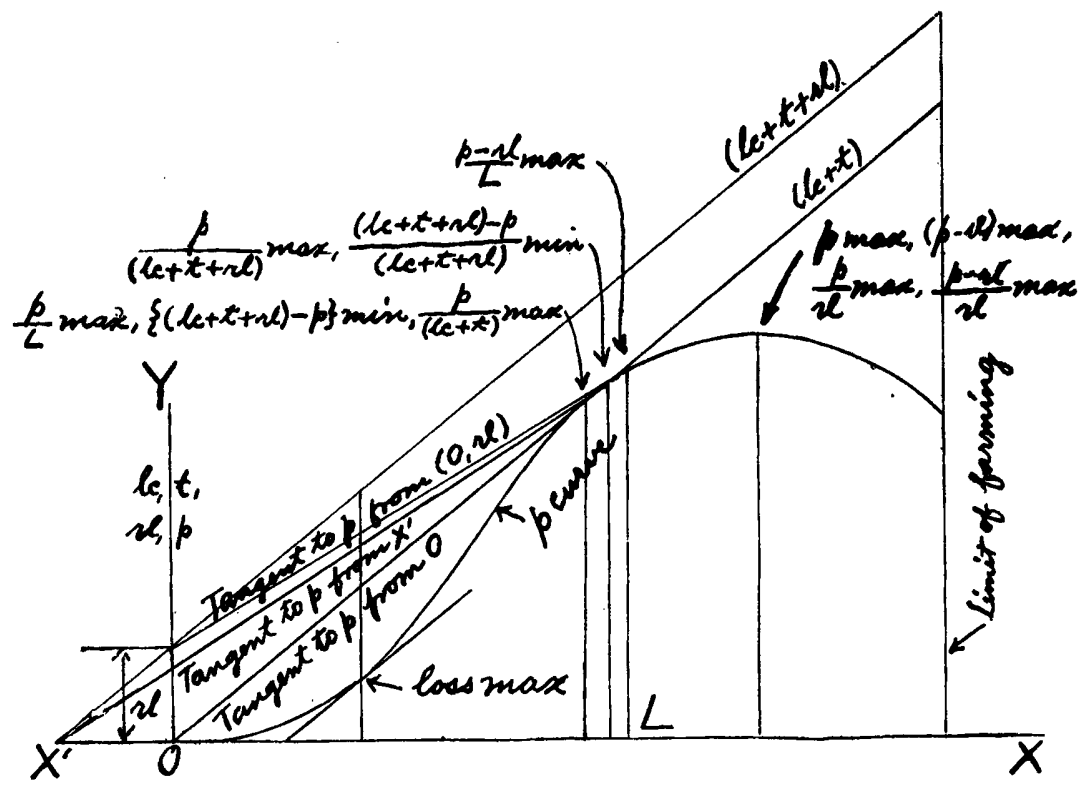

Fig. 21. (1 given)

(ii) $\mathrm{p} \max =\mathrm{rl}$

Table A (I) (d) (ii) (Fig. 22)

\begin{tabular}{c}
\hline $\mathrm{p} \max , \mathrm{p} / \mathrm{rl} \max$ \\
\hline $\mathrm{p} /(\mathrm{l} \mathrm{c}+\mathrm{t}+\mathrm{rl}) \max$ or $\{(\mathrm{lc}+\mathrm{t}+\mathrm{r} \mathrm{l})-\mathrm{p}\} /(\mathrm{lc}+\mathrm{t}+\mathrm{rl}) \min$ \\
\hline $\mathrm{p} / \mathrm{l}, \max ,\{(\mathrm{lc}+\mathrm{t}+\mathrm{rl})-\mathrm{p}\} \min , \mathrm{p} /(\mathrm{lc}+\mathrm{t}) \max$ \\
\hline$\{(\mathrm{lc}+\mathrm{t})-\mathrm{p}\} \max ,\{(\mathrm{lc}+\mathrm{t}+\mathrm{rl})-\mathrm{p}\} \max$ \\
\hline
\end{tabular}




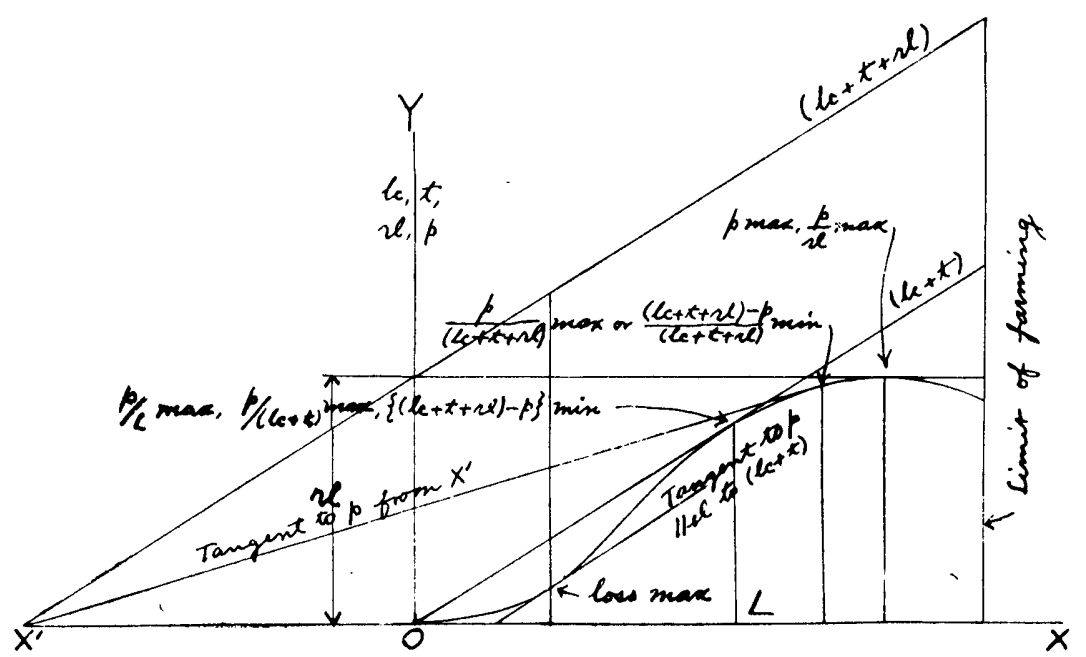

Fig. 22. (1 given)

(iii) $\mathrm{p} \max <\mathrm{rl}$

Table A (I) (d) (iii). (Fig, 23).

\begin{tabular}{|c|}
\hline$(\mathrm{rl}-\mathrm{p}) / \mathrm{L}, \min$ \\
\hline $\mathrm{p} \max ,(\mathrm{rl}-\mathrm{p}) \min , \mathrm{p} / \mathrm{rl} \max ,(\mathrm{rl}-\mathrm{p}) / \mathrm{rl} \min$ \\
\hline $\mathrm{p} /(\mathrm{lc}+\mathrm{t}+\mathrm{rl}) \max$ or $\{(\mathrm{lc}+\mathrm{t}+\mathrm{rl})-\mathrm{p}\} /(\mathrm{l} \mathrm{c}+\mathrm{t}+\mathrm{rl}) \min$ \\
\hline $\mathrm{p} / \mathrm{L} \max ,\{\mathrm{lc}+\mathrm{t}+\mathrm{rl})-\mathrm{p}\} \min , \mathrm{p} /(\mathrm{lc}+\mathrm{t}) \max$ \\
\hline$\{(\mathrm{lc}+\mathrm{t})-\mathrm{p}\} \max ,\{(\mathrm{lc}+\mathrm{t}+\mathrm{rl})-\mathrm{p}\} \max$ \\
\hline
\end{tabular}




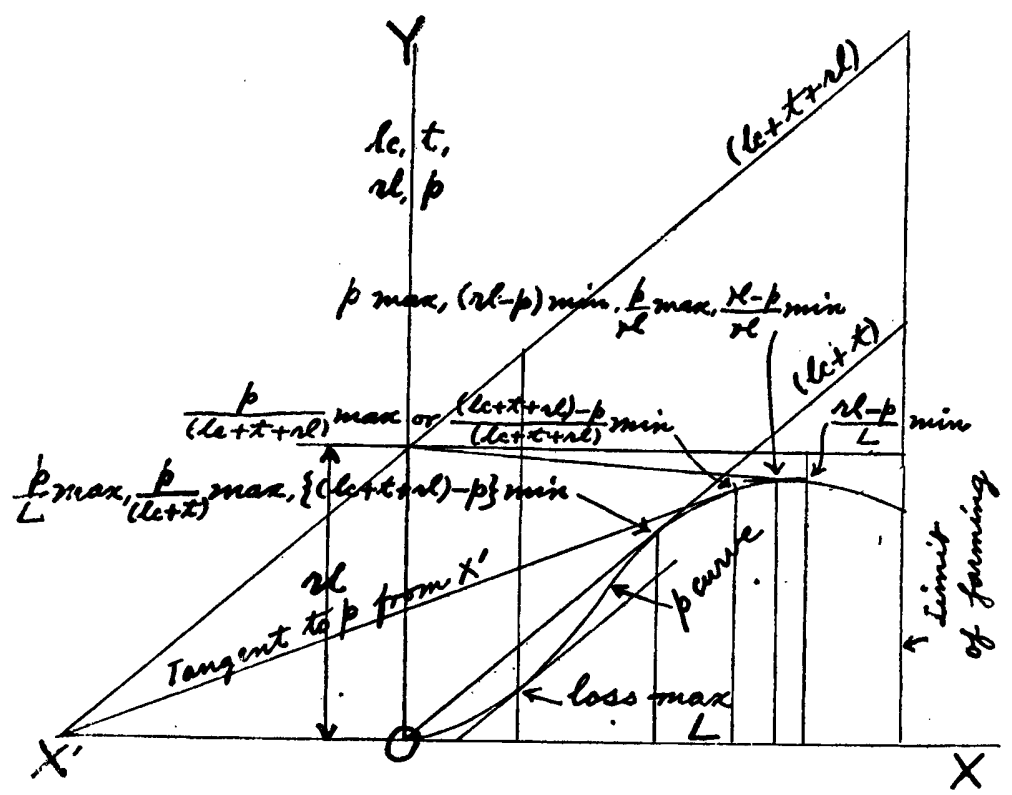

Fig. 23. (I given)

(e) Where gross profit is negative

(i) $\mathrm{p} \max >\mathrm{rl}$

Table A (I) (e) (i). (Fig. 24).

\begin{tabular}{c}
$\frac{\mathrm{p} \max ,(\mathrm{p}-\mathrm{rl}) \max , \mathrm{p} / \mathrm{rl} \max ,(\mathrm{p}-\mathrm{rl}) / \mathrm{rl} \max }{(\mathrm{p}-\mathrm{rl}) / \mathrm{L} \max }$ \\
\hline $\mathrm{p} /(\mathrm{lc}+\mathrm{t}+\mathrm{rl}) \max$ or $\{(\mathrm{lc}+\mathrm{t}+\mathrm{rl})-\mathrm{p}\} /(\mathrm{lc}+\mathrm{t}+\mathrm{r} \mathrm{l}) \min$ \\
\hline $\mathrm{p} / \mathrm{L} \max , \mathrm{p} /(\mathrm{lc}+\mathrm{t}) \max$ or $\{(\mathrm{lc}+\mathrm{t})-\mathrm{p}\} /(\mathrm{lc}+\mathrm{t}) \min$ \\
\hline$\{(\mathrm{lc}+\mathrm{t})-\mathrm{p}\} \min ,\{\mathrm{lc}+\mathrm{t}+\mathrm{rl})-\mathrm{p}\} \min *$ \\
\hline$\{(\mathrm{lc}+\mathrm{t})-\mathrm{p}\} \max ,\{(\mathrm{lc}+\mathrm{t}+\mathrm{rl})-\mathrm{p}\} \max +$
\end{tabular}

* $† *$ exists until, as $p$ decreases or as $(l c+t) / L$ increases, its intensity coincides with that of $\dagger$, where both $*$ and $\dagger$ extinguish. Such intensity of culture corresponds to the point of inflexion of $p$ curve (or to the point of $p$ increment curve where the phenomenon of decreasing returns begins to occur as $\mathrm{L}$ increases) where the line of inflexion is parallel to $(l c+t)$. 


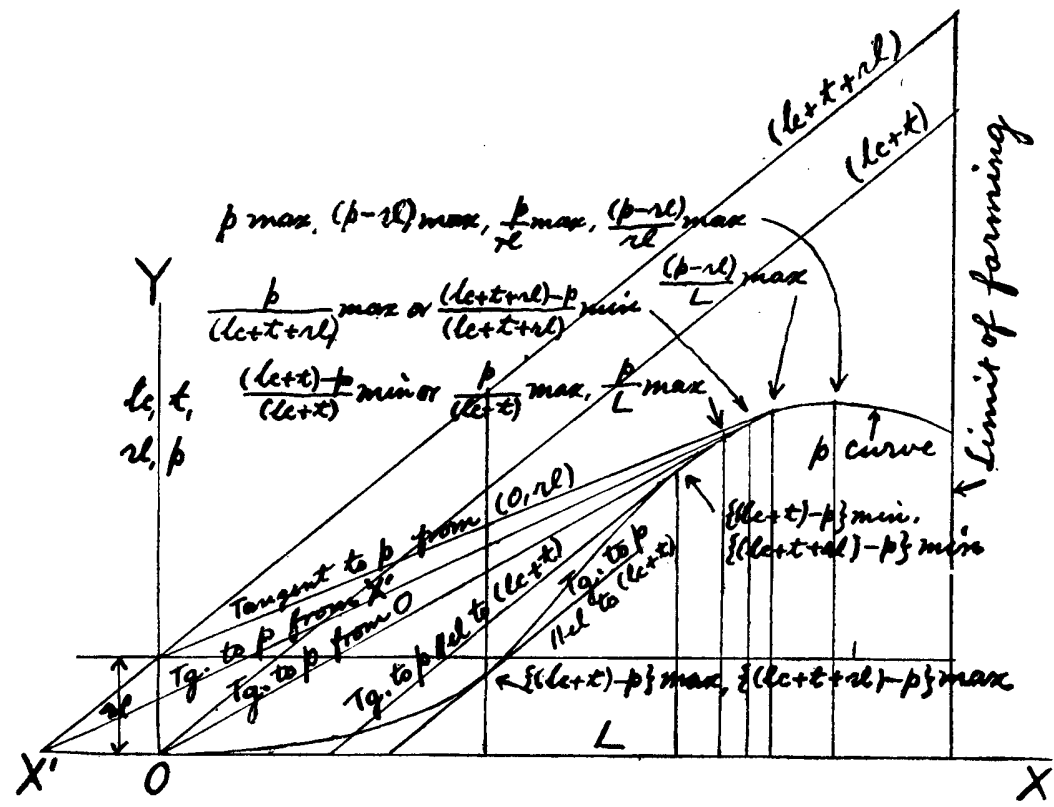

Fig. 24. (1 given)

(ii) $\mathrm{p} \max =\mathrm{r} 1$

Table A (1) (e) (ii). (Fig. 25)

$\mathrm{p} \max , \mathrm{p} / \mathrm{rl} \max$

$\mathrm{p} /(\mathrm{lc}+\mathrm{t}+\mathrm{rl}) \max$ or $\{(\mathrm{lc}+\mathrm{t}+\mathrm{rl})-\mathrm{p}\} /(\mathrm{lc}+\mathrm{t}+\mathrm{rl}) \min$

$\mathrm{p} / \mathrm{L} \max , \mathrm{p} /(\mathrm{lc}+\mathrm{t}) \max$ or $\{(\mathrm{l}+\mathrm{t}+\mathrm{t}) \mathrm{p}\} /(\mathrm{lc}+\mathrm{t}) \min$

$\{(\mathrm{lc}+\mathrm{t})-\mathrm{p}\} \min ,\{(\mathrm{lc}+\mathrm{t}+\mathrm{rl})-\mathrm{p}\} \min$ *

$\{(\mathrm{lc}+\mathrm{t})-\mathrm{p}\} \max ,\{(\mathrm{lc}+\mathrm{t}+\mathrm{rl})-\mathrm{p}\} \max \dagger$ 


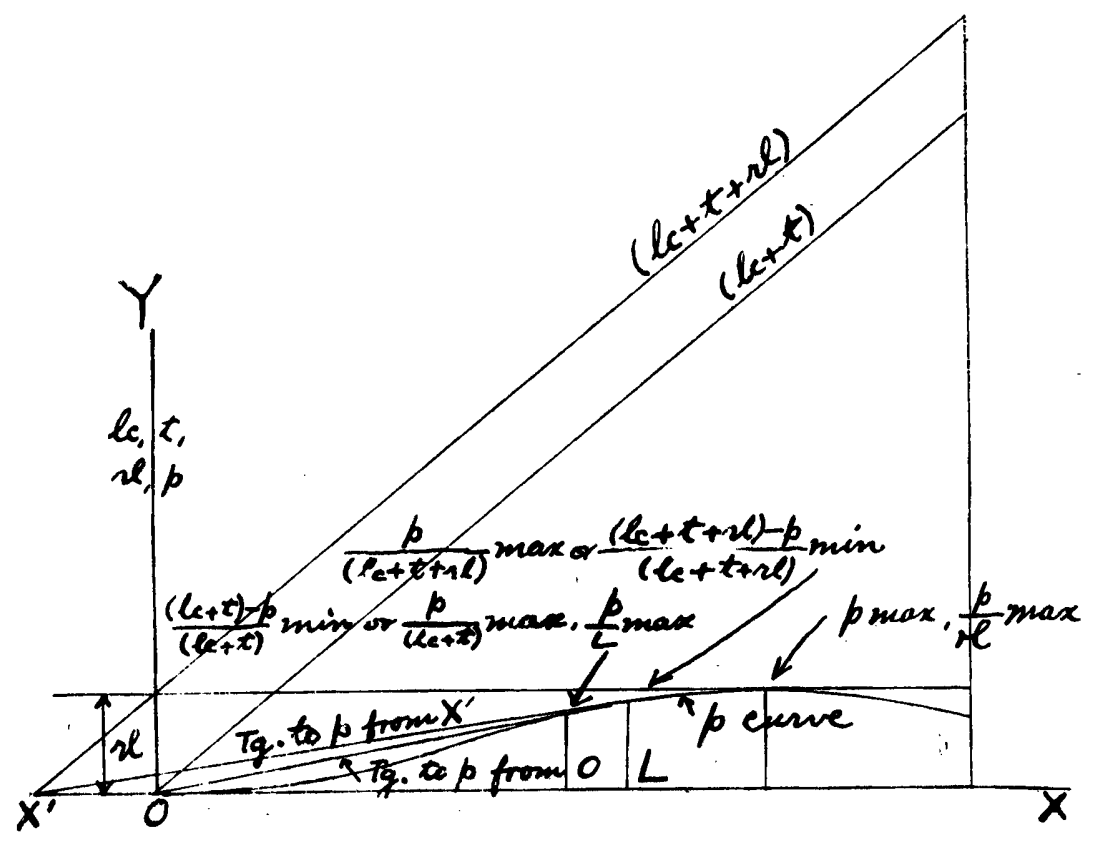

Fig. 25. (l given). Here, loss max and loss min. may exist.

(iii) $\mathrm{p} \max <\mathrm{rl}$

Table A (I) (e) (iii). (Fig. 26)

\begin{tabular}{|c|}
\hline$(\mathrm{rl}-\mathrm{p}) / \mathrm{L} \min$ \\
\hline $\mathrm{p} \max ,(\mathrm{rl}-\mathrm{p}) \min , \mathrm{p} / \mathrm{rl} \max ,(\mathrm{rl}-\mathrm{p}) / \mathrm{rl} \min$ \\
\hline $\mathrm{p} /(\mathrm{lc}+\mathrm{t}+\mathrm{r}))^{\max }$ or $\{(\mathrm{lc}+\mathrm{t}+\mathrm{rl})-\mathrm{p}\} /(\mathrm{lc}+\mathrm{t}+\mathrm{rl}) \min$ \\
\hline $\mathrm{p} / \mathrm{L}, \max , \mathrm{p} /(\mathrm{lc}+\mathrm{t}) \max$ or $\{(\mathrm{lc}+\mathrm{t})-\mathrm{p}\} /(\mathrm{lc}+\mathrm{t}) \min$ \\
\hline$\left.\{(\mathrm{lc}+\mathrm{t})-\mathrm{p}\} \min ^{*}\{\mathrm{lc}+\mathrm{t}+\mathrm{rl})-\mathrm{p}\right\} \min *$ \\
\hline$\{(\mathrm{lc}+\mathrm{t})-\mathrm{p}\} \max ,\{(\mathrm{lc}+\mathrm{t}+\mathrm{rl})-\mathrm{p}\} \max \dagger$ \\
\hline
\end{tabular}




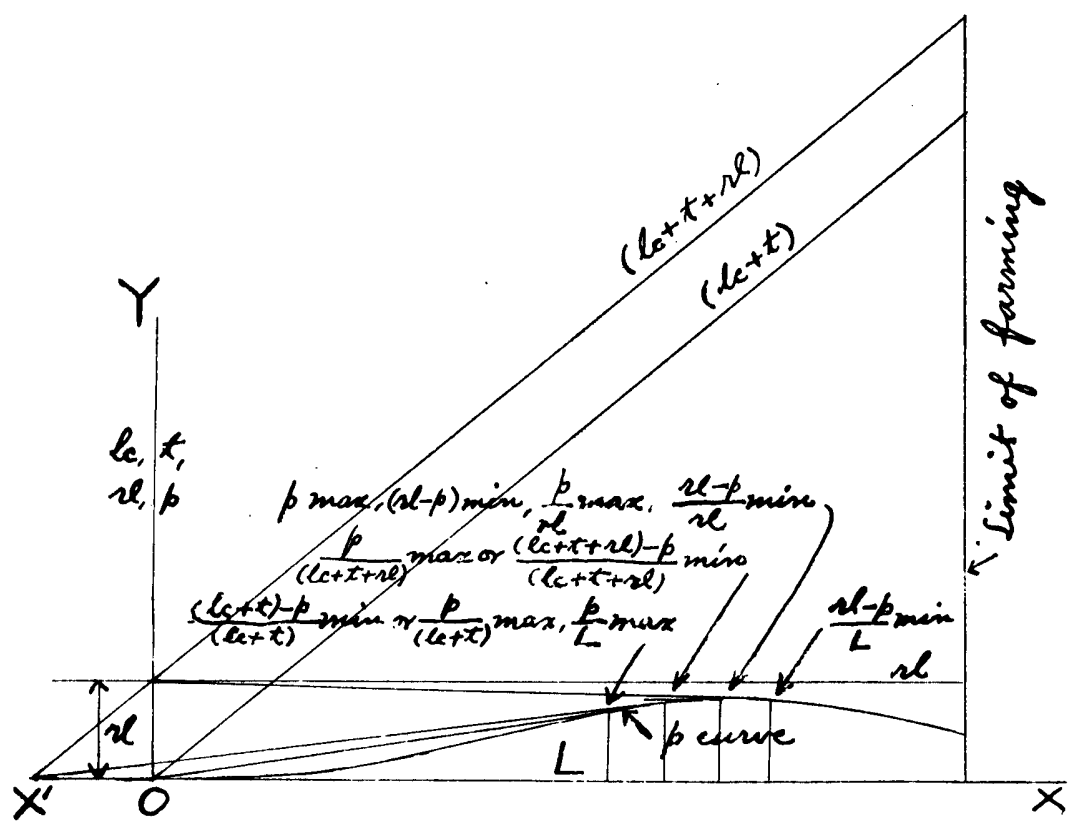

Fig. 26. (l given). Here, loss max and loss min. may exist.

Notice ( $\mathrm{I})$ :- -Regarding the relative positions of $\mathrm{L}$ to give $(\mathrm{p}=\mathrm{rl})$, $\{\mathrm{p}=(\mathrm{l} c+\mathrm{t})\}$ and $\{\mathrm{rl}=(\mathrm{lc}+\mathrm{t})\}$ in the case of the fixed tenancy by money, the following five cases can be considered when gross profit is positive and $\mathrm{p} \max >\mathrm{rl}:-$

(i) Case where $\mathrm{Gp}$ is entirely within the range of $\mathrm{rl}>(\mathrm{lc}+\mathrm{t})$, as shown in Fig. 27.

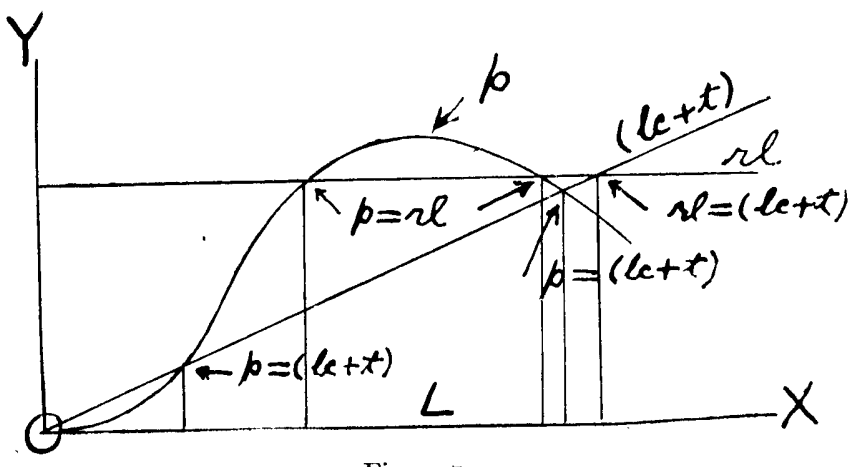

Fig. 27. 
(ii) Case where $\mathrm{Gp}$ is within the range of $\mathrm{rl}>(\mathrm{lc}+\mathrm{t})$ but its intensive limit is at $\mathrm{p}=\mathrm{rl}=(\mathrm{lc}+\mathrm{t})$, as shown in Fig. 28 .

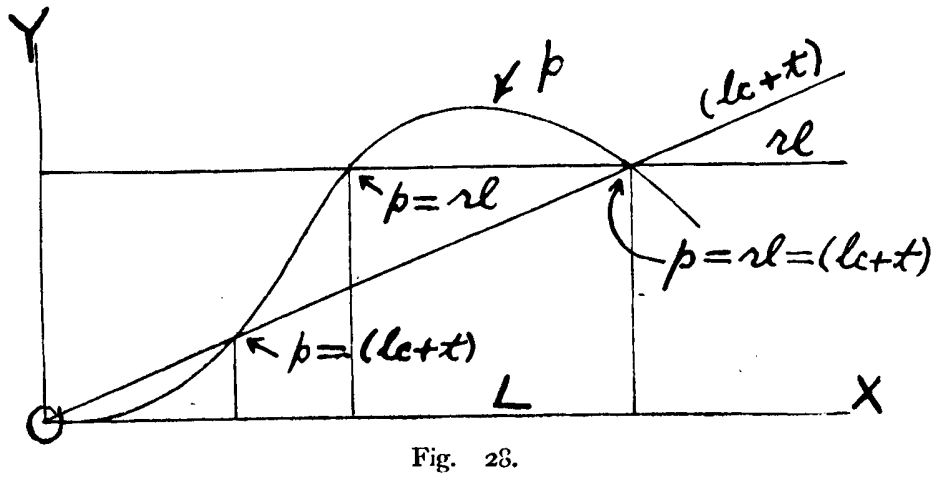

(iii) Case where Gp extends over both ranges of $\mathrm{rl}>(\mathrm{lc}+\mathrm{t})_{*}$ and $\mathrm{rl}<(\mathrm{lc}+\mathrm{t})$, as shown in Fig. 29 .

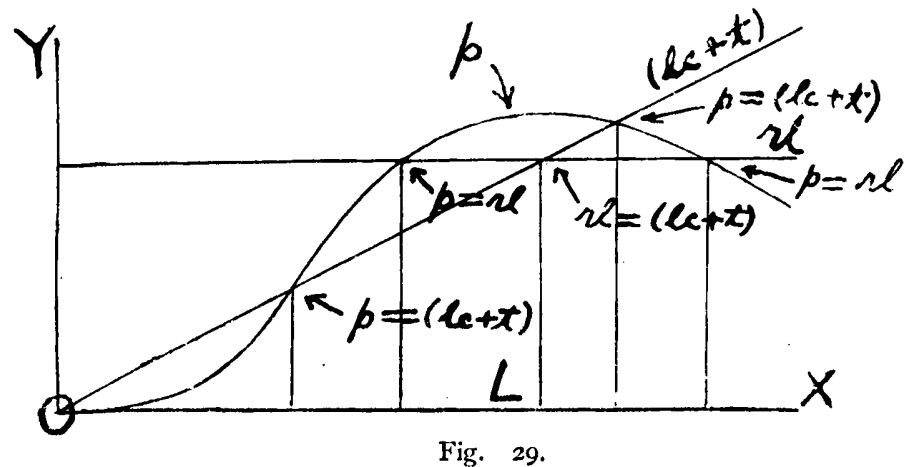

(iv) Case where $\mathrm{Gp}$ is within the range of $\mathrm{rl}<(\mathrm{lc}+\mathrm{t})$ but its extensive limit is at $\mathrm{p}=\mathrm{rl}=(\mathrm{lc}+\mathrm{t})$, as shown in Fig. 30 .

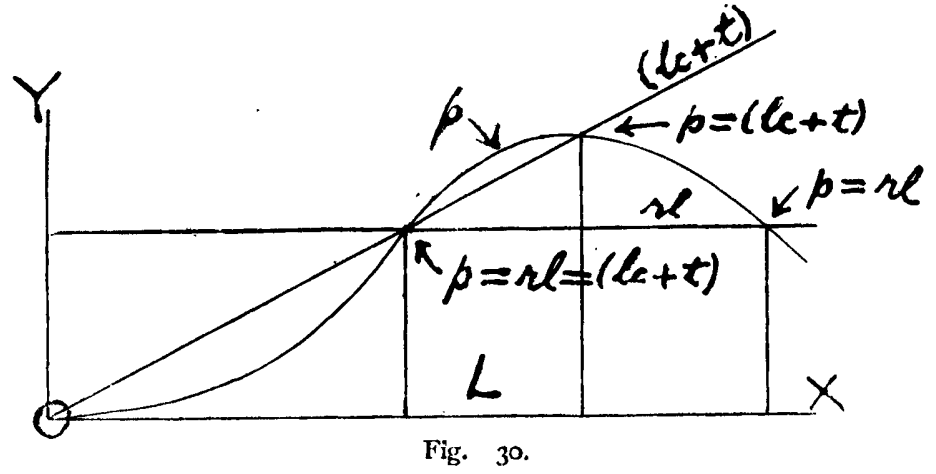


(v) Case where $\mathrm{Gp}$ is entirely within the range of $\mathrm{rl}<(\mathrm{lc}+\mathrm{t})$, as shown in Fig. 31 .

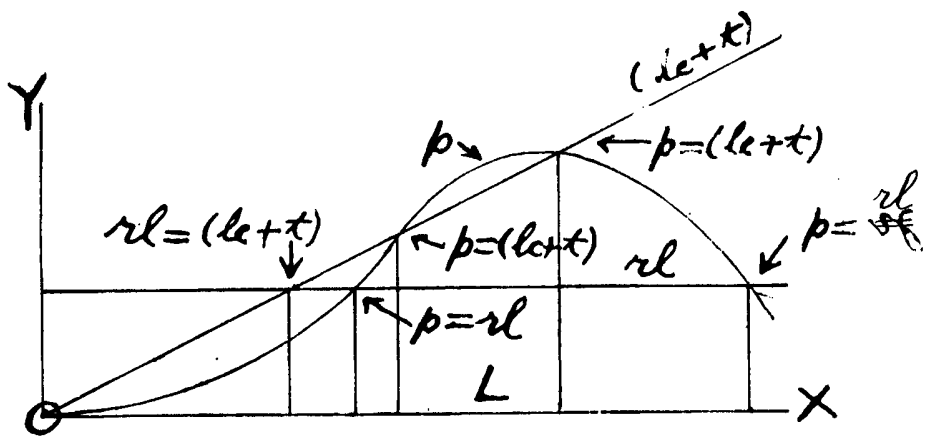

Fig. $3 \mathbf{r}$.

Notice (2):-Regarding the effect of $t$ on the intensities of culture. In case ( $\mathrm{I}), \mathrm{t}$ is assumed to be proportional to $\mathrm{L}$. This assumption is adopted for making the construction of the figures simple and for convenience of easy understanding. Generally speaking, $t$ may be classified into three fundamental groups i.e.

(a) Those which are fixed in amount and have no concern with $\mathrm{L}$.

(b) Those which are proportional to $\mathrm{L}$.

(c) Those which change their amounts at uncertain rates as L changes.

In the actual cases, one or more of these groups may come to occurence separately or in some combinations. The features of these $t$ appearing on the figures in ( $I$ ) case may be shown on Fig. 32 for (a), Fig. 33 for (b) and Fig. 34 and Fig. 35 for $(c)$. In (b), the effect of $t$ on the intensities of culture is so simple as there is no need of

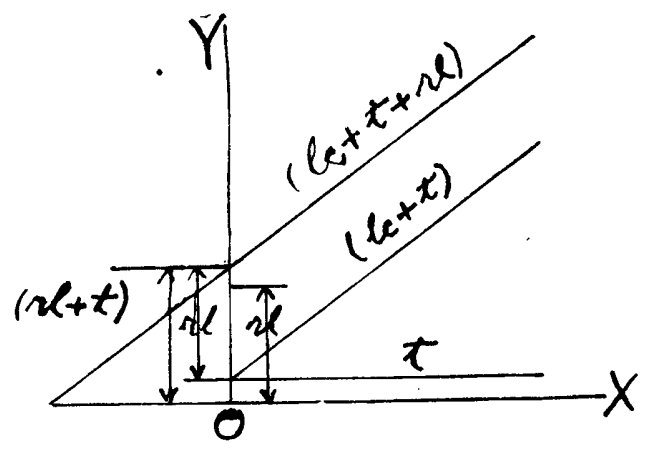

Fig. 32. 
explanation. In $(a)$, the $(\mathrm{lc}+\mathrm{t})$ line starts at $(\mathrm{O}, \mathrm{t})$ instead of the origin $\mathrm{O}$ and the effect of $\mathrm{t}$ on the intensities is also simple. In both these cases, several goals have some shifts of intensities in consequence of $\mathrm{t}$ introduced or not; and in the case of $(a)$, the relative positions of intensities of some goals may differ from those tabulated above. In this investigation, the discussion is limited to the $(b)$ case only.

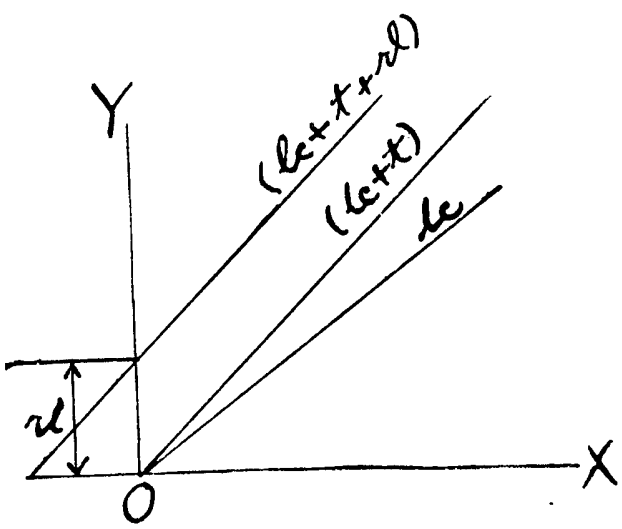

Fig. 33

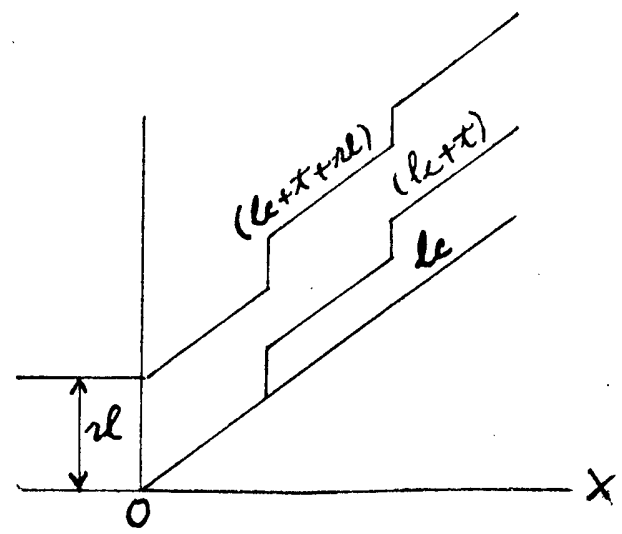

Fig. 34.

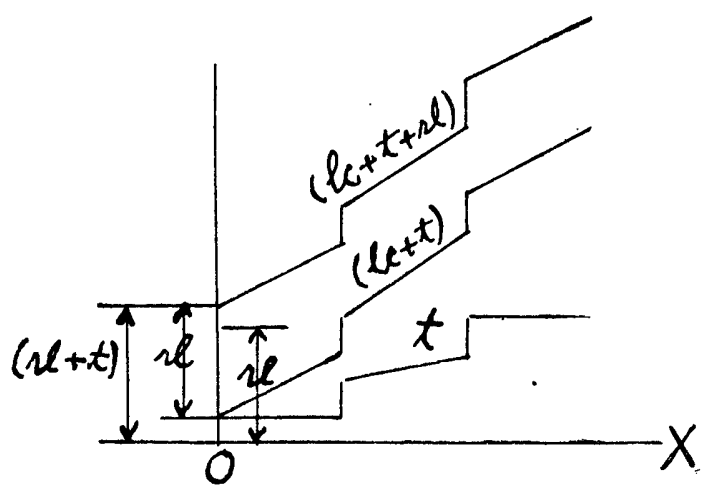

Fig. 35 .

(2) Case of share tenancy by money

(a) Where net profit exists 
Table A (2) (a) (Fig. 36)

\begin{tabular}{l}
\hline \hline $\mathrm{p} \max ,(\mathrm{p}-\mathrm{rs}) \max$ \\
\hline $\mathrm{Gp} \max$ \\
\hline $\mathrm{Np} \max$ \\
\hline $\mathrm{p} / \mathrm{L} \max , \mathrm{Gp} / \mathrm{L} \max ,(\mathrm{p}-\mathrm{rs}) / \mathrm{L} \max , \mathrm{Np} / \mathrm{L} \max , \mathrm{p} /(\mathrm{lc}+\mathrm{t}) \max$ or \\
$\mathrm{Gp} /(\mathrm{lc}+\mathrm{t}) \max , \mathrm{p} /(\mathrm{lc}+\mathrm{t}+\mathrm{rs}) \max$ or $\mathrm{Np} /(\mathrm{lc}+\mathrm{t}+\mathrm{rs}) \max$ \\
\hline$\{(\mathrm{lc}+\mathrm{t}+\mathrm{rs})-\mathrm{p}\} \max$ \\
\hline$\{(\mathrm{lc}+\mathrm{t})-\mathrm{p}\} \max$ \\
\hline
\end{tabular}

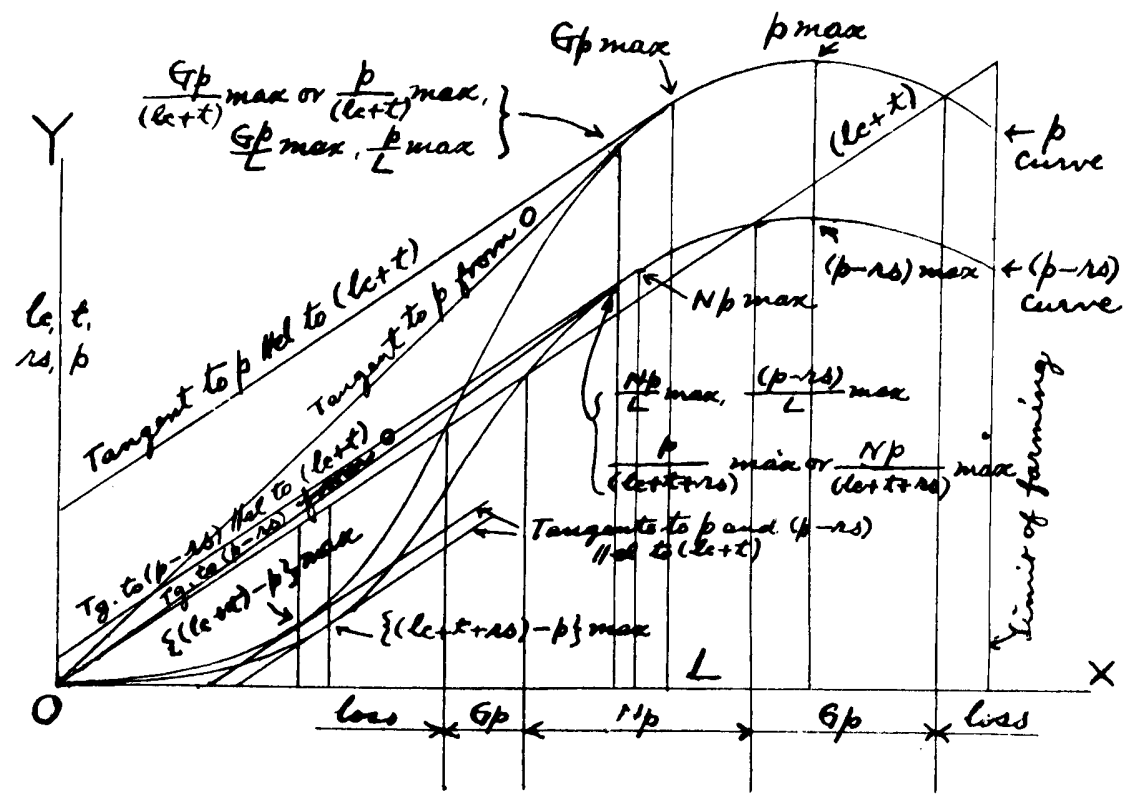

Fig. 36. (1 given)

Special attention should be called for the fact that in (2) (a) the intensities of culture at $\mathrm{Gp} m a x$ and at $\mathrm{Np}$ max are different to each other and those at $\mathrm{Gp} / \mathrm{L} \max$ and at $\mathrm{Np} / \mathrm{L} \max$ are the same, while in (I) (a) those at Gp max and at Np max are the same and those at 
$\mathrm{Gp} / \mathrm{L} \max$ and $\mathrm{Np} / \mathrm{L} \max$ are different to each other; and that in (2) (a) those of $\{(\mathrm{lc}+\mathrm{t})-\mathrm{p}\} \quad$ max and $\{(\mathrm{lc}+\mathrm{t}+\mathrm{rs})-\mathrm{p}\}$ max are different to each other while in ( $I$ ) (a) they are the same.

(b) Where net profit $=\mathrm{O}$

Table A (2) (b). (Fig. 37)

\begin{tabular}{c}
\hline$\frac{\mathrm{p} \max ,(\mathrm{p}-\mathrm{rs}) \max }{\mathrm{Gp} \max }$ \\
\hline $\begin{array}{r}\mathrm{p} / \mathrm{I}, \max , \mathrm{Gp} / \mathrm{L}, \max ,(\mathrm{p}-\mathrm{rs}) / \mathrm{L} \text { max, } \mathrm{p} /(\mathrm{lc}+\mathrm{t}) \max \text { or } \mathrm{Gp} /(\mathrm{lc}+\mathrm{t}) \max , \\
\mathrm{p} /(\mathrm{l}+\mathrm{t}+\mathrm{rs}) \max \end{array}$ \\
\hline$(\mathrm{l} \mathrm{c}+\mathrm{t}+\mathrm{rs})-\mathrm{p}\} \max$ \\
$\{(\mathrm{lc}+\mathrm{t})-\mathrm{p}\} \max$
\end{tabular}

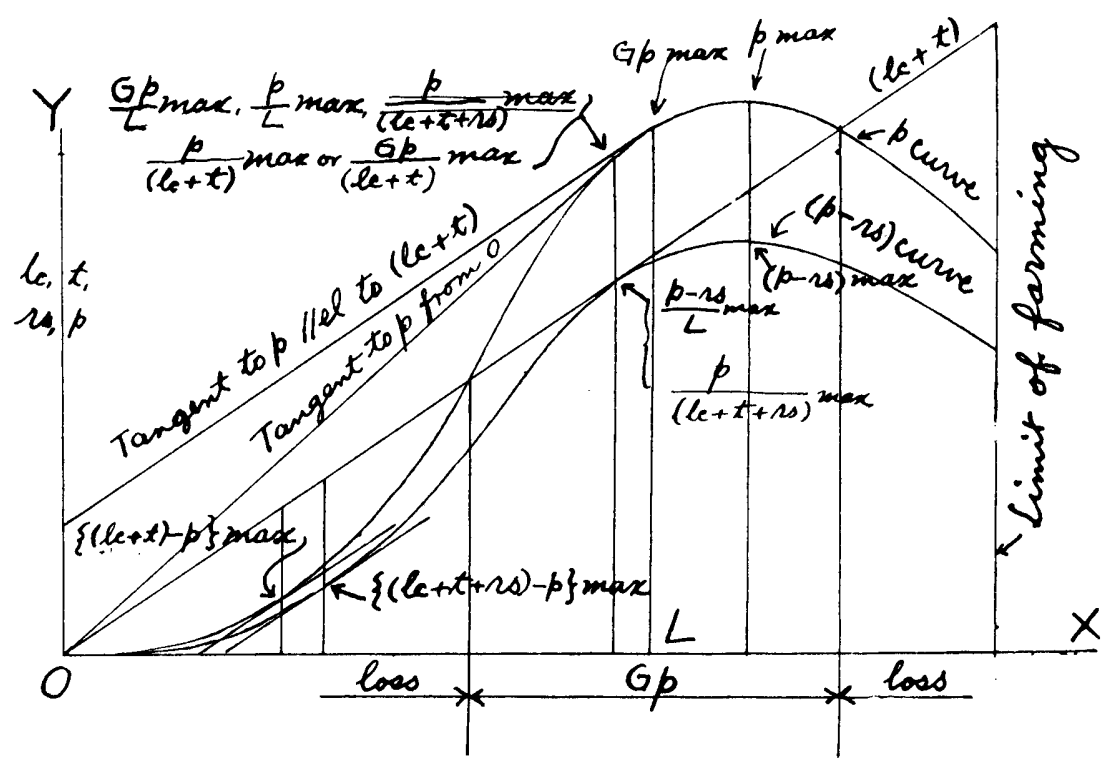

Fig. 37. (1 given) 
(c). Where net profit is negative and gross profit is positive Table A (2) (c). (Fig. 38)

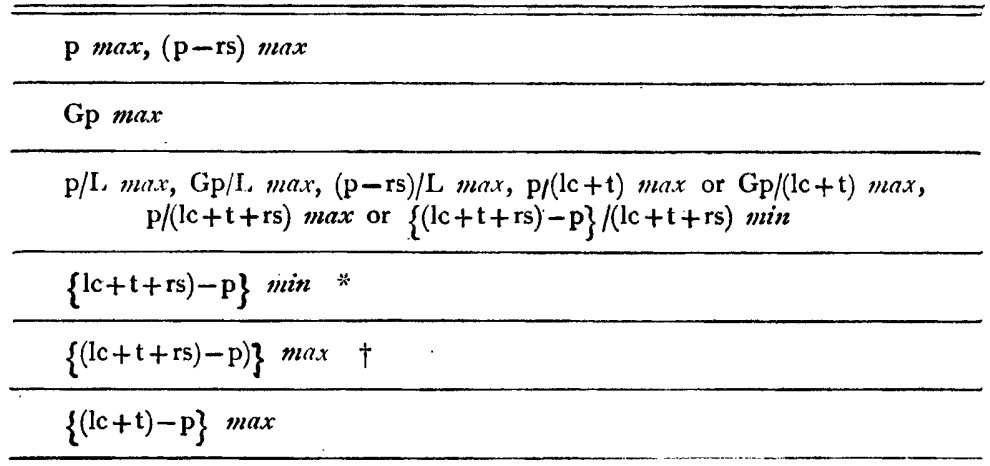

* $\dagger *$ exists until, as $p$ decreases or as $(l c+t) / I$, increases, its intensity coincides with that of $\dagger$, where both $*$ and $\dagger$ extinguish. Such intensity of culture corresponds to the point of inflexion of $p$ or $(p-r s$ ) curve (or to the point of $p$ increment curve where the phenomenon of decreasing returns begins to occur as $\mathrm{I}$, increases) where the line of inflexion is parallel to $(\mathrm{lc}+\mathrm{t})$.

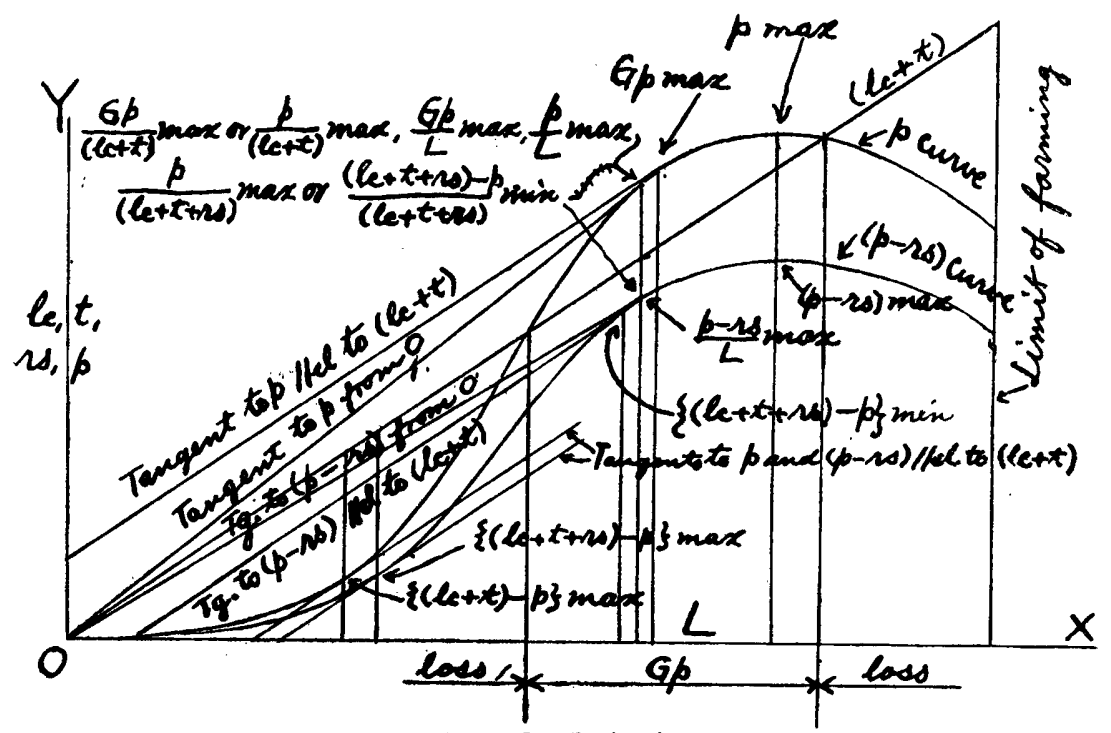

Fig. 38. (1 given) 
(d) Where gross profit $=0$

Table A (2) (d). (Fig. 39)

\begin{tabular}{|c|}
\hline $\mathrm{p} \max ,(\mathrm{p}-\mathrm{rs}) \max$ \\
\hline $\begin{array}{l}\mathrm{p} / \mathrm{L}, \max ,(\mathrm{p}-\mathrm{rs}) / \mathrm{I}, \max , \mathrm{p} /(\mathrm{l} \mathrm{c}+\mathrm{t}) \max , \mathrm{p} /(\mathrm{lc}+\mathrm{t}+\mathrm{rs}) \max \text { or } \\
\{(\mathrm{lc}+\mathrm{t}+\mathrm{rs})-\mathrm{p}\} /(\mathrm{lc}+\mathrm{t}+\mathrm{rs}) \min \end{array}$ \\
\hline$\{(\mathrm{lc}+\mathrm{t}+\mathrm{rs})-\mathrm{p}\} \min *$ \\
\hline$\{(\mathrm{lc}+\mathrm{t}+\mathrm{rs})-\mathrm{p}\} \max \dagger$ \\
\hline$\{(l c+t)-p\} \max$ \\
\hline
\end{tabular}

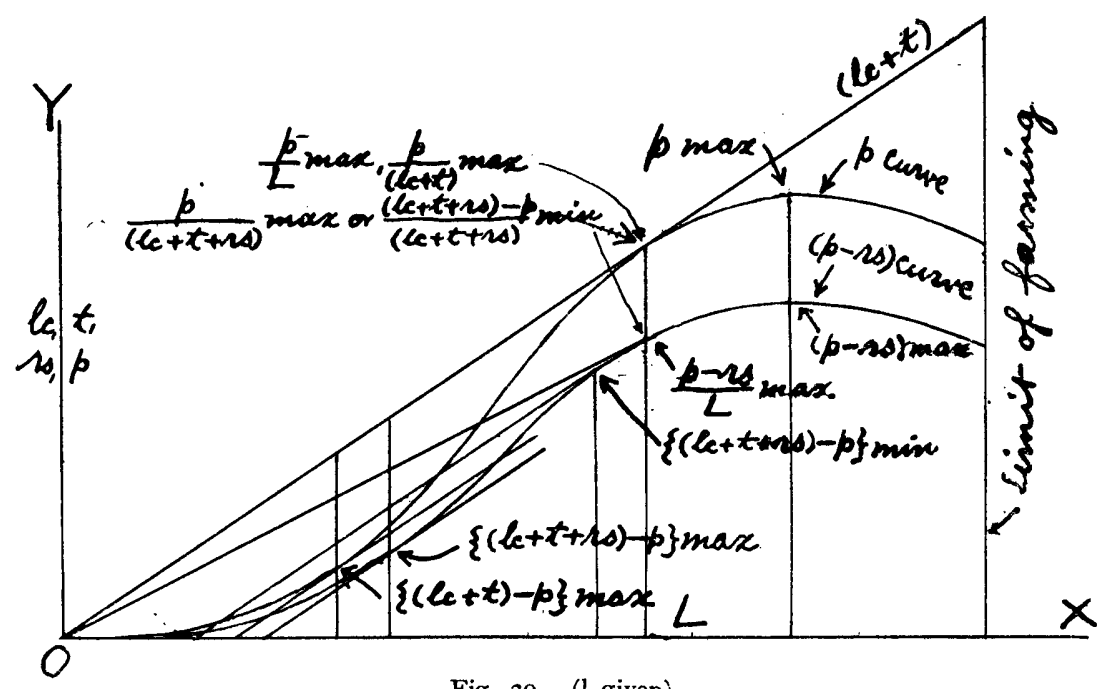

Fig. 39. (1 given) 
(e) Where gross profit is negative

Table A (2) (e). (Fig. 40)

\begin{tabular}{|c|}
\hline $\mathrm{p} \max ,(\mathrm{p}-\mathrm{rs}) \max$ \\
\hline $\begin{array}{c}\mathrm{p} / \mathrm{L}, \max ,(\mathrm{p}-\mathrm{rs}) / \mathrm{L} \max , \mathrm{p} /(\mathrm{lc}+\mathrm{t}) \max \text { or }\{(\mathrm{lc}+\mathrm{t})-\mathrm{p}\} /(\mathrm{lc}+\mathrm{t}) \min \\
\mathrm{p} /(\mathrm{lc}+\mathrm{t}+\mathrm{rs}) \max \text { or }\{(\mathrm{lc}+\mathrm{t}+\mathrm{rs})-\mathrm{p}\} /(\mathrm{lc}+\mathrm{t}+\mathrm{rs}) \min \end{array}$ \\
\hline$\{(\mathrm{lc}+\mathrm{t})-\mathrm{p}\}$ min $\otimes$ \\
\hline$\{(\mathrm{lc}+\mathrm{t}+\mathrm{rs})-\mathrm{p}\} \min *$ \\
\hline$\{(\mathrm{lc}+\mathrm{t}+\mathrm{rs})-\mathrm{p}\} \max \dagger$ \\
\hline
\end{tabular}

The relation between $\otimes$ and $\omega$ is the same as that between * and $\dagger$.

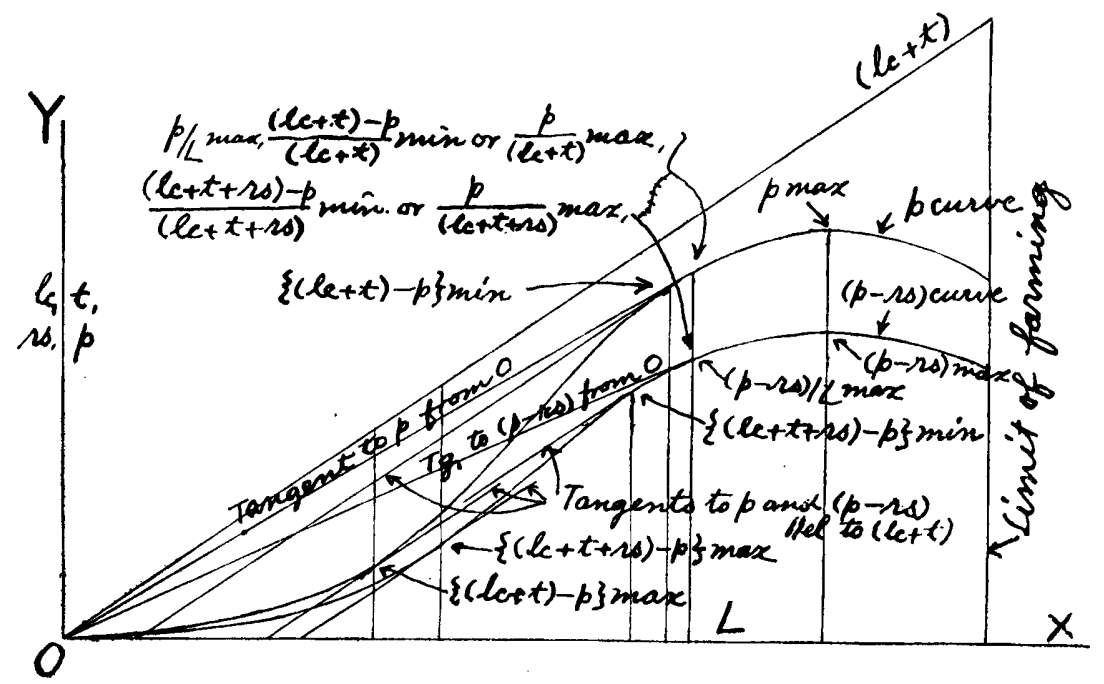

Fig. 40. (l given)

Notice :-Regarding the relative positions of $\mathrm{L}$ to give $\{\mathrm{p}=(\mathrm{lc}+\mathrm{t})\}$ and $\{p=(l c+t+r s)\}$, L to give $\{p=(l c+t+r s)\}$, when they exist, come always between $\mathrm{L}$, to give $\{\mathrm{p}=(\mathrm{lc}+\mathrm{t})\}$.

(3) Case of tenancy by substance

This is the case where the cases I A and II A A) I) or II A A) 2) are combined. In this case, the intensity to give $(P-R)$ max 
or $\{\mathrm{p}-($ price of $\mathrm{R})\} \max$ coincides with that to give $\mathrm{P} \max$ or $\mathrm{p} \max$ and the intensity to give $(\mathrm{P}-\mathrm{R}) / \mathrm{L}$ max coincides with that to give $\{\mathrm{p}-($ price of $\mathrm{R})\} / \mathrm{L} \max$ and when $\mathrm{Np}$ is positive with that to give $\mathrm{Np} / \mathrm{L}$ max respectively.

\section{1). CASE WHERE AREA OF LAND IS NOT FIXED}

Here the curves of the prices form a solid. Discussion of the cases of tenancy by substance is omitted for this case.

I) Case where, as 1 increases, both $p$ and $L$ increase in proportion with 1

The solid surface generated by $p$ curves in this case is quite similar to that generated by $\mathrm{P}$ curves in the case IB I). All properties described above about the intensities of culture to give $\mathrm{P}$ max and $\mathrm{P} / \mathrm{L}$ max in the case $\mathrm{IB}$ I) are noticed to exist in this case about those to give $\mathrm{p} \max$ and $\mathrm{p} / \mathrm{L}$ max. The intensities of culture to give $\mathrm{Gp} \max , \mathrm{Gp} / \mathrm{L} \max ,(\mathrm{p}-\mathrm{r}) \max ,(\mathrm{p}-\mathrm{r}) / \mathrm{L} \max , \mathrm{Np} \max , \mathrm{Np} / \mathrm{L} \max$, $\mathrm{p} /(\mathrm{lc}+\mathrm{t}) \max$ or $\mathrm{Gp} /(\mathrm{lc}+\mathrm{t}) \max , \mathrm{p} /(\mathrm{l} \mathrm{c}+\mathrm{t}+\mathrm{r}) \max$ or $\mathrm{Np} /(\mathrm{lc}+\mathrm{t}+\mathrm{r})$ max, etc. on the respective 1 in this case are arranged in the same way as those in II A A). The lines of the intensities of culture constructed on the $\mathrm{XZ}$ plane by projecting the points of the same meaning in the $p$ curve solid surface are the straight lines radiating from the origin. For example are shown on Fig. 41 and Plate 39 the states of these lines in a case of fixed tenancy by money when net profit exists. Here the following properties are noticed:-

(I) Those 1 and $\mathrm{L}$ combinations which have the same meaning at the respective 1 or $L$ have the same intensity of culture throughout.

(2) The intensity of culture, where any certain 1 combines with $\mathrm{L}$ so as to give $\mathrm{p} \max ,(\mathrm{p}-\mathrm{r}) \max , \mathrm{Gp} \max , \mathrm{Np} \max , \mathrm{p} / \mathrm{L} \max ,(\mathrm{p}-\mathrm{r}) / \mathrm{L}$ $\max , \mathrm{Gp} / \mathrm{L} \max$ or $\mathrm{Np} / \mathrm{L} \max$ on 1 , is the intensity of culture where $\mathrm{p} / \mathrm{l}$, $(\mathrm{p}-\mathrm{r}) / \mathrm{l}, \mathrm{Gp} / \mathrm{l}, \mathrm{Np} / \mathrm{l}, \mathrm{p},(\mathrm{p}-\mathrm{r}), \mathrm{Gp}$ or $\mathrm{Np}$ is $\max$ at the $\mathrm{L}$ respectively.

(3) The intensity of culture, where any certain $\mathrm{L}$ combines with 1 so as to give $\mathrm{p} / \mathrm{I} \max ,(\mathrm{p}-\mathrm{r}) / 1 \max , \mathrm{Gp} / 1 \max , \mathrm{Np} / \mathrm{l} \max , \mathrm{p} \max ,(\mathrm{p}-\mathrm{r})$ max, Gp max or $\mathrm{Np} \max$ at $\mathrm{L}$, is the intensity of culture where $\mathrm{p}$, $(\mathrm{p}-\mathrm{r}), \mathrm{Gp}, \mathrm{Np}, \mathrm{p} / \mathrm{L},(\mathrm{p}-\mathrm{r}) / \mathrm{L}, \mathrm{Gp} / \mathrm{L}$ or $\mathrm{Np} / \mathrm{L}$ is $\max$ on the 1 respectively.

(4) The intensity of culture to give $\mathrm{p} \max$, ( $\mathrm{p}-\mathrm{r}$ ) max, Gp max, $\mathrm{Np} \max , \mathrm{p} / \mathrm{L} \max ,(\mathrm{p}-\mathrm{r}) / \mathrm{L} \max , \mathrm{Gp} / \mathrm{L} \max$ or $\mathrm{Np} / \mathrm{L} \max$ on 1 , is 
the same as that to give $\mathrm{p} / \mathrm{l} \max ,(\mathrm{p}-\mathrm{r}) / 1 \max , \mathrm{Gp} / 1$ max, $\mathrm{Np} / 1$ max, $\mathrm{p} \max ,(\mathrm{p}-\mathrm{r}) \max , \mathrm{Gp} \max$ or $\mathrm{Np} \max$ at $\mathrm{L}$ respectively.

(5) The intensity of culture, where any certain 1 or $\mathrm{L}$ combines with $\mathrm{L}$ or $\mathrm{l}$ so as to give $\mathrm{p} / \mathrm{rl} \max , \mathrm{p} /(\mathrm{lc}+\mathrm{t}) \max$ or $\mathrm{p} /(\mathrm{l} \mathrm{c}+\mathrm{t}+\mathrm{r}) \max$ on 1 or at $\mathrm{L}$ respectively, is the intensity of culture of the same meaning at the $L$ or on the 1 respectively.

(6) The intensity of culture which gives $\mathrm{p} / \mathrm{rl} \max , \mathrm{p} /(\mathrm{l} c+\mathrm{t}) \max$ or $\mathrm{p} /(\mathrm{lc}+\mathrm{t}+\mathrm{r}) \max$ on 1 gives $\mathrm{p} / \mathrm{rl} \max , \mathrm{p} /(\mathrm{l} \mathrm{c}+\mathrm{t}) \max$ or $\mathrm{p} /(\mathrm{l} \mathrm{c}+\mathrm{t}+\mathrm{r})$ $\max$ at $\mathrm{L}$ at the same time respectively.

(7) Comparing $\mathrm{p} \max ,(\mathrm{p}-\mathrm{r}) \max$, Gp max or $\mathrm{Np} \max$ at different 1 or $\mathrm{L}$ respectively, the greater is 1 or $\mathrm{L}$ the greater is the amount.

(8) Comparing $\mathrm{p} / \mathrm{L} \max ,(\mathrm{p}-\mathrm{r}) / 1 \max , \mathrm{Gp} / \mathrm{L} \max$ or $\mathrm{Np} / \mathrm{L} \max$ on different 1 or $\mathrm{p} / 1 \max ,(\mathrm{p}-\mathrm{r}) / 1 \max , \mathrm{Gp} / \mathrm{l} \max$ or $\mathrm{Np} / 1 \max$ at different $L$, they are always the same in amount respectively with no concern with the amount of 1 or $\mathrm{L}$.

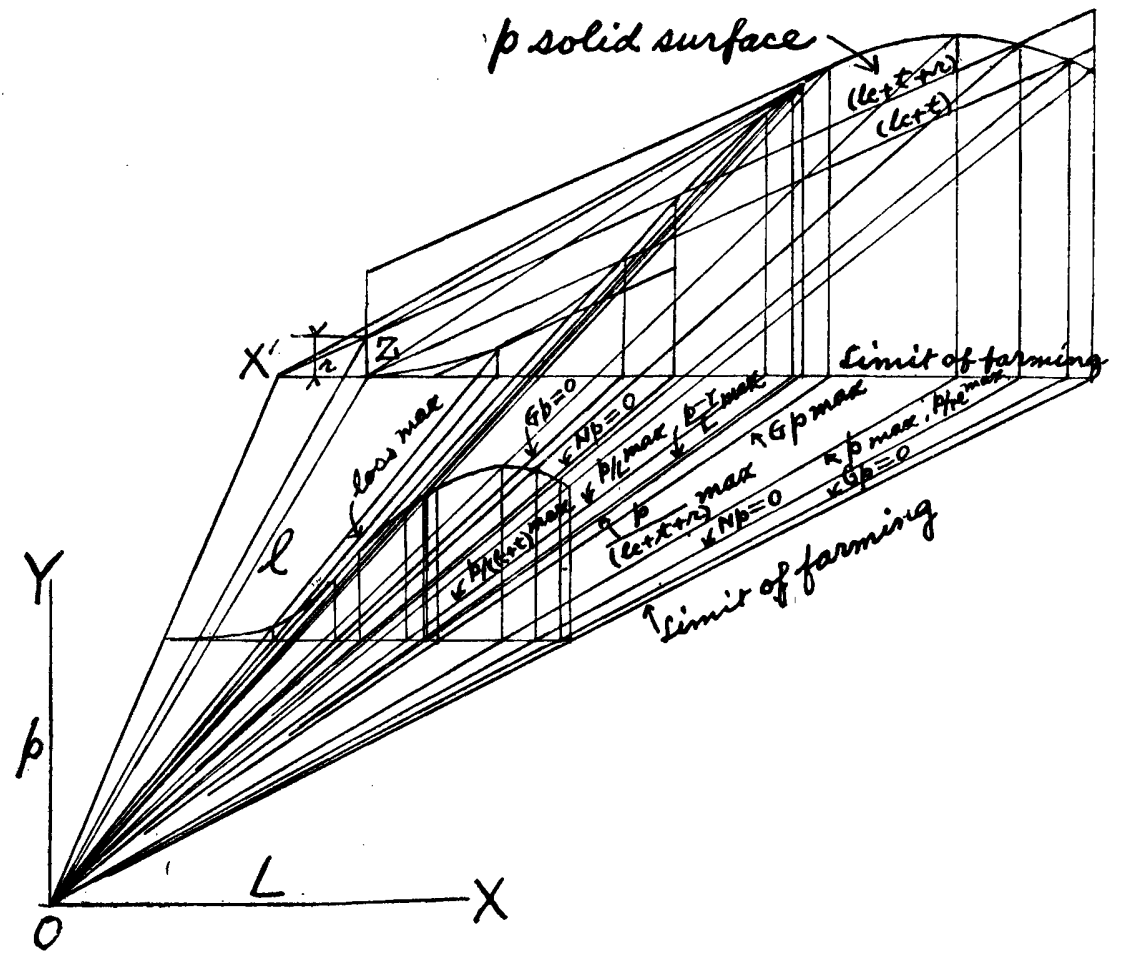

Fig. 4I. 
(9) Comparing $\mathrm{p} / \mathrm{rl} \max , \mathrm{p} /(\mathrm{lc}+\mathrm{t}) \max$ or $\mathrm{p} /(\mathrm{lc}+\mathrm{t}+\mathrm{r}) \max$ at different 1 or $\mathrm{L}$, they are always the same in amount respectively with no concern with the amount of 1 and $\mathrm{L}$.

(I0) Orders of the intensities of culture for several goals are the same as those in case A).

(I I) While a law of decreasing returns exists on each of different 1, another law of decreasing returns exists at the same time at each of different $\mathrm{L}$. The intensities of culture to give $(\mathrm{p} / \mathrm{r} 1$ max $),\{\mathrm{p} /(\mathrm{lc}+\mathrm{t})$ $m a x\},\{\mathrm{p} /(\mathrm{l} \mathrm{c}+\mathrm{t}+\mathrm{r})$ max $\},(\mathrm{Gp}=\mathrm{O})$ and $(\mathrm{Np}=\mathrm{O})$ on one of these $\mathrm{p}$ curves have the same meaning on the other $p$ curves respectively. Plate 39 is to show the relation.

All the properties described above are to be proved, but here some important ones only are proved for example.

Example I:-The intensity of culture, where any certain $1 \mathrm{com}-$ bines with $\mathrm{L}$ so as to give $\mathrm{p} /(\mathrm{lc}+\mathrm{t}+\mathrm{r}) \max$ on 1 , is the intensity of culture of the same meaning at the $\mathrm{L}$.

Proof:-In Fig. 42, the combination to be $\mathrm{p} /(\mathrm{lc}+\mathrm{t}+\mathrm{r}) \max$ on 1 , any certain 1 , is denoted by $(\mathrm{Ll})$, where the amount of $\mathrm{p}$ is $\mathrm{p}_{\mathrm{o}}$ and the corresponding amount of $(l c+t)$ is $(l c+t)_{0}$. If $\left(\mathrm{Ll}_{\mathrm{r}} \mathrm{p}_{\mathrm{x}}\right)$ is any other point on the $\mathrm{p}$ curve solid surface, situated in the vicinity of $\left(\mathrm{Llp}_{\mathrm{o}}\right)$ and having the same $L$ as $\left(I, 1 p_{o}\right)$, then $p_{o} /\left\{(l c+t)_{0}+r\right\}>p_{1} /\left\{(l c+t)_{0}+r_{1}\right\}$ is to be proved.

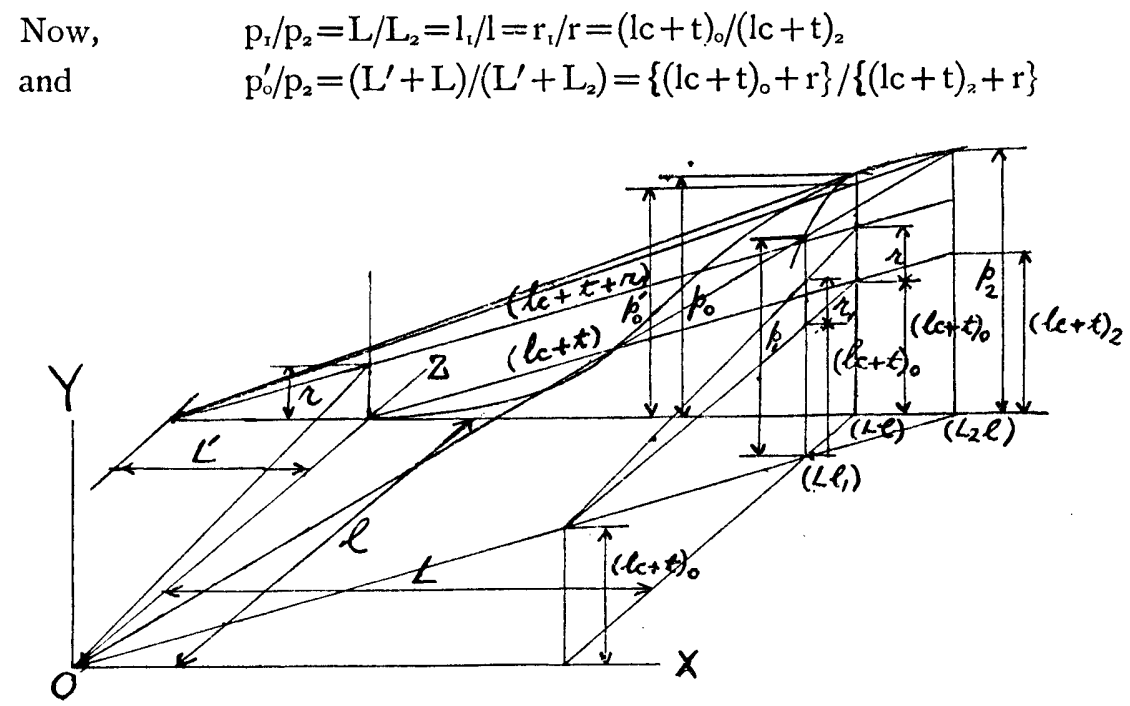

Fig. 42. 


$$
\therefore \quad \begin{aligned}
\mathrm{p}_{\mathrm{o}}^{\prime} /\left\{(\mathrm{lc}+\mathrm{t})_{0}+\mathrm{r}\right\} & =\mathrm{p}_{2} /\left\{(\mathrm{lc}+\mathrm{t})_{2}+\mathrm{r}\right\} \\
& =\mathrm{p}_{2} /\left\{(\mathrm{lc}+\mathrm{t})_{0} \times \mathrm{r} / \mathrm{r}_{1}+\mathrm{r}\right\} \\
& =\mathrm{p}_{2} \times \mathrm{r}_{\mathrm{r}} / \mathrm{r} \div\left\{(\mathrm{lc}+\mathrm{t})_{\mathrm{o}}+\mathrm{r} \times \mathrm{r}_{\mathrm{r}} / \mathrm{r}\right\} \\
& \left.=\mathrm{p}_{\mathrm{I}} /\{\mathrm{lc}+\mathrm{t})_{0}+\mathrm{r}_{\mathrm{r}}\right\}
\end{aligned}
$$

and

$$
\mathrm{p}_{\mathrm{o}}>\mathrm{p}_{\mathrm{o}}^{\prime}
$$

$\therefore \quad \mathrm{p}_{\mathrm{o}} /\left\{(\mathrm{lc}+\mathrm{t})_{\mathrm{o}}+\mathrm{r}\right\}>\mathrm{p}_{\mathrm{r}} /\left\{(\mathrm{lc}+\mathrm{t})_{\mathrm{o}}+\mathrm{r}_{\mathrm{r}}\right\}$, the proposition.

Example II:-The intensity of culture, where any certain $1 \mathrm{com}$ bines with $\mathrm{L}$. so as to give $\{\mathrm{p}-(\mathrm{lc}+\mathrm{t})\} \max$ on 1 , is the intensity of culture where $\{\mathrm{p}-(\mathrm{lc}+\mathrm{t})\} / 1$ is $\max$ at the $\mathrm{L}$.

Proof:-In Fig. 43, the combination to give $\{\mathrm{p}--(\mathrm{lc}+\mathrm{t})\}$ max on 1 , any certain 1 , is denoted by $(\mathrm{Ll})$, where the amount of $\mathrm{p}$ is $\mathrm{p}_{0}$ and the corresponding amount of $(l c+t)$ is $(l c+t)_{0}$. If $\left(L_{1} p_{1}\right)$ is any other point on the $p$ curve solid surface, situated in the vicinity of $\left(\mathrm{Ll} \mathrm{p}_{\mathrm{o}}\right)$ and having the same $L$ as $\left(\mathrm{Llp}_{\mathrm{o}}\right)$, then $\left\{\mathrm{p}_{\mathrm{o}}-(\mathrm{lc}+\mathrm{t})_{0}\right\} / 1>\left\{\mathrm{p}_{\mathrm{r}}-(\mathrm{lc}+\mathrm{t})_{0}\right\} / I_{\mathrm{r}}$ is to be proved.

$$
\begin{array}{lc}
\text { Now, } & \left\{\mathrm{p}_{2}-(\mathrm{lc}+\mathrm{t})_{2}\right\} / 1=\left\{\mathrm{p}_{\mathrm{r}}-(\mathrm{lc}+\mathrm{t})_{\circ}\right\} / \mathrm{l}_{\mathrm{l}} \\
\text { and } & \mathrm{p}_{\mathrm{o}}-(\mathrm{lc}+\mathrm{t})_{\circ}>\mathrm{p}_{\mathrm{L}}-(\mathrm{lc}+\mathrm{t})_{2} \\
\therefore & \left\{\mathrm{p}_{\mathrm{o}}-(\mathrm{lc}+\mathrm{t})_{0}\right\} / 1>\left\{\mathrm{p}_{\mathrm{r}}-(\mathrm{lc}+\mathrm{t})_{0}\right\} / \mathrm{l}_{\mathrm{r}}, \text { the proposition. }
\end{array}
$$

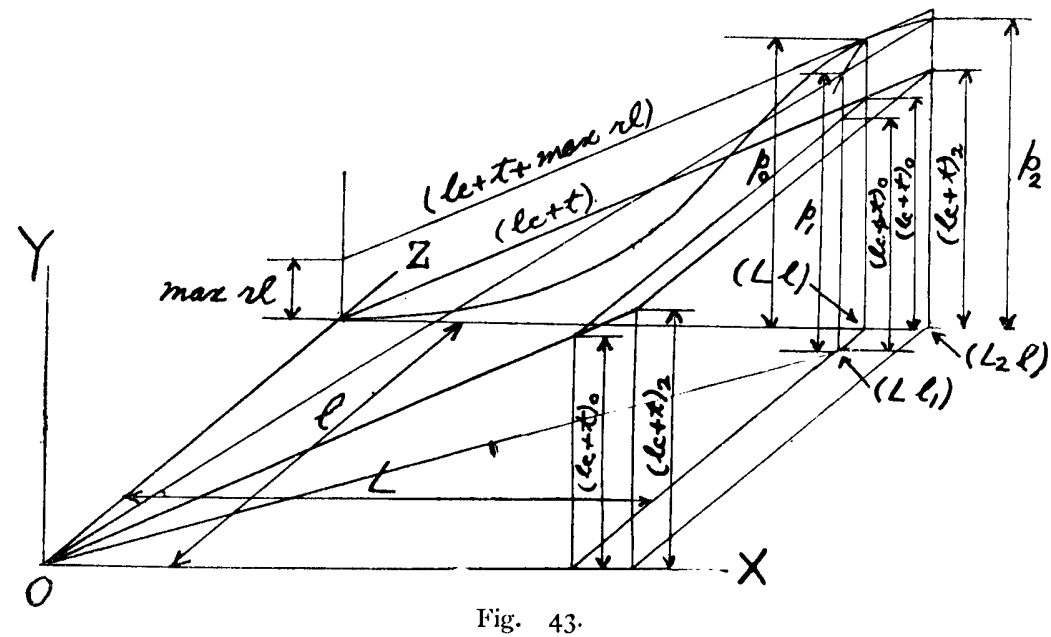

Example III :-The intensity of culture, where any certain 1 combines with $\mathrm{L}$ so as to give $(\mathrm{p}-\mathrm{r}) / \mathrm{L}$ max on $\mathrm{l}$, is the intensity of culture where $(p-r)$ is max at the $L$.

Proof:-In Fig. 44, the combination to give $(p-r) / L$ max on 1 , any certain 1 , is denoted by ( $L, 1)$, where the amount of $p$ is $p_{o}$ and the corresponding amount of $r$ is $r_{o}$. If $\left(\mathrm{Ll}_{1} \mathrm{p}_{1}\right)$ is any other point on 
the $\mathrm{p}$ curve solid surface, situated in the vicinity of $\left(\mathrm{Llp}_{\circ}\right)$ and having the same $L$ as $\left(L l p_{o}\right)$, then $\left(p_{o}-r_{0}\right)>\left(p_{1}-r_{1}\right)$ is to be proved.

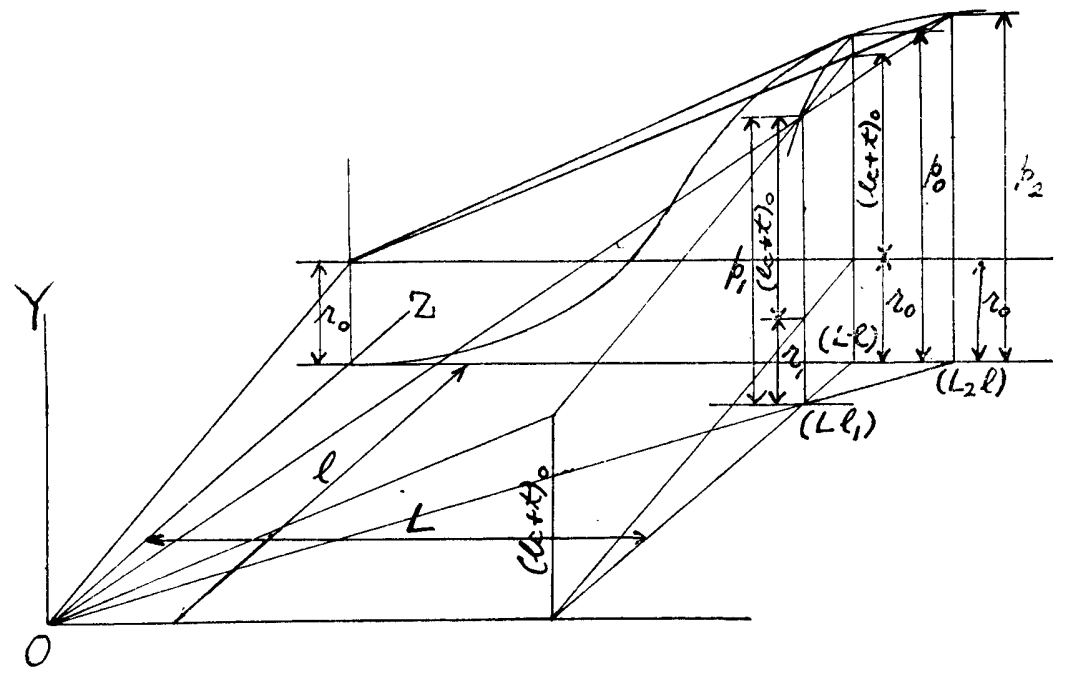

Fig. 44.

Now, $\quad \mathrm{r}_{\mathrm{o}} / \mathrm{r}_{\mathrm{r}}=1 / \mathrm{l}_{\mathrm{r}}=\mathrm{L}_{2} / \mathrm{L}=\mathrm{p}_{2} / \mathrm{p}_{\mathrm{r}}$

and $\quad\left(p_{0}-r_{0}\right) / L>\left(p_{2}-r_{0}\right) / L_{2}$ or $\left(p_{0}-r_{0}\right)>\left(p_{2}-r_{0}\right) \times L / L_{2}$ $\left(\mathrm{p}_{\mathrm{o}}-\mathrm{r}_{\mathrm{o}}\right)>\left(\mathrm{p}_{\mathrm{s}} \times \mathrm{L}_{2} / \mathrm{L}-\mathrm{r}_{1} \times \mathrm{L}_{2} / \mathrm{L}\right) \times \mathrm{L} / \mathrm{L}_{2}$

or $\left(p_{o}-r_{0}\right)>\left(p_{1}-r_{1}\right)$, the proposition.

For references' sake, the state of changes of $r$ and $(l c+t)$ in the fixed tenancy by money is shown on Fig. 45 .

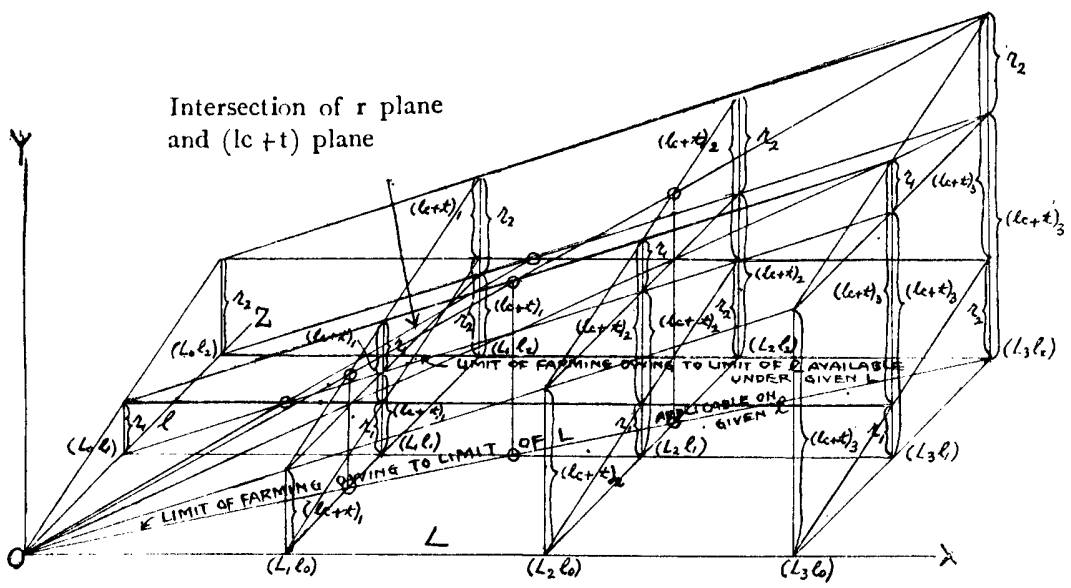

Fig. 45 . 
2) Case where $L$ to obtain $\mathrm{p}$ proportional to 1 increases, as 1 increases, not in proportion with 1

The solid surface generated by p curve in this case is quite similar to that generated by $\mathrm{P}$ curve in the case IB 2). All properties described above about the intensities of culture to give $\mathrm{P} / \mathrm{L}$ max and $\mathrm{P}$ max in the case IB 2) are noticed to exist in this case about those to give $\mathrm{p} / \mathrm{L} \max$ and $\mathrm{p} \max$. The intensities of culture to give Gp max, $(\mathrm{p}-\mathrm{r}) \max , \mathrm{Np} \max , \mathrm{Gp} / \mathrm{L} \max ,(\mathrm{p}-\mathrm{r}) / \mathrm{L} \max , \mathrm{Np} / \mathrm{L} \max , \mathrm{p} / \mathrm{rl} \max$ or $(\mathrm{p}-\mathrm{rl}) / \mathrm{rl} \max , \mathrm{p} /(\mathrm{lc}+\mathrm{t}) \max$ or $\mathrm{Gp} /(\mathrm{lc}+\mathrm{t}) \max , \mathrm{p} /(\mathrm{lc}+\mathrm{t}+\mathrm{r}) \max$ or $\mathrm{Np} /(\mathrm{lc}+\mathrm{t}+\mathrm{r})$ max, etc. on the respective $\mathrm{l}$ in this case are arranged in the same way as those in II A A). The mutual intensity relations of the points of the same meanings in the $p$ curve solid surface are clearly understood by the curves of the intensities of culture constructed by their projections on the XZ plane. The name "chart of intensities" may fairly be introduced for the plan showing such curves of intensities. Here we can notice that there may be several different features of the curves of the intensities of culture plotted on the chart in the case of the fixed tenancy by money, according to:-

first, the relations of $\mathrm{P}$ with 1 and $\mathrm{L}$, which govern the form of the $\mathrm{P}$ solid curve and

secondly, the relative values of $p / P, r l / 1$ and $(l c+t) / L$.

Some cases of the $\mathrm{p}$ solid curves in relation with the $\mathrm{rl}$ and $(\mathrm{lc}+\mathrm{t})$ planes are shown on Plates 40 and $4 \mathrm{I}$.

In (A) on the plate 40 , the part of the $p$ solid, where Gp are positive, is entirely within the range of $\mathrm{rl}>(\mathrm{lc}+\mathrm{t})$.

In (B) on the plate 40, such part of the $p$ solid extends over both $\mathrm{rl}>(\mathrm{lc}+\mathrm{t})$ and $\mathrm{rl}<(\mathrm{lc}+\mathrm{t})$ ranges.

In $(A)$ on the plate $4 \mathrm{I}$, it is entirely within the range of $r l<(l c+t)$.

In (B) on the plate $4 \mathrm{l}$, it is at first entirely within the range of $\mathrm{rl}>$ $(\mathrm{lc}+\mathrm{t})$ and afterwards comes to be entirely within the range of $\mathrm{rl}<$ $(\mathrm{lc}+\mathrm{t})$ as 1 increases.

These A (40), B (40), and A (4I) correspond to (i), (iii) and (v) of II A A) notice (I) respectively.

The chart of the intensities of culture on Plate 42 is to explain a case of A (4I) above described. Plate 43 is the chart of the intensities of culture to explain a case of the share tenancy by money.

Here, the following properties are noticed :-

( $\mathrm{I})$ If any certain $\mathrm{l}$ combines with $\mathrm{L}$ so as to give $\mathrm{p}$ max, $(\mathrm{p}-\mathrm{r})$ 
max, Gp max, $\mathrm{Np}$ max, $\mathrm{Np} / \mathrm{L} \max , \mathrm{Gp} / \mathrm{L} \max ,(\mathrm{p}-\mathrm{r}) / \mathrm{L} \max$ or $\mathrm{p} / \mathrm{L}$ max on 1 , the combination gives $\mathrm{p} / 1$ max, $(\mathrm{p}-\mathrm{r}) / 1$ max, Gp/l max, $\mathrm{Np} / 1 \max , \mathrm{Np} \max , \mathrm{Gp} \max ,(\mathrm{p}-\mathrm{r}) \max$ or $\mathrm{p} \max$ at the $\mathrm{L}$ respectively.

(2) If any certain $\mathrm{L}$ combines with 1 so as to give $\mathrm{p} / 1$ max, $(\mathrm{p}-\mathrm{r}) / 1 \max , \mathrm{Gp} / 1$ max, $\mathrm{Np} / 1$ max, $\mathrm{Np}$ max, Gp max, $(\mathrm{p}-\mathrm{r}) \max$ or $\mathrm{p} \max$ at $\mathrm{L}$, the combination gives $\mathrm{p} \max ,(\mathrm{p}-\mathrm{r}) \max , \mathrm{Gp} \max , \mathrm{Np}$ $\max , \mathrm{Np} / \mathrm{L} \max , \mathrm{Gp} / \mathrm{L} \max ,(\mathrm{p}-\mathrm{r}) / \mathrm{L} \max$ or $\mathrm{p} / \mathrm{L} \max$ on the 1 respectively.

(3) The intensity of culture of the combination giving $\mathrm{p}$ max, $(\mathrm{p}-\mathrm{r}) \max , \mathrm{Gp}$ max, Np max, Np/L max, Gp/L max, $(\mathrm{p}-\mathrm{r}) / \mathrm{L}$ max or $\mathrm{p} / \mathrm{L}$ max on $\mathrm{l}$ is not generally the same as that giving $\mathrm{p} / \mathrm{l}$ max $(\mathrm{p}-\mathrm{r}) / 1 \max , \mathrm{Gp} / \mathrm{l} \max . \mathrm{Np} / 1 \max , \mathrm{Np} \max , \mathrm{Gp} \max ,(\mathrm{p}-\mathrm{r}) \max$ or $\mathrm{p}$ max at $\mathrm{L}$ respectively.

(4) If any certain 1 or $\mathrm{L}$ combines with $\mathrm{L}$ or 1 so as to give $\mathrm{p} / \mathrm{rl} m_{a x} \mathrm{p} /(\mathrm{lc}+\mathrm{t}) \max$ or $\mathrm{p} /(\mathrm{lc}+\mathrm{t}+\mathrm{r}) \max$ on $\mathrm{l}$ or at $\mathrm{L}$ respectively, the combination has the same meaning at the $\mathrm{L}$ or on the 1 respectively i.e. the 1 and $\mathrm{L}$ combination which gives $\mathrm{p} / \mathrm{rl} \max , \mathrm{p} /(\mathrm{lc}+\mathrm{t}) \max$ or $\mathrm{p} /(\mathrm{lc}+\mathrm{t}+\mathrm{r}) \max$ on 1 gives $\mathrm{p} / \mathrm{rl} \max , \mathrm{p} /(\mathrm{lc}+\mathrm{t}) \max$ or $\mathrm{p} /(\mathrm{lc}+\mathrm{t}+\mathrm{r}) \max$ at $\mathrm{L}$ at the same time respectively.

(5) Comparing $\mathrm{p}$ max on different 1 , the greater is 1 the greater is the amount i.e. p MAX in the mathematical sense, throughout the whole system, is at the combination corresponding to the intersection of the $\mathrm{p}$ max curve with the limit of farming on the intensity chart and $\mathrm{p} M A X$ in the sense of the biggest amount of $\mathrm{p}$ may be at an 1 greater than the 1 corresponding to $\mathrm{p} M A X$ in the mathematical sense.

(6) Comparing $(\mathrm{p}-\mathrm{r})$ max on different 1 ,

(a) in the fixed tenancy by money, $(\mathrm{p}-\mathrm{rl}) \max$ is greatest at the combinaton where $(\mathrm{p}-\mathrm{rl})$ max curve in the $\mathrm{p}$ curve solid surface is highest vertically up above the plane $\mathrm{rl}$ i.e. at such a combination, $(\mathrm{p}-\mathrm{rl})$ max has its greatest amount $(\mathrm{p}-\mathrm{rl}) M A X$ in the whole system of farming and

(b) in the share tenancy by money, ( $\mathrm{p}-\mathrm{rs})$ MAX in the mathematical sense, throughout the whole system, is at the combination corresponding to the intersection of the $(\mathrm{p}-\mathrm{rs})$ max curve with the limit of farming on the intensity chart and $(\mathrm{p}-\mathrm{rs}) M A X$ in the sense of the biggest amount of $(\mathrm{p}-\mathrm{rs})$ may be at an 1 greater than the 1 corresponding to ( $\mathrm{p}-\mathrm{rs}) M A X$ in the mathematical sense.

(7) Comparing Gp max on different 1 , it is greatest at the com- 
bination where Gp max curve in the $\mathrm{p}$ curve solid surface is highest vertically up above the plane $(\mathrm{l}+\mathrm{t})$ i.e. at sucli a combination, Gp max has its greatest amount $\mathrm{Gp} M A X$ in the whole system of farming.

(8) Comparing $\mathrm{Np}$ max on different 1, it is greatest at the combination where the NP max curve in the $\mathrm{p}$ (in the case of the fixed tenancy by money) or ( $p-r s$ ) (in the case of the share tenancy by money) curve solid surface is highest vertically up above the plane $(\mathrm{l}+\mathrm{t}+\mathrm{rl}$ ) (in the former case) or $(\mathrm{l}+\mathrm{t}$ ) (in the latter case) i.e. at such a combination, $\mathrm{Np}$ max has its greatest amount $\mathrm{Np} M A X$ in the whole system of farming.

(9) Comparing $\mathrm{p} /(\mathrm{lc}+\mathrm{t}+\mathrm{r}) \max$ at different 1 or $\mathrm{L}$, it is greatest at the combination corresponding to the tangent point of the tangent line drawn from the origin to the curve projected on the $\mathrm{XZ}$ plane by $\mathrm{p} /(\mathrm{lc}+\mathrm{t}+\mathrm{r})$ max curve in the $\mathrm{p}$ curve solid surface i.e. at such a combination, $\mathrm{p} /(\mathrm{lc}+\mathrm{t}+\mathrm{r})$ max has its greatest amount $\mathrm{p} /(\mathrm{l} \mathrm{c}+\mathrm{t}+\mathrm{r})$ $M A X$ in the whole system of farming.

(Io) Comparing $(\mathrm{p}-\mathrm{r}) / \mathrm{L} \max$ or $\mathrm{Np} / \mathrm{L}$ max on different $\mathrm{l}$, it is greatest at the combination corresponding to the tangent point of the tangent line drawn from the origin to the curve projected on the $\mathrm{XZ}$ plane by $(\mathrm{p}-\mathrm{r}) / \mathrm{L}$ max or $\mathrm{Np} / \mathrm{L}$ max curve in the $\mathrm{p}$ (in the case of the fixed tenancy by money) or $(p-r s)$ (in the case of the share tenancy by money) curve solid surface respectively i.e. at such a combination, $(\mathrm{p}-\mathrm{r}) / \mathrm{L} \max$ or $\mathrm{Np} / \mathrm{L} \max$ has its greatest amount $(\mathrm{p}-\mathrm{r}) / \mathrm{L}$ $M A X$ or $\mathrm{Np} / \mathrm{L} M A X$ in the whole system of farming respectively.

(I I) Comparing $\mathrm{p} / \mathrm{L} \max , \mathrm{Gp} / \mathrm{L} \max , \mathrm{p} /(\mathrm{lc}+\mathrm{t}) \max$ or $\mathrm{Gp} /(\mathrm{lc}+\mathrm{t})$ max on different 1 , it is greatest at the combination corresponding to the tangent point of the tangent line drawn from the origin to the curve projected on the $\mathrm{XZ}$ plane by $\mathrm{p} / \mathrm{L}$ max, Gp/L max, $\mathrm{p} /(\mathrm{Ic}+\mathrm{t})$ max or $\mathrm{Gp} /(\mathrm{lc}+\mathrm{t})$ max curve in the $\mathrm{p}$ curve solid surface respectively i.e. at such a combination, $\mathrm{p} / \mathrm{L} \max , \mathrm{Gp} / \mathrm{L} \max , \mathrm{p} /(\mathrm{lc}+\mathrm{t}) \max$ or $\mathrm{Gp} /(\mathrm{lc}+\mathrm{t})$ max has its greatest amount $\mathrm{p} / \mathrm{L} M A X, \mathrm{Gp} / \mathrm{L} M A X, \mathrm{p} /(\mathrm{lc}+\mathrm{t}) M A X$ or $\mathrm{Gp} /(\mathrm{lc}+\mathrm{t}) M A X$ in the whole system of farming respectively.

(12) Comparing $\mathrm{p} / \mathrm{rl} \max$ at different 1 or $\mathrm{L}$, they are always the same in amount with no concern with the amount of 1 or $L . p / r s$ is constant throughout the whole system.

(13) The form of the $p$ curve solid and the features of the goal lines on it are interesting to observe, among which are :-

(i) The solid looks like the foot of a mountain standing on a base plane somewhat triangle-shaped, with two vertical precipices at 
the farming limit sides and a straight edge at the 1 side forming the base line of the base triangle, say. The surface of the solid is gently sloped up from the 1 side towards the vertex of the base triangle and has a kind of hump swelled up along the slope.

(ii) Gp ordinates generate a mountain-like solid standing on the plane $(\mathrm{l} c+\mathrm{t})$.

(iii) $\mathrm{Np}$ ordinates generate a mountain-like solid,

(a) in the case of the fixed tenancy by money, standing on the plane $(\mathrm{lc}+\mathrm{t}+\mathrm{r})$ and

(b) in the case of the share tenancy by money, standing on the plane $(l c+t)$ and having the heights less than those of the Gp solid by the amounts of the corresponding rs.

(iv) The curves of $(p=r l),(p=l c+t)$ and $(p=l c+t+r)$ surround the solid obliquely so far as realizable. Here the curve of $(p=r l)$ and the curve $(p=l c+t)$ cross or not to each other, according to the relative values of $\mathrm{p}, \mathrm{rl}$ and $(\mathrm{lc}+\mathrm{t})$.

(v) The lines of the same net profit rate $\{\mathrm{Np} /(\mathrm{lc}+\mathrm{t}+\mathrm{r})\}$ may be drawn on the solid surface (the projections of these lines on $\mathrm{XZ}$ plane are shown on Fig. 46). They make oblique layers and surround the

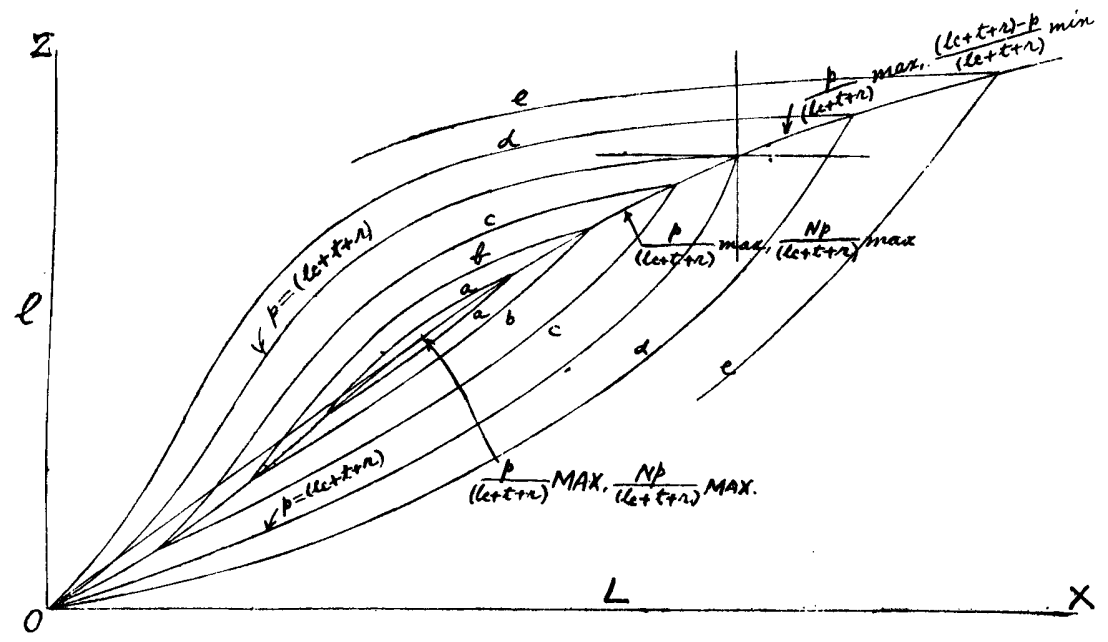

Fig. 46.

Notice :-(I) Net profit rates, same along $a, b, c$, etc. respectively.

(2) Np rate along $a>$ that along $\delta>$ that along $c>$ that along $\{\mathrm{p}=(\mathrm{lc}+\mathrm{t}+\mathrm{r})\}$ $=\mathbf{I}>$ that along $d>$ that along e, etc. 
hump of the solid and at the centre of them is the $\mathrm{p} /(\mathrm{lc}+\mathrm{t}+\mathrm{r}) \cdot M A X$ or $\mathrm{Np} /(\mathrm{lc}+\mathrm{t}+\mathrm{r}) M A X$.

(I4) The 1 and $\mathrm{L}$ combinations of the same meanings have in general the different intensities of culture but there may be those having the same intensities.

(15) The 1 and $\mathrm{L}$ combinations to give $M A X$ values described above may not exist within the limit of farming. In such cases, the combinations to give the greatest amounts realizable are generally at the intersections of the max lines and the limit of farming.

The properties described above are all to be proved, but here some important ones only are proved for example.

Example I :-Comparing $(\mathrm{p}-\mathrm{r}) / \mathrm{L}$ max on different 1 , it is greatest at the 1 and $\mathrm{L}$ combination corresponding to the tangent point of the tangent line drawn from the origin to the curve projected on the $\mathrm{XZ}$ plane by $(p-r) / L, \max$ curve in the $\mathrm{p}$ curve solid surface in the fixed tenancy by money i.e. at such a combination $(p-r) / L$ max has its greatest amount $(\mathrm{p}-\mathrm{r}) / \mathrm{L} M A X$ in the whole system of farming.

Proof:-In Fig. 47, $\left(p_{2}-r_{2}\right) / L_{2}>\left(p_{r}-r_{1}\right) / L_{r}$ or $\left(p_{3}-r_{3}\right) / L_{3}$ is to be proved.

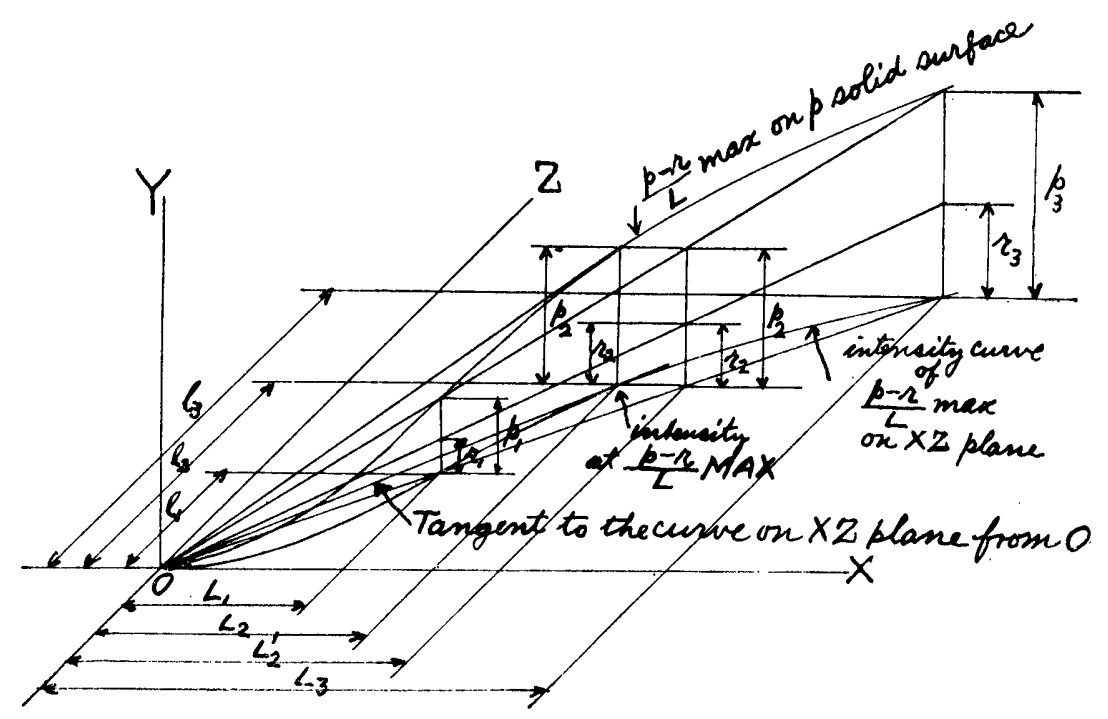

Fig. 47 .

Now, $\quad r_{1} / l_{1}=r_{2} / l_{2}=r_{3} / l_{3}=k_{1}$ say or $\left\{\begin{array}{l}r_{1}=k_{1} l_{1} \\ r_{2}=k_{1} l_{2} \\ r_{3}=k_{r} l_{3}\end{array}\right.$ 


$$
\begin{aligned}
& \mathrm{p}_{\mathrm{I}} / \mathrm{l}_{\mathrm{r}}=\mathrm{p}_{2} / \mathrm{l}_{2}=\mathrm{p}_{3} / \mathrm{l}_{3}=\mathrm{k}_{2} \text { say or }\left\{\begin{array}{l}
\mathrm{p}_{\mathrm{r}}=\mathrm{k}_{2} \mathrm{l}_{\mathrm{r}} \\
\mathrm{p}_{2}=\mathrm{k}_{2} l_{2} \\
\mathrm{p}_{3}=\mathrm{k}_{2} l_{3}
\end{array}\right. \\
& 1_{\mathrm{I}} / \mathrm{L}_{\mathrm{I}}=1_{2} / \mathrm{L}_{2}^{\prime}=1_{3} / \mathrm{L}_{3}=k_{3} \text { say or }\left\{\begin{array}{l}
1_{1}=k_{3} \mathrm{~L}_{\mathrm{I}} \\
1_{2}=k_{3} \mathrm{~L}_{2}^{\prime} \\
1_{3}=k_{3} \mathrm{~L}_{3}
\end{array}\right. \\
& \therefore \quad p_{\mathrm{r}}-\mathrm{r}_{\mathrm{r}}=\left(\mathrm{k}_{2}-\mathrm{k}_{\mathrm{t}}\right) \mathrm{l}_{\mathrm{r}}=\mathrm{k}_{3}\left(\mathrm{k}_{2}-\mathrm{k}_{\mathrm{r}}\right) \mathrm{L}_{\mathrm{t}} \\
& \mathrm{p}_{2}-\mathrm{r}_{2}=\left(\mathrm{k}_{2}-\mathrm{k}_{\mathrm{r}}\right) \mathrm{l}_{2}=\mathrm{k}_{3}\left(\mathrm{k}_{2}-\mathrm{k}_{\mathrm{r}}\right) \mathrm{L}_{2}^{\prime} \\
& \text { and } \quad \mathrm{p}_{3}-\mathrm{r}_{3}=\left(\mathrm{k}_{2}-\mathrm{k}_{\mathrm{r}}\right) \mathrm{l}_{3}=\mathrm{k}_{3}\left(\mathrm{k}_{\mathrm{z}}-\mathrm{k}_{\mathrm{r}}\right) \mathrm{L}_{3} \\
& \therefore \quad\left(\mathrm{p}_{\mathrm{r}}-\mathrm{r}_{\mathrm{r}}\right) / \mathrm{L}_{\mathrm{r}}=\left(\mathrm{p}_{2}-\mathrm{r}_{2}\right) / \mathrm{L}_{2}^{\prime}=\left(\mathrm{p}_{3}-\mathrm{r}_{3}\right) / \mathrm{L}_{3}=\mathrm{k}_{3}\left(\mathrm{k}_{2}-\mathrm{k}_{\mathrm{r}}\right) \\
& \text { Now } \quad \mathrm{L}_{2}<\mathrm{L}_{2}^{\prime} \therefore\left(\mathrm{p}_{2}-\mathrm{r}_{2}\right) / \mathrm{L}_{2}^{\prime}<\left(\mathrm{p}_{2}-\mathrm{r}_{2}\right) / \mathrm{L}_{2} \\
& \therefore \quad\left(p_{2}-r_{2}\right) / L_{2}>\left(p_{r}-r_{1}\right) / L_{1} \text { or }\left(p_{3}-r_{3}\right) / L_{3} \text {, the proposition. }
\end{aligned}
$$

Example II :-Comparing $\mathrm{p} /(\mathrm{lc}+\mathrm{t}+\mathrm{r}) \max$ at different 1 , it is greatest at the 1 and $\mathrm{L}$ combination corresponding to the tangent point of the tangent line drawn from the origin to the curve projected on the $\mathrm{XZ}$ plane by $\mathrm{p} /(\mathrm{l} \mathrm{c}+\mathrm{t}+\mathrm{r})$ max curve in the $\mathrm{p}$ curve solid surface i.e. at such a combination, $\mathrm{p} /(\mathrm{l} \mathrm{c}+\mathrm{t}+\mathrm{r}) \max$ has its greatest amount $\mathrm{p} /(\mathrm{lc}+\mathrm{t}+\mathrm{r}) M A X$ in the whole system of farming.

Proof for the case of the fixed tenancy by money:-In Fig. 48, $\mathrm{p}_{2} /(\mathrm{lc}+\mathrm{t}+\mathrm{r})_{2}>\mathrm{p}_{\mathrm{I}} /(\mathrm{lc}+\mathrm{t}+\mathrm{r})_{1}$ or $\mathrm{p}_{3} /(\mathrm{l} c+\mathrm{t}+\mathrm{r})_{3}$ is to be proved.

$$
\quad \quad \quad \quad \quad p_{2} /(l c+t+r)_{2}^{\prime}=p_{1} /(l c+t+r)_{1}=p_{3} /(l c+t+r)_{3}
$$

and

$$
(\mathrm{lc}+\mathrm{t}+\mathrm{r})_{2}<(\mathrm{lc}+\mathrm{t}+\mathrm{r})_{2}^{\prime}
$$

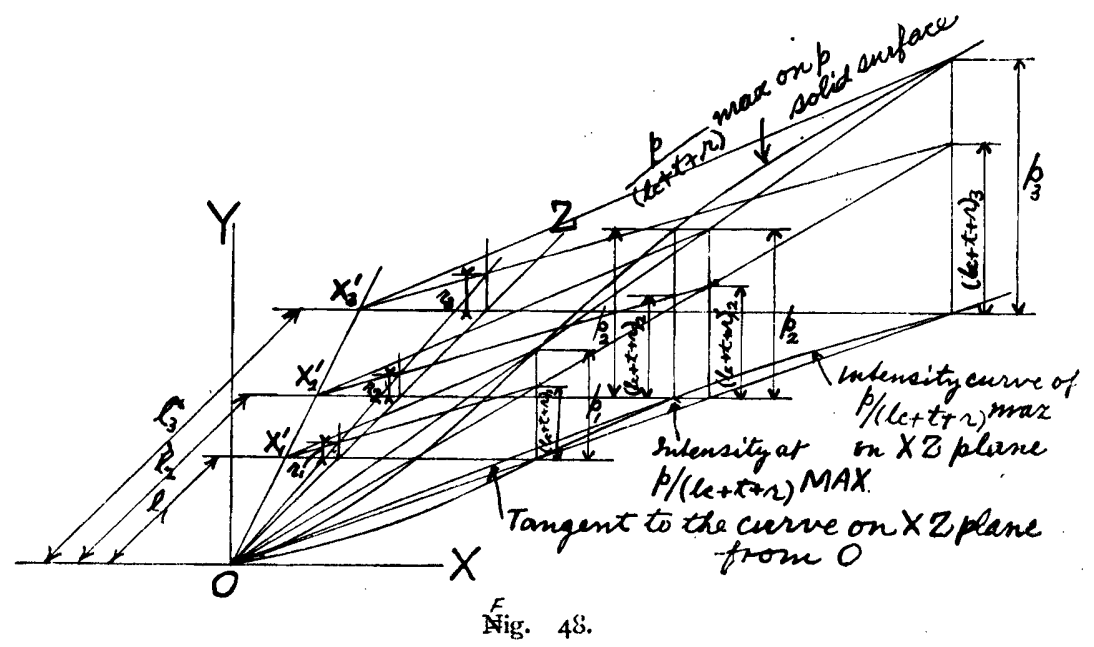


or

$$
\mathrm{p}_{2} /(\mathrm{lc}+\mathrm{t}+\mathrm{r})_{2}>\mathrm{p}_{2} /(\mathrm{lc}+\mathrm{t}+\mathrm{r})_{2}^{\prime}
$$

$\therefore \quad \mathrm{p}_{2} /(\mathrm{lc}+\mathrm{t}+\mathrm{r})_{2}>\mathrm{p}_{\mathrm{I}} /(\mathrm{lc}+\mathrm{t}+\mathrm{r})_{\mathrm{r}}$ or $\mathrm{p}_{3} /(\mathrm{lc}+\mathrm{t}+\mathrm{r})_{3}$, the proposition.

Proofs for other cases are omitted.

\section{3) Other cases}

These cases correspond to $1 \mathrm{~B} 3$ ) and contain those where II $\mathrm{A}$ B) I) and II A B) 2) are combined. These cases being impossible to discuss generally, the discussion on them is entirely omitted in this investigation.

\section{B. CASE WHERE PRICES OF PRODUCTS AND OF ALL PRODUCTION \\ ELEMENTS ARE NOT FIXED}

It is impossible to discuss this case generally. Among the several cases belonging to this case, those where the rates of prices of the products only are varied may be mentioned for reference. In such cases, the order relations among the intensities of culture for several goals, as described before, may come to disappear abruptly. While the $\mathrm{P}$ curve changes its ordinates gradually, it does not necessarily follow that the $\mathrm{p}$ curve gradually changes too; and as the result, the intensities regarding the profits may be as shown on Fig. 49 (a) and (b). The state of the intensities of culture in $\mathrm{B}$ case will be observed
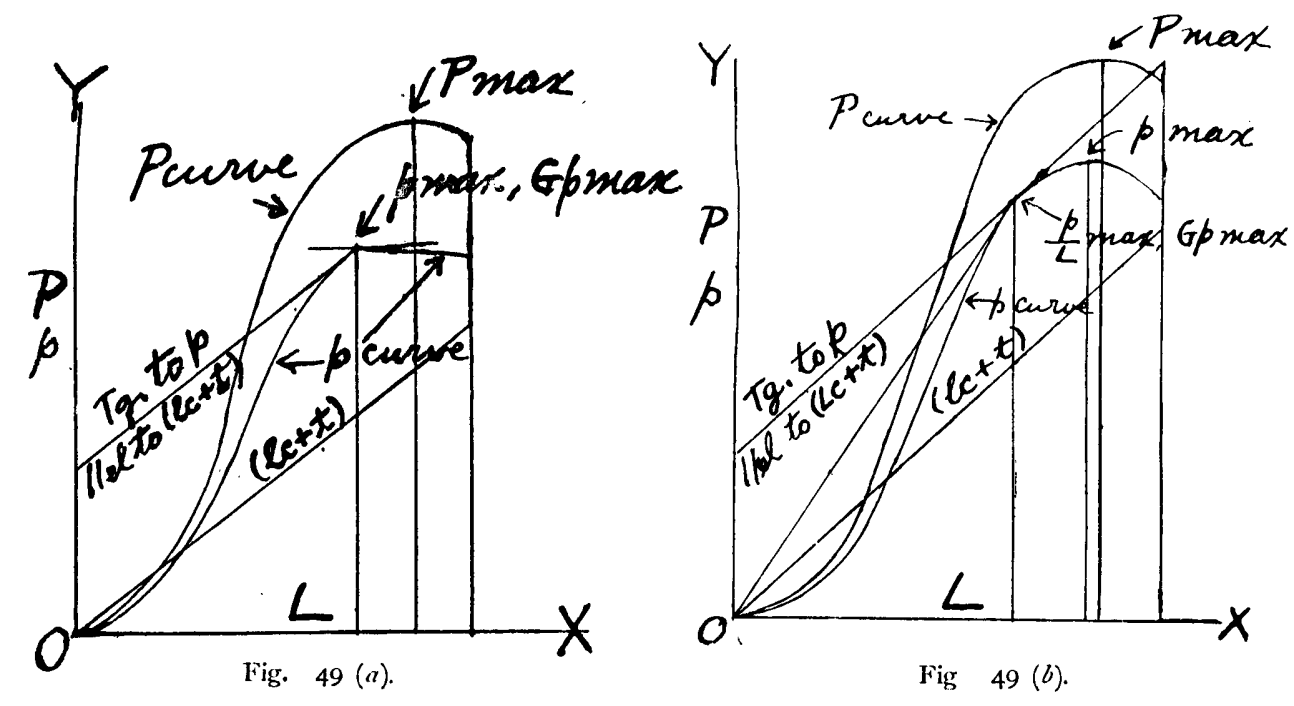
properly by the application of the considerations described in A case. If the changes of the prices and their influences are properly estimated or assumed, it will not be difficult to decide their effects upon the size of farm and thus to get the wise counter-measures against the changes of the prices to suit the circumstances. In this essay the further discussion on this case is omitted, except a few notes on two fundamental cases important to discuss the problems of the size of farm later on i.e.

(1) Case where

(i) $\mathrm{p}$ is proportional to $\mathrm{P}$,

(ii) $r$ is proportional to $l$ or $p$,

(iii) $(\mathrm{lc}+\mathrm{t})$ corresponding to $\mathrm{p}$ proportional to 1 increases, as 1 increases, not in proportion with 1

and (iv) $\mathrm{L}$ to obtain p proportional to 1 increases, as 1 increases, not in proportion with 1. (Fig. 50).

Here it will be noticed that the properties concerned with $(l c+t)$ do not generally exist as in A B) 2) and we can notice that

(a) there are one or more series of intensities giving Gp max, $\mathrm{Gp} / \mathrm{L} \max , \mathrm{Np} \max , \mathrm{Np} / \mathrm{L} \max , \mathrm{p} /(\mathrm{lc}+\mathrm{t}) \max$ or $\mathrm{p} /(\mathrm{lc}+\mathrm{t}+\mathrm{r}) \max$ on 1 and at $\mathrm{L}$ respectively,

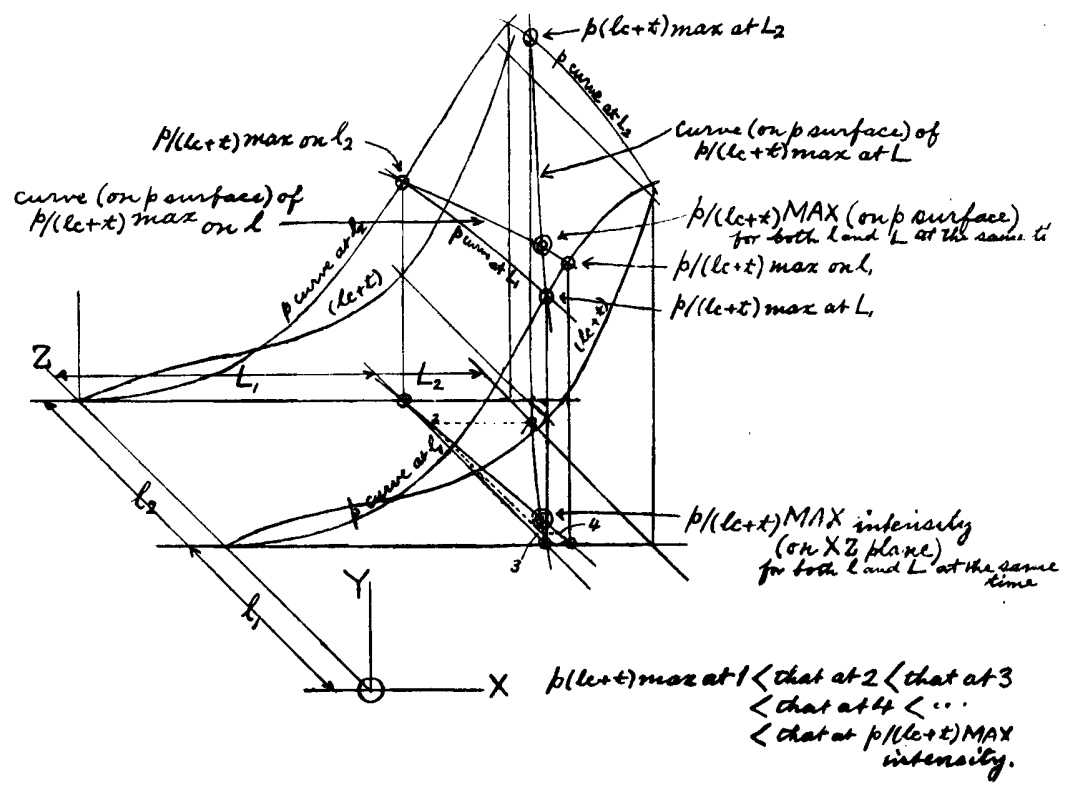

Fig. 50 . 
(b) there are one or more intensities giving $\mathrm{Gp} M \Lambda X, \mathrm{Gp} / \mathrm{L} M I \Lambda X$, Np $M A X$ or $\mathrm{Np} / \mathrm{L} M A X$ on 1 and at $\mathrm{L}$ respectively and

(c) one or more intensities each giving $\mathrm{p} /(\mathrm{lc}+\mathrm{t}) M I A Y$ or $\mathrm{p} /(\mathrm{lc}+\mathrm{t}+\mathrm{r}) M A X$ on 1 and at $\mathrm{L}$ at the same time.

(2) Case where

(i) $\mathrm{p}$ is proportional to $\mathrm{P}$,

(ii) $\mathrm{rl}$ corresponding to p proportional to 1 increases, as 1 increases, not in proportion with 1 ,

(iii) $(\mathrm{l}+\mathrm{t})$ corresponding to $\mathrm{p}$.proportional to 1 increases, as 1 increases, not in proportion with 1

and (iv) $\mathrm{L}$ to obtain $\mathrm{p}$ proportional to 1 increases, as 1 increases, not in proportion with 1 . (Fig. $5 \mathrm{I}$ ).

Here it will be noticed that the properties concerned with $\mathrm{rl}$, bcsides those concerned with $(\mathrm{l}+\mathrm{t})$, do not generally exist as in A B) 2) and we can notice that

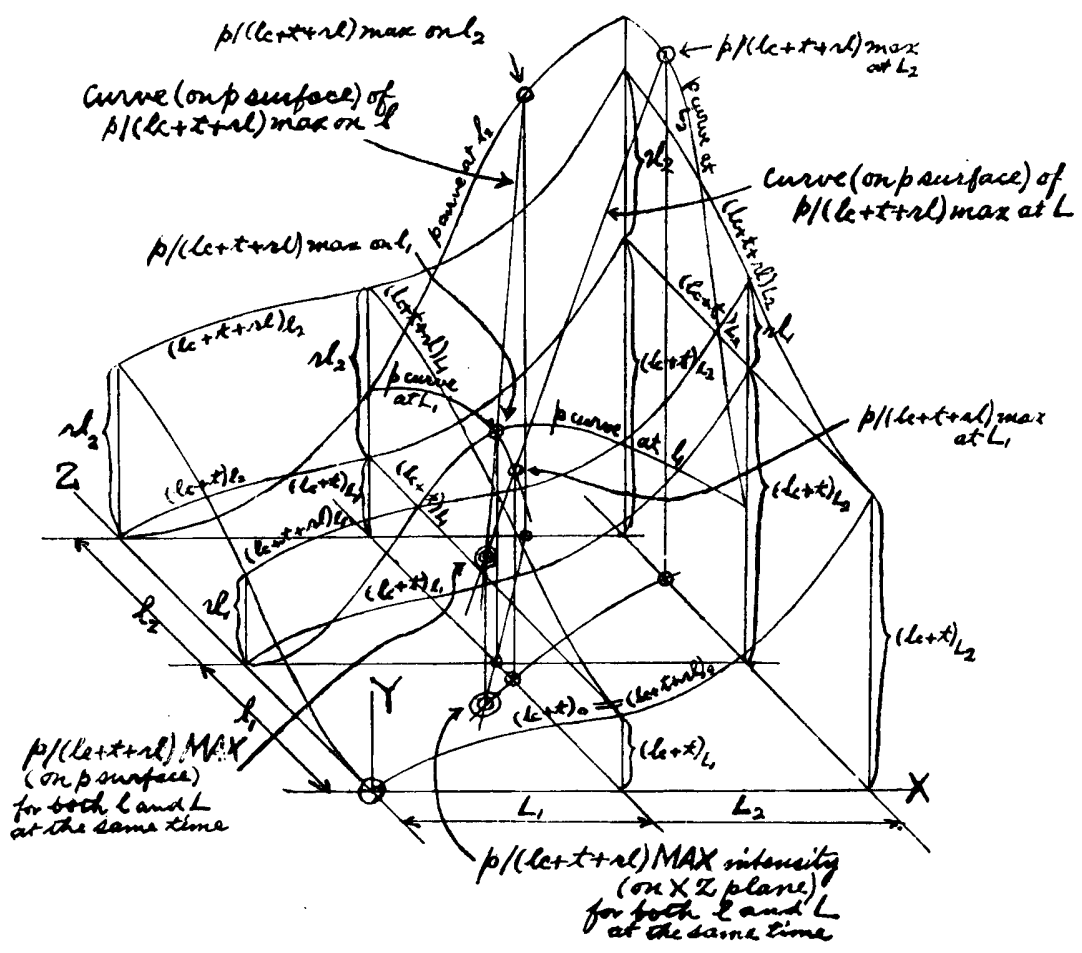

Fig. 5 I. 
(a) there are one or more series of intensities giving $(\mathrm{p}-\mathrm{rl})$ max, $(\mathrm{p}-\mathrm{rl}) / \mathrm{L}$ max or $\mathrm{p} / \mathrm{rl}$ max on $\mathrm{l}$ and at $\mathrm{L}$ respectively,

(b) there are one or more intensities giving ( $\mathrm{p}-\mathrm{rl}) M A X$ or $(\mathrm{p}-\mathrm{rl}) / \mathrm{L} M A X$ on 1 and at $\mathrm{L}$ respectively and

(c) one or more intensities each giving $\mathrm{p} / \mathrm{rl} M A X, \mathrm{p} /(\mathrm{lc}+\mathrm{t}) M A X$ or $\mathrm{p} /(\mathrm{lc}+\mathrm{t}+\mathrm{r}) M A X$ on $\mathrm{l}$ and at $\mathrm{L}$ at the same time.

Here should be mentioned the graphical method to find 1 and $\mathrm{I}$, to be combined to give $\mathrm{p} /(\mathrm{lc}+\mathrm{t}+\mathrm{r}) M A X$ on 1 . Set on 1 axis the ordinates denoting the amounts of $\mathrm{p} /(\mathrm{lc}+\mathrm{t}+\mathrm{r}) \max$ on 1 and find the greatest ordinate. The amount denoted by the ordinate last found is $\mathrm{p} /(\mathrm{l} \mathrm{c}+\mathrm{t}+\mathrm{r}) M A X$, the corresponding 1 being the 1 to give $\mathrm{p} /(\mathrm{l} \mathrm{c}+\mathrm{t}+\mathrm{r})$ $M A X$ on 1 . The $\mathrm{L}$ to combine with the 1 , to give $\mathrm{p} /(\mathrm{lc}+\mathrm{t}+\mathrm{r}) \max$ on 1 , is the $\mathrm{L}$ to be combined with 1 to give $\mathrm{p} /(\mathrm{lc}+\mathrm{t}+\mathrm{r}) M A X$ on 1 .

\section{PROPER COMBINATIONS OF PRODUCTION ELEMENTS}

By the preceding chapter, it is clear that when a certain crop is planted on a certain portion of land by a certain process of technic, there are, as the result of the existence of the technical law of decreasing returns on profit, the proper combinations of 1 and $L$ to suit the given circumstances, and such combinations can generally be ascertained by a graphical method applied on $\mathrm{P}$ or $\mathrm{p}$ curves provided that $\mathrm{I}$ is set on a line. We must here notice that:-

(I) $\mathrm{L}$ being composed of several kinds of the production elements, it is impossible to denote the combinations of their substantial quantities by single lengths of abscissa on the figures.

(2) As the principle, the production elements being combined to suit the goals to win, their proportions composing the combinations to be represented by $L$ are different according to the goals. Therefore, it is quite absurd to try to compare the intensities of culture for different goals by the abscissa set on the common $\mathrm{L}$ line.

(3) $\mathrm{L}$ being the combination of the quantities of the different units, the idea of the "intensity of culture" does not hold good in comparison of the combinations of the production elements, except in the following three cases and some combinations of them :-

(i) Where only one of the production elements is varied in quantity, - all other elements remaining the same.

(ii) Where the production elements of each combination are the 
same in kind and where the quantities of more than one element of one combination are larger than those of another combination, no one being less simultaneously.

(iii) Where one or more elements are present in onc combination and absent in the other, all other elements being the same both in kinds and quantities in two combinations.

Thus it follows that all considerations stated in the preceding chapter are, if left as they are, abstract and of almost no practical use, except when only one of the production elements conıposing $\mathrm{L}$ is varied in quantity, others remaining the same. They can, however, be converted to be real for general cases by treating $L$ so that each of the quantities of a production element set on I, axis represents perfectly and fixes definitely the corresponding substantial quantities of all other elements to be combined to compose $\mathrm{L}$. In this case too, the word "intensity of culture" cannot generally be used for the comparison of the combinations.

The principle involved in the said treatment is the key to the solution of the problem of the size of farm. Standing on this principle, this chapter explains how to compare generally the combinations of the production elements by their substantial quantities, thus the considerations in the preceding chapter being brought to the practical use with some alterations on the conclusions. Here note that in this chapter are discussed those cases only where $\mathrm{P}$ and $\mathrm{p}$ curves have only one maximum point respectively and where the prices and the price rates of the products and the production elements are all fixed and that all other cases, if the data are sufficient, can be solved on the same principle. And also note that in this investigation, as before mentioned, $L$ is conventionally analized into $\mathrm{M}, \mathrm{E}, \mathrm{N}$ and $\mathrm{S}$.

I. PROPER COMBINATIONS OF TWO ELEMEN'S TO WIN THE GOALS WHEN ALL OTHER ELEMENTS ARE KEPT FIXED

It is well known that when the quantity of any one of the production elements is changed in succession, all other elements being fixed, there exists the law of decreasing returns in regard to the element. We can thus obtain $\mathrm{P}$ or $\mathrm{p}$ curve set on the axis denoting the successive quantities of one of $1, M, E, N$ and $S$, in the way quite the same as described before for $\mathrm{L}$. And it is also possible that we can-set $P$ or $p$ solid surface by changing the quantity of any other 
element in succession and setting it on the third axis. The $\mathrm{P}$ or $\mathrm{p}$ solicl surface thus obtained may stand on the axes denoting any two of the production elements, in the same way as that in the preceding chapter stands on the $I$ and $L$ axes. Here we must notice that while the properties of some such $\mathrm{P}$ or $\mathrm{p}$ solid surface are similar to those of the solid surface set on $\mathrm{L}$ and $\mathrm{L}$, those of others are not similar, according to the combinations of the elements set on the axes. In the actual state of practice, the solid standing on 1 and $M, 1$ and $E$, 1 and $N, M$ and $E$ or $E$ and $N$ belongs to the former case and the solid on $\mathrm{N}$ and $\mathrm{S}$ belongs to the latter case.

In the former case, we can decide the proper quantities of the two production elements to combine to win the "corresponding goals," in the same way as investigated in the preceding chapter for 1 and L. In the latter case, we must decide them by the application of the idea obtained in the investigation on 1 and $\mathrm{L}$. Here attention should be called to the term "corresponding goals." Take for explanation the case where the two varying elements are 1 and $M$, and the "corresponding goals" will be as shown in the following table.

\begin{tabular}{|c|c|}
\hline Goals in the case of 1 and $I$, & Corresponding goals in this case \\
\hline $\mathrm{P} / \mathrm{L} \max$ & $\mathrm{P} / \mathrm{M} \max$ \\
\hline $\mathrm{p} / \mathrm{I} \cdot \max$ & $\mathrm{p} / \mathrm{M} \max$ \\
\hline $\mathrm{Gp} / \mathrm{L}, \max$ & $\left\{\mathrm{P}-\left(\mathrm{m}+\mathrm{t}_{m}\right)\right\} \mathrm{M}$ max \\
\hline$(\mathrm{p}-\mathrm{r}) / \mathrm{L}, \max$ & $(\mathrm{p}-\mathrm{r}) / \mathrm{M} \max$ \\
\hline $\mathrm{Np} / \mathrm{L}, \max$ & $\left\{\mathrm{p}-\left(\mathrm{m}+\mathrm{t}_{m}+\mathrm{r}\right) / \mathrm{M} \max \right.$ \\
\hline$P \max$ & $\mathrm{P} \max$ \\
\hline$p \max$ & $\mathrm{p} \max$ \\
\hline Gp $m a x$ & $\left\{\mathrm{p}-\left(\mathrm{m}+\mathrm{t}_{m}\right)\right\} \max$ \\
\hline$(\mathrm{p}-\mathrm{r}) \max$ & $(\mathrm{p}-\mathrm{r}) \max$ \\
\hline Np $\max$ & $\left\{\mathrm{p}-\left(\mathrm{m}+\mathrm{t}_{m}+\mathrm{r}\right)\right\} \max$ \\
\hline $\mathrm{p} / \mathrm{rl} \operatorname{ma} \alpha x$ & $\mathrm{p} / \mathrm{rl} \max$ \\
\hline$(\mathrm{p}-\mathrm{rl}) / \mathrm{rl} \max$ & $(\mathrm{p}-\mathrm{r}) / \mathrm{rl} \max$ \\
\hline
\end{tabular}




\begin{tabular}{|c|c|}
\hline $\mathrm{p} /(\mathrm{lc}+\mathrm{t}) \max$ & $\mathrm{p} /\left(\mathrm{m}+\mathrm{t}_{m}\right) \max$ \\
\hline $\mathrm{Gp} /(\mathrm{lc}+\mathrm{t}) \max$ & $\left\{\mathrm{p}-\left(\mathrm{m}+\mathrm{t}_{m}\right)\right\} /\left(\mathrm{m}+\mathrm{t}_{m}\right) \max x$ \\
\hline $\mathrm{p} /(\mathrm{lc}+\mathrm{t}+\mathrm{r}) \max$ & $\mathrm{p} /\left(\mathrm{m}+\mathrm{t}_{m}+\mathrm{r}\right) \max$ \\
\hline $\mathrm{Np} /(\mathrm{lc}+\mathrm{t}+\mathrm{r}) \max$ & $\left\{\mathrm{p}-\left(\mathrm{m}+\mathrm{t}_{m}+\mathrm{r}\right)\right\} /\left(\mathrm{m}+\mathrm{t}_{m}+\mathrm{r}\right) \max x$ \\
\hline$\{(\mathrm{lc}+\mathrm{t})-\mathrm{p}\} \min$ & $\left\{\left(\mathrm{m}+\mathrm{t}_{m}\right)-\mathrm{p}\right\}$ min \\
\hline$\{(\mathrm{lc}+\mathrm{t})-\mathrm{p}\} /(\mathrm{lc}+\mathrm{t}) \min$ & $\left\{\left(\mathrm{m}+\mathrm{t}_{m}\right)-\mathrm{p}\right\} /\left(\mathrm{m}+\mathrm{t}_{m}\right) m i n$ \\
\hline$\{(\mathrm{lc}+\mathrm{t}+\mathrm{r})-\mathrm{p}\}$ min & $\left\{\left(m+t_{m}+r\right)-p\right\}$ min \\
\hline$\{(\mathrm{lc}+\mathrm{t}+\mathrm{r})-\mathrm{p}\} /(\mathrm{l} \mathrm{c}+\mathrm{t}+\mathrm{r}) \min$ & $\left\{\left(\mathrm{m}+\mathrm{t}_{m}+\mathrm{r}\right)-\mathrm{p}\right\} /\left(\mathrm{m}+\mathrm{t}_{m}+\mathrm{r}\right) \min$ \\
\hline
\end{tabular}

As evident from the table, in this case there is no goal concerned with $L$. And to get the goals concerned with $(l c+t)$ or $(l c+t+r)$, we must add $\left(e+t_{c}\right),\left(n+t_{n}\right)$ and $\left(s+t_{s}\right)$, which are all the fixed values in the case under consideration, to the corresponding $\left(m+t_{m}\right)$, which corresponds to $(\mathrm{lc}+\mathrm{t})$ in 1 and $\mathrm{L}$ case, along the ordinates, the further process of treating the goals being the same as before. Special attention should be payed in this case to the facts:-

(I) $\mathrm{p} /(\mathrm{lc}+\mathrm{t}) \max$ or $\mathrm{p} /(\mathrm{lc}+\mathrm{t}+\mathrm{r}) \max$ exist for 1 and M separately i.e. the curve of intensities to get $\mathrm{p} /(\mathrm{lc}+\mathrm{t}) \max$ or $\mathrm{p} /(\mathrm{lc}+\mathrm{t}+\mathrm{r}) \max$ on 1 is different with that at $M$, as shown on Fig. 52 .

(2) There are in general one or more series of intensities giving $\mathrm{p} / \mathrm{rl}$ max, $\mathrm{p} /\left(\mathrm{m}+\mathrm{t}_{m}\right) \max$ or $\mathrm{p} /\left(\mathrm{m}+\mathrm{t}_{m}+\mathrm{r}\right)$ max on $\mathrm{l}$ and at $\mathrm{M}$ respectively and when $\left(m+t_{m}\right) / M=$ constant and $r l / l=$ constant they give those max amounts on 1 and at $M$ at the same time respectively.

(3) There are one or more intensities each giving $\mathrm{p} / \mathrm{rl} M A X$, $\mathrm{p} /\left(\mathrm{m}+\mathrm{t}_{m}\right) M A X$ or $\mathrm{p} /\left(\mathrm{m}+\mathrm{t}_{m}+\mathrm{r}\right) M A X$ on $\mathrm{l}$ and at $\mathrm{M}$ at the same time.

(4) As there may be several kinds and proportions of $M$, we can get several combinations to win the same goal, one for each of these kinds and proportions.

Quite similar properties can be observed for any other combination of two elements in general and it will always be noticed that there are innumerable combinations giving max amounts and one or more, in general, combinations giving $M A X$ amounts of the same meaning. The proper combination most suitable for the object of farming is, of course, that which gives $M A X$ amount of the goal to win under the given circumstances. 


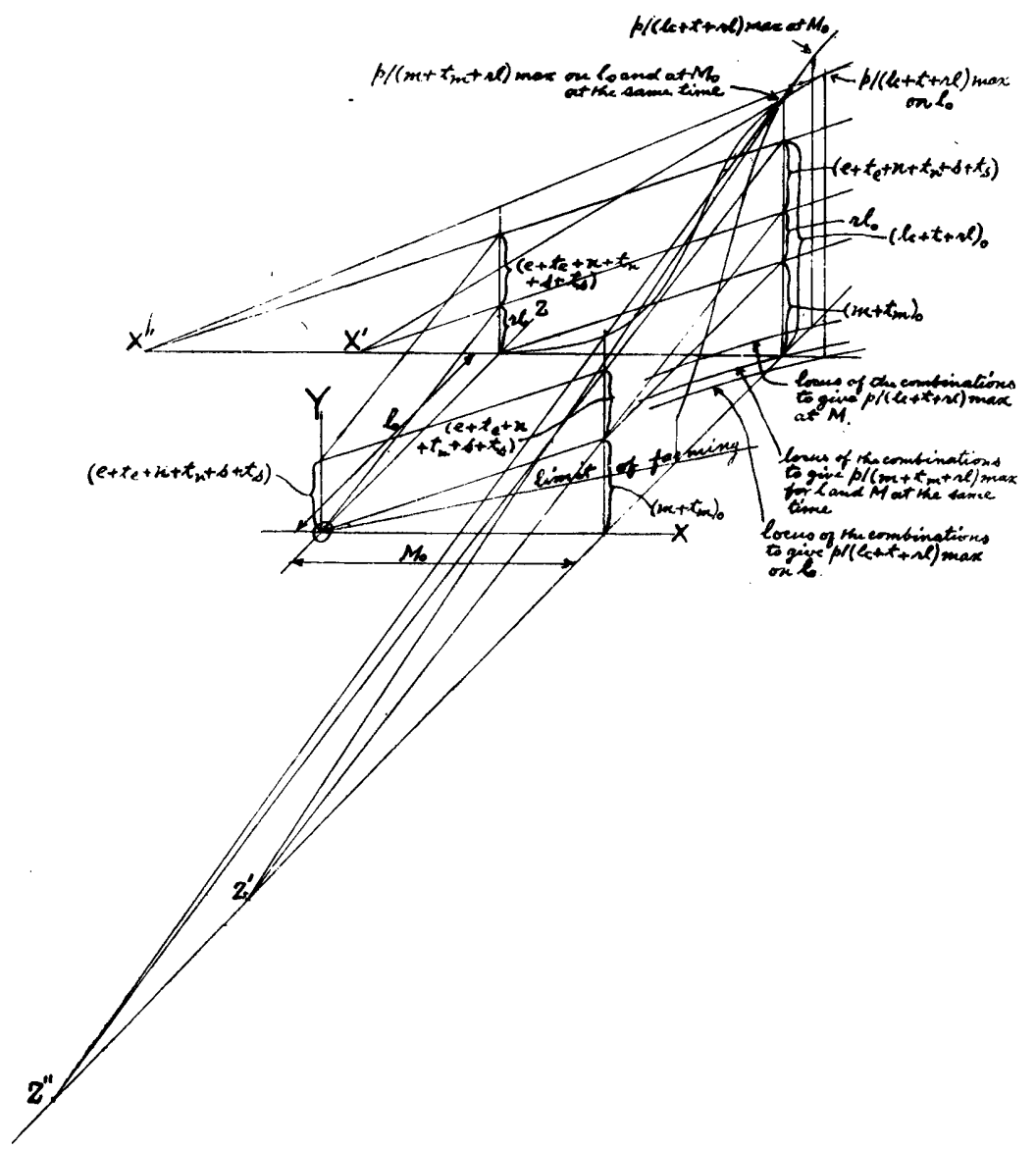

Iig. 52.-In this figure, the feature of the locus of $\mathrm{N}$ and $\mathrm{S}$ combinations to get $\mathrm{p} /(\mathrm{lc}+\mathrm{t}+\mathrm{r})$ max $x$ at $S$ is assumed to be the same as that of the locus of 1 and $I$, combinations discussed in chapter II to get $\mathrm{p} /(\mathrm{lc}+\mathrm{t}+\mathrm{r}) \max$ at $\mathrm{I}$.

Here the word "innumerable" should be noticed. In order to realize innumerable such combinations the elements set on the axes must be dividable as desired. $\mathrm{M}$ and $\mathrm{E}$ are not dividable in their forms of construction indeed, and there may rise the question as to the dividability of $\mathrm{M}$ and $\mathrm{E}$. Here we must notice, however, that when we discuss them as the elements of the production, the time of their employment should be taken into consideration and that the time is dividable and it is the usual practice to adopt a system by which the time of employment of $M$ and $E$ is adjusted to secure their highest efficiency. So, the word "innumerable" may be used here without mistake. 
Thus there exist in general one or more proper combinations of any two of the production elements $1, \mathrm{M}, \mathrm{E}, \mathrm{N}$ and $\mathrm{S}$ to win the goal and it is practicable to ascertain such combinations provided that there are sufficient data to suit the purposes in hand.

\section{PROPER COMBINATIONS OF AL.L PRODUCTION ELEMENTS TO WIN THE GOALS}

Here the graphical method is applied on the production elements so that each of the quantities of an element set on OX axis represents perfectly and fixes definitely the corresponding quantities of all other elements composing $\mathrm{L}$. It is convenient to have all data on the products and the production elements tabulated as shown on Plate 44 .

A Case of the utmost profitable combination

The term " utmost profitable" may have different meanings according to the uses. On discussing the size of farm, I let it mean "having the utmost net profit rate" i.e. to have $\mathrm{Np} /(\mathrm{lc}+\mathrm{t}+\mathrm{r}) M A X$ and let the term "most profitable" mean " having the largest net profit rate" i.e. to have $\mathrm{Np} /(\mathrm{lc}+\mathrm{t}+\mathrm{r})$ max. Now, many kinds of utmost profitable combinations can be considered and if $\mathrm{L}$ is analized into four, as treated above, they may be classified into four as follows:-

Class (I) Combinations utmost profitable for any one of the production elements.

Class (2) Combinations utmost profitable for any one of the production elements and most profitable for another at the same time.

Class (3) Combinations utmost profitable for any one of the production elements and most profitable for other two at the same time.

Class (4) Combinations utmost profitable for any two of the production elements and most profitable for other three at the same time.

To have the utmost profitable combination it is desirable that we can find a combination which is utmost profitable for all production elements at the same time, but according to my investigation such a combination does not exist in general and we must satisfy ourselves with Class (4) combinations. Here it will be noticed that this last conclusion does not agree with that which is stated in II, where it is assumed that $\mathrm{L}$ can be set on one line.

Now we proceed to explain how to find these combinations. 
(I) For each set of $1, \mathrm{M}$ and $\mathrm{E}$, set $\mathrm{p}$ solid on the axes $\mathrm{N}$ and $\mathrm{S}$ and for each of these solids find the proper combination of $\mathrm{N}$ and $S$ to be utmost profitable at $S$. Here we should notice that as the kind and proportion of $\mathrm{N}$ may vary, there may be many such $\mathrm{p}$ solids for the same $1, M$ and $E$, one solid for each kind and proportion of $\mathrm{N}$. If there is no choice on the kind and proportion of $\mathrm{N}$, find the combination utmost profitable at $S$ for each solid, and out of these combinations obtained, select the one where the value of the fraction $\mathrm{Np} /(\mathrm{lc}+\mathrm{t}+\mathrm{r})$ is greatest, for each set of $1, \mathbf{M}$ and $\mathrm{E}$. If there is any choice or limitation, select the ones having $\mathrm{Np} /(\mathrm{lc}+\mathrm{t}+\mathrm{r})$ greatest within the circle of choice or limitation. In the table above referred to, the final combinations of $\mathrm{N}$ and $\mathrm{S}$ are

$$
\begin{aligned}
& N_{1110} \text { and } S_{1110 M} \text { for } l_{1}, M_{11} \text { and } E_{111}, \\
& N_{1120} \text { and } S_{120 M} \text { for } l_{1}, M_{12} \text { and } E_{112}, \\
& N_{1210} \text { and } S_{1210 M} \text { for } I_{1}, M_{12} \text { and } E_{121}, \\
& N_{1220} \text { and } S_{1220 M} \text { for } 1_{1}, M_{12} \text { and } E_{122}, \\
& \text { ect. etc., here the kind and proportion of } N \text { being }
\end{aligned}
$$

assumed to be one simply. These final $\mathrm{N}$ and $\mathrm{S}$ combined with the corresponding $1, \mathrm{M}$ and $\mathrm{E}$ respectively compose the combinations utmost profitable at $S$, the corresponding $p$ and $(l c+t+r)$ as well as the the kind and proportion of $\mathrm{N}$ to be combined being definitely fixed respectively at the same time. We must notice here that, besides those explained above, there are other combinations utmost profitable at $\mathrm{S}$, which will be obtained similarly for each set of several $1, \mathrm{M}$ and $\mathrm{N}$, several 1, E and $\mathrm{N}$ and several $\mathrm{M}, \mathrm{E}$ and $\mathrm{N}$. The number of different combinations utmost profitable at any one specified element (corresponding to $\mathrm{S}$ in the above explanation) is in general ${ }_{4} \mathrm{C}_{3}=4$. Combinations utmost profitable at any other element can be obtained quite similarly. Attention should be payed to keep the records on the series of combinations of $\mathrm{N}$ and $\mathrm{S}$ to give $\mathrm{Np} /(\mathrm{lc}+\mathrm{t}+\mathrm{r}) \max$ at $\mathrm{S}$, for each kind and proportion of $\mathrm{N}$, as they are important data for the further investigation.

(2) For each set of 1 and $M$, set $p$ solid on the axes $E$ and $N$, accompanying $S$, found in (I) to give, at each of $E, N p /(l c+t+r) \max$ at $\mathrm{S}$, in combination with $\mathrm{N}$ (Fig. 53). As there may be several kinds and proportions of $\mathrm{N}$, there may be several such $\mathrm{p}$ solids; for each of these solids, find the proper combination of $\mathrm{E}$ and $\mathrm{N}$, as well as $\mathrm{S}$ to accompany, to be utmost profitable at $\mathrm{N}$, and select the one 


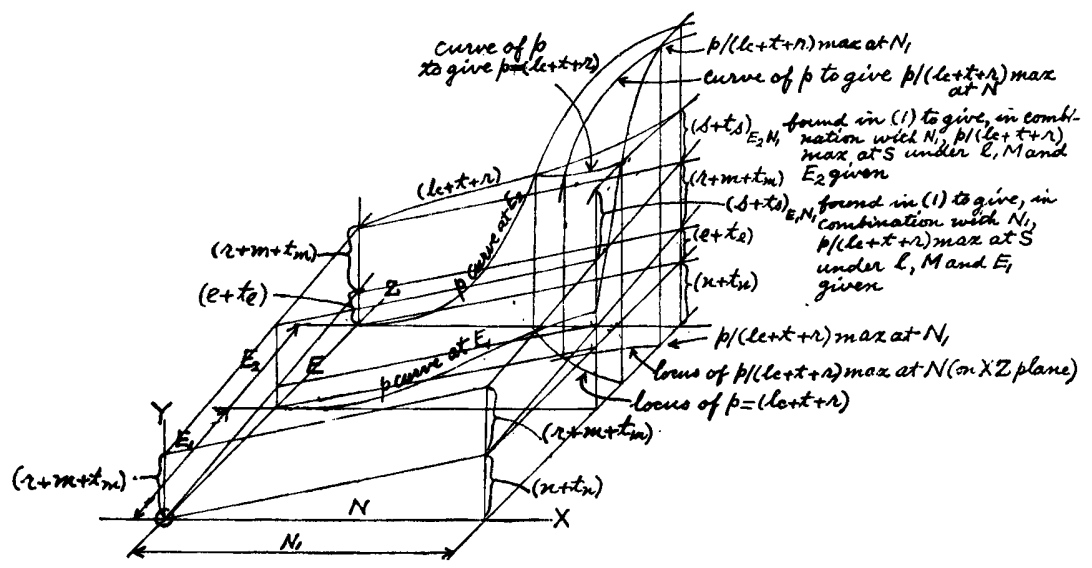

Fig. 53 ( 1 and $M$ given). In this figure, the feature of the locus of $p /(I c+t+r) \max$ at $S$ in (I) is assumed to be the same as that of the locus of $p /(l c+t+r) \max$ at $I$, on the chart of the intensities constructed for the relation between 1 and $J$. in Chapter II.

where the value of the fraction $\mathrm{Np} /(\mathrm{lc}+\mathrm{t}+\mathrm{r})$ is greatest. Moreover, as the kind and proportion of $\mathrm{E}$ may vary, there may be many such greatest $\mathrm{Np} /(\mathrm{lc}+\mathrm{t}+\mathrm{r})$ for the same $\mathrm{l}$ and $\mathrm{M}$. Again select the one where $\mathrm{Np} /(\mathrm{lc}+\mathrm{t}+\mathrm{r})$ is greatest. In the table above referred to, the final combinations of $\mathrm{E}$ and $\mathrm{N}$ are

$\mathrm{E}_{\mathrm{rno}}$ and $\mathrm{N}_{\mathrm{rroM}}$ for $\mathrm{l}_{\mathrm{r}}$ and $\mathrm{M}_{11}$ accompanying $\mathrm{S}_{\mathrm{rroMm}}$,

$E_{120}$ and $N_{120 M}$ for $l_{1}$ and $M_{12}$ accompanying $S_{r 20 M m}$,

$\mathrm{E}_{210}$ and $\mathrm{N}_{210 M}$ for $\mathrm{I}_{2}$ and $\mathrm{M}_{2 \mathrm{I}}$ accompanying $\mathrm{S}_{210 M m}$,

$\mathrm{E}_{22 \mathrm{O}}$ and $\mathrm{N}_{22 \mathrm{OM}}$ for $\mathrm{l}_{2}$ and $\mathrm{M}_{22}$ accompanying $\mathrm{S}_{220 \mathrm{Mm}}$,

$$
\text { etc., etc., here the kind and proportion }
$$

of $\mathrm{F}$ and $\mathrm{N}$ being assumed to be one for each simply. These final $\mathrm{E}, \mathrm{N}$ and $\mathrm{S}$ combined with the corresponding 1 and $\mathrm{M}$ respectively compose the combinations utmost profitable at $\mathrm{N}$ and most profitable at $S$ at the same time, the corresponding $p$ and $(l c+t+r)$ as well as the kind and proportion of $\mathrm{E}$ and $\mathrm{N}$ to be combined being definitely fixed respectively at the same time. We must notice here that, besides those explained above, there are other combinations utmost profitable at $\mathrm{N}$ and most profitable at $\mathrm{S}$ at the same time, which will be obtained similarly for each set of several 1 and $E$ and several $M$ and $E$. The number of different combinations utmost profitable at any one specified element (corresponding to $\mathrm{N}$ in the above explanation) and most profitable for another specified element (corresponding to $S$ in the 
above explanation) at the same time is in general ${ }_{3} \mathrm{C}_{2}=3$. Combinations utmost profitable for any other element and most profitable for another at the same time can be obtained quite similarly. Attention should be payed to keep the records on the series of combinations of $\mathrm{E}$ and $\mathrm{N}$ to give $\mathrm{Np} /(\mathrm{lc}+\mathrm{t}+\mathrm{r}) \max$ at $\mathrm{N}$ and $\mathrm{S}$ at the same time for each kind and proportion of $\mathrm{E}$ and $\mathrm{N}$, as they are important data for the further investigation.

(3) For each 1, set $\mathrm{p}$ solid on the axes $\mathrm{M}$ and $\mathrm{E}$, accompanying $\mathrm{N}$ and $\mathrm{S}$, found in (2) to give, at each of $\mathrm{M}, \mathrm{Np} /(\mathrm{lc}+\mathrm{t}+\mathrm{r}) \max$ at $\mathrm{N}$ and $\mathrm{S}$ at the same time, in combination with $\mathrm{E}$. As there may be several kinds and proportions of $E$ and $N$, there may be several such $p$ solids; for each of these solids find the proper combination of $M$ and $\mathrm{E}$, as well as $\mathrm{N}$ and $\mathrm{S}$ to accompany, to be utmost profitable at $\mathrm{E}$, and select the one where the value of the fraction $\mathrm{Np} /(\mathrm{lc}+\mathrm{t}+\mathrm{r})$ is greatest. Moreover, as the kind and proportion of $\mathrm{M}$ may vary, there may be many such greatest $\mathrm{Np} /(\mathrm{lc}+\mathrm{t}+\mathrm{r})$ for the same 1 . Again select the one where $\mathrm{Np} /(\mathrm{lc}+\mathrm{t}+\mathrm{r})$ is greatest. In the table above referred to, the final combinations of $\mathrm{M}$ and $\mathrm{E}$ are

$\mathrm{M}_{10}$ and $\mathrm{E}_{\mathrm{roM}}$ for $\mathrm{l}_{\mathrm{r}}$ accompanying $\mathrm{N}_{10 M m}$ and $\mathrm{S}_{\mathrm{roMm} m}$,
$\mathrm{M}_{20}$ and $\mathrm{E}_{20 M}$ for $\mathrm{l}_{2}$ accompanying $\mathrm{N}_{20 M m}$ and $\mathrm{S}_{20 M m m}$,
etc., $\quad$ etc., here the kind and proportion of $\mathrm{M}, \mathrm{E}$ and $\mathrm{N}$ being assumed to be one for each simply. These final $\mathrm{M}, \mathrm{E}$, $\mathrm{N}$ and $\mathrm{S}$ combined with the corresponding 1 respectively compose the combinations utmost profitable for $E$ and most profitable for $N$ and $S$ at the same time, the corresponding $p$ and $(l c+t+r)$ as well as the kind and proportion of $\mathrm{M}, \mathrm{E}$ and $\mathrm{N}$ to be combined being definitely fixed respectively at the same time. We must notice here that, besides those explained above, there are other combinations utmost profitable for $\mathrm{E}$ and most profitable for $\mathrm{N}$ and $\mathrm{S}$ at the same time, which will be obtained similarly for each of several $M$. The number of different combinations utmost profitable for any one specified element (corresponding to $\mathrm{E}$ in the above explanation) and most profitable for other two specified elements (corresponding to $\mathrm{N}$ and $\mathrm{S}$ in the above explanation) at the same time is in general ${ }_{2} \mathrm{C}_{\mathbf{r}}=2$. Combinations utmost profitable for any other element and most profitable for other two at the same time can be obtained quite similarly. Attention should be payed to keep the records on the series of combinations of $M$ and $\mathrm{E}$ to give $\mathrm{Np} /(\mathrm{lc}+\mathrm{t}+\mathrm{r}) m a \dot{x}$ at $\mathrm{E}, \mathrm{N}$ and $\mathrm{S}$ at the same time for 
each kind and proportion of $\mathrm{M}, \mathrm{E}$ and $\mathrm{N}$, as they are important data for the further investigation.

(4) Set $p$ solid on the axes 1 and $M$, accompanying $E, N$ and $S$, found in (3) to give, at each of $1, \mathrm{~Np} /(\mathrm{lc}+\mathrm{t}+\mathrm{r})$ max at $\mathrm{E}, \mathrm{N}$ and $\mathrm{S}$ at the same time, in combination with $M$. As there may be several kinds and proportions of $M, E$ and $N$, there may be several such $p$ solids; for each of these solids find the proper combination of 1 and $\mathrm{M}$, as well as $\mathrm{E}, \mathrm{N}$ and $\mathrm{S}$ to accompany, to be utmost profitable on 1 and at $M$ at the same time, and select the one where the value of the fraction $\mathrm{Np} /(\mathrm{l} c+\mathrm{t}+\mathrm{r})$ is greatest. In the table above referred to, the final combination is

$1_{M}$ and $\mathrm{M}_{M M}$ accompanying $\mathrm{E}_{M M m}, \mathrm{~N}_{M M m m}$ and $\mathrm{S}_{M M n m m}$, here the kind and proportion of $\mathrm{M}$ as well as $\mathrm{E}, \mathrm{N}$ and $\mathrm{S}$ being assumed to be one for each simply. The final $1, \mathrm{M}, \mathrm{E}, \mathrm{N}$ and $\mathrm{S}$ compose one and only one combination utmost profitable for 1 and $M$ and most profitable for $\mathrm{E}, \mathrm{N}$ and $\mathrm{S}$ at the same time, the corresponding $\mathrm{p}$ and $(\mathrm{l}+\mathrm{t}+\mathrm{r})$ as well as the kind and proportion of $M, E$ and $N$ to be combined being definitely fixed respectively at the same time. Combinations utmost profitable for any other two and most profitable for other three at the same time can be obtained quite similarly, among which are those utmost profitable for 1 and any one of $\mathrm{E}, \mathrm{N}$ and $\mathrm{S}$ and most profitable for other three at the same time.

As to the question which of these last combinations should be adopted to suit the purpose, we must examine the meanings of these combinations and the weight of each element in the actual circumstances as well as the values of the fraction $\mathrm{Np} /(\mathrm{l} c+\mathrm{t}+\mathrm{r}) M A X$ at respective cases and select the most desirable one to suit the object of comparison.

The 1 thus adopted is the proper size of farm observed through the law of decreasing returns in A case and is nothing but the quantity of 1 , destined and found, to combine with the other production elements to make the combination most desirable.

\section{B Cases to win other goals}

Similar processes of treatment to $A$ are practicable for all other goals, except the process stated in $\mathrm{A}(4)$ which is applicable for $\mathrm{p} / \mathrm{rl}$ $M A X$ or $(\mathrm{p}-\mathrm{rl}) / \mathrm{rl} M A X$ and $\mathrm{p} /(\mathrm{lc}+\mathrm{t}) M A X$ or $\mathrm{Gp} /(\mathrm{l} \mathrm{c}+\mathrm{t}) M A X$ but not applicable for other goals, where Class (4) combinations do not exist and instead of them there exist the combinations giving $M A X$ 
value of goal for any one of the production elements and max values for other three at the same time. In B we must satisfy ourselves with these last combinations as the most clesirable possible ones. The process to find such combination is quite similar to that explained in A (3). If the elements, for which the combinations have to win the goal, are not specified, the number of such combinations of different meanings is ${ }_{5} \mathrm{C}_{\mathrm{r}} \times{ }_{4} \mathrm{C}_{3}=2 \mathrm{O}$. As to the question which of these conbinations is to be adopted, we must select the one most desirable to suit the object of comparison. To solve the problems of the size of farm, we will have to deal with those which give the values of the goals to be $M A X$ on 1 and $\max$ at the other three elements.

Here it is to be put in mind that the solid curves plotted to solve the problems of the values of the products should be constructed by setting $\mathrm{p}$, while those to solve the problems of the substantial quantities of the products, by setting $\mathrm{P}$ along $\mathrm{OY}$ axis. And it is to be noticed that the utmost profitable combinations are essential in the sense of giving $M A X$ values for two elements and max values for other three elements at the same time, and that the combinations to give $\mathrm{p} /(\mathrm{lc}+\mathrm{t})$ $M A X$ or $\mathrm{Gp} /(\mathrm{lc}+\mathrm{t}) M A X$ and $\mathrm{p} / \mathrm{rl} M A X$ or $(\mathrm{p}-\mathrm{rl}) / \mathrm{rl} M A X$ respectively are also essential in the similar senses, while all other combinations cannot give $M A X$ values for two elements at the same time. And it should be put in mind that the goal to win is governed by the object of farming, not by the number of elements for which $M A X$ are secured.

\section{II. EXTENT OF APPLICATION}

A When the production elements are fixed or limited in quantities

All above stated are when the quantities of the production elements are all unlimited. Actually, however, they are limited in general. When they are limited, on the chart of intensities find the intersection of the limiting line of such element and the line of intensities to win the goal. The combination corresponding to the intersection is the required proper combination to win the goal in this case. It is unavoidable that the greater the number of such limited elements the smaller the field of choice, but it should be noticed that such limitations do not always have the binding power on the existence and selection of the proper combination. Examples are shown below for the case 
where the utmost profitable combination is shifted by the limitation on the production element.

( $I$ ) If 1 is fixed or 'limited $\left\{I_{\circ}\right.$ in Fig. $\left.54(a)\right\}$, draw the line having $l_{0}$ as ordinates and parallel to the $\mathrm{M}$ axis, to meet the $\mathrm{Np}$ / $(\mathrm{l}+\mathrm{t}+\mathrm{r})$ max line at $\left(\mathrm{l}_{0} \mathrm{M}_{\mathrm{r}}\right) . \mathrm{l}_{0}$ aud $\mathrm{M}_{\mathrm{t}}$ will give the utmost profitable combination of 1 and $M$ under the given circumstances.

(2) If $\mathrm{M}$ is fixed or limited $\left\{\mathrm{M}_{\circ}\right.$ in Fig. $\left.54(b)\right\}$, draw the line having $\mathrm{M}_{0}$ as abscissae and parallel to the 1 axis, to meet the $\mathrm{Np} /$ $(l c+t+r)$ max line at $\left(l_{1} M_{0}\right) . \quad l_{r}$ and $M_{o}$ will give the utmost profitable combination of 1 and $M$ under the given circumstances.
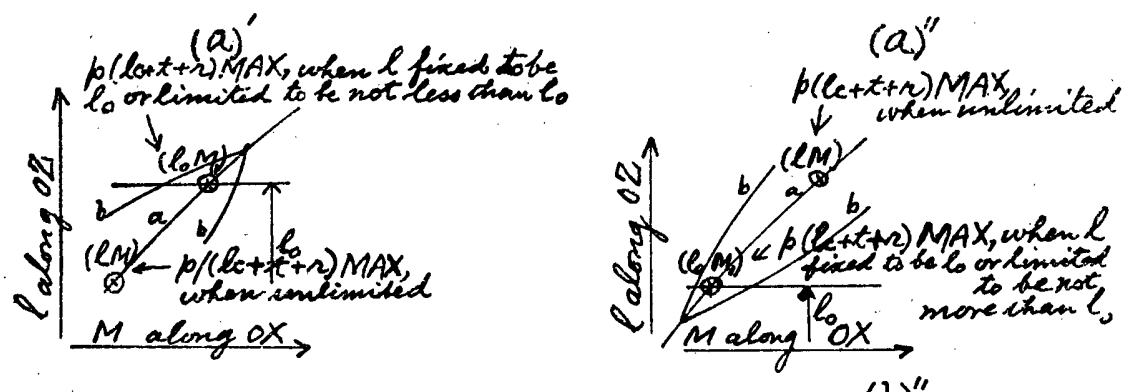

(b)
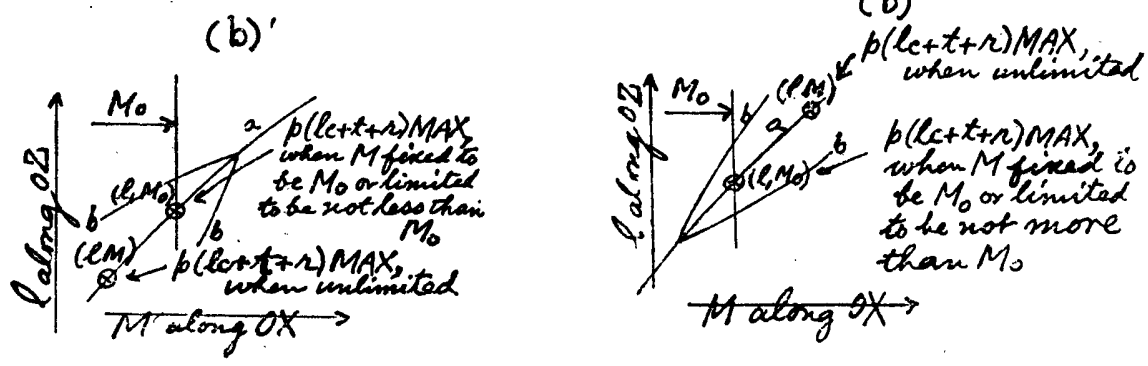

Fig. 54. $a=\mathrm{p} /(\mathrm{lc}+\mathrm{t}+\mathrm{r}) \max$ curve

$b=$ Same net profit rate line.

B Cases to win mixed goals

There may be the cases where the different goals are aimed for the different elements. For example, it may be desired to have a proper combination to give

(1) $\mathrm{P} M A Y$ for $1, \mathrm{P} / \mathrm{M} \max$ for $\mathrm{M}, \mathrm{P} / \mathrm{E} \max$ for $\mathrm{E}$ and $\mathrm{P} / \mathrm{N} \max$ for $\mathrm{N}$ at the same time,

(2) $\mathrm{p} /(\mathrm{lc}+\mathrm{t}+\mathrm{r}) M A X$ for 1 and $\mathrm{N}, \mathrm{p} / \mathrm{M} \max$ for $\mathrm{M}, \mathrm{p} / \mathrm{e} \max$ for $\mathrm{E}$ and $\mathrm{p} \max$ for $\mathrm{S}$ at the same time, 
(3) $\mathrm{p} /(\mathrm{lc}+\mathrm{t}+\mathrm{r}) M A X$ for 1 and $\mathrm{N}, \mathrm{p} /$ (wages payed for hired labour) max for hired labour, $\mathrm{p} /($ family-labour) max for family-labour, $\mathrm{p} / \mathrm{e} \max$ for $\mathrm{E}$ and $\mathrm{p} \max$ for $\mathrm{S}$ at the same time or

(4) $\mathrm{p} M A X$ for $1, \mathrm{P} / \mathrm{m} \max$ for $\mathrm{M}, \mathrm{P} / \mathrm{e} \max$ for $\mathrm{E}$ and $\mathrm{P} / \mathrm{n} \max$ for $\mathrm{N}$ at the same time. Such cases may possibly be solved by a similar process to that described above. Here in (3), M must be subdivided into (family-labour) and (hired labour) and these labours must be treated as two different production elements; and in (4), if $\mathrm{p} / \mathrm{P}$ is not constant, $\mathrm{p}$ and $\mathrm{P}$ must be plotted along the same vertical ordinates on the same corresponding bases where required.

C The production elements which are not economic goods

In the agricultural production, there are many technically essential production elements which are not the economic goods, i e. which cannot bc valuated by the money values, but can be measured in quantities by their own units, such as the temperature, the humidity, the rays of light, the conditions of soil, etc., etc. In ordinary cases of the agricultural enterprises, all such physical and biological elements are specified in a vague way by the lands and are put outside the economists' field of consideration under the law of decreasing returns in spite of the technical investigations recently developing in this line, because they are governed by nature and are out of the reach of our entire control and chiefly because they cannot be valuated by the money values. As obvious from the above investigation, however, the comparison of combinations of the production elements by their quantities, not by their costs, is possibly practicable, provided that the quantities of the clements can be measured by their own units. So, if the more reasonable combinations of the production elements are expected for the agriculture, it is, methinks, to be highly emphasized to bring all such clements into our circle of comparison under the law of decreasing returns, in the same steps as and in co-operation with the technical investigations, though they are not entirely under our control. This is essential to get free from the otherwise unavoidable limitations of applications which are put on the conclusions arrived at by the economists.

\section{Determination of size of farm}

From the above described it is evident that if the amounts of the products are known for all necessary cases of the several combinations 
of the production elements, the existence of special proper combinations of these elements to suit the object of farming under the given circumstances can be ascertained concretely, so far as the combinations of the elements are concerned. But we must notice that besides the proper combinations of production elements thus found through the law of decreasing returns, there are many other factors to determine the size of farm, such as the managerial ability, technical limit of farming, financial condition of the enterpriser, forecasting of price, social policy, order of society, etc. Thus the proper combination of the production elements derived as described above is not the only authority to determine the size of farm, but it must be remembered that it is a mistake to assume that the size of farm can be fairly decided without paying attention to the substantial quantitics of tl:e production elements to be combined with it. Especially it must be put in mind that when the combination of the elements becomes unsuitable for the object of farming owing to some variations of the circumstances, say the fluctuation of the price, the problem how to adjust the farming should be solved by the aid of the fair application of the principle involved in the law of decreasing returns on profit.

E Application to other enterprises or industries

(I) Animal husbandry

All stated above are for the crop farning, but it scems to bc likcly that the method of investigation is applicable for the animal husbandry too. Generally speaking, the crop farming and the animal husbandry may be compared thus:-

\begin{tabular}{|c|c|c|}
\hline \multicolumn{2}{|r|}{ Crop farming } & Animal husbandry. \\
\hline \multicolumn{2}{|c|}{1} & $\begin{array}{l}\text { lean animals for fattening, } \\
\text { breeding animals or milking cows }\end{array}$ \\
\hline \multicolumn{2}{|c|}{$\mathbf{M}$} & manual lalsour \\
\hline \multirow{4}{*}{ E } & buildings & buildings \\
\hline & tools and machinery & instruments ard utensils \\
\hline & working animals & land necessary for keeping animals \\
\hline & fodder for working animals & bedding \\
\hline
\end{tabular}




\begin{tabular}{l|l|l}
\hline$N$ & fodder \\
\hline$S$ & (nil) \\
\hline$t$ & $t$ \\
\hline
\end{tabular}

In the crop farming, the lincs of combinations of the same maning bend at first towards extensive and then towards intensive in consequence of the properties existing among the crop, land and $L$. In the animal husbandry too, it is believed that the lines of combinations of the same meaning tend in the similar way in consequence of the properties existing among the animals and the production elements, owing to $(a)$ the reasonable equipments to be prepared for the small number of heads and (b) the large quantities of fodder and bedding required for the large number of heads, which involve the great trouble of artificial feed and carc as well as the trouble owing to the natural and economical limitations of supply of the materials. Several cases may be considered about the animal husbandry according to the kinds of animals, modes of keeping them and the kinds of products. Special classifications of the production elements will be necessary to suit the cases in order to solve the problem adequately.

(2) Others

The method of investigation on the proper combination of the production elements introduced in this investigaticn $f(r$ the crop farming is believed to be applicable for all other enterpises and incustrics having the similar elements of production.

\section{DISCUSSION AND CONCLUSION}

(I) The technical law of decreasing returns on profit explains the technical relations existing among the crop and the production elements. So, the curves set by this law are, by nature, independent of the prices of either the products or the production clements and remain invariable so far as the technical conditions arc not altercl. H. C. Taylor fairly explains the law in this point, introducing the term "composite units made up of laborers and capital goods." Here, however, it must be noticed that the curves existing on a given size of land should not generally be treated to be similar to those on another 
size of land, owing to the technical reasons involved in the process of farming. H. C. Taylor neglects this latter point by treating $\mathrm{P}$ or $\mathrm{p}$ curve to remain similar for different sizes or extents of land except when under the influences due to "differences in the physical and biological characters of land and in location with respect to the market."

(2) The properties called the technical law of decreasing returns, existing between a certain production element and the returns, and those properties, which make the features of the decreasing return curves dissimilar when another production element in combination is changed in quantities successively, form in co-operation the basis of existence of the proper combinations of the production elements. So, the proper amounts of the elements to combine to suit the object are generally to be determined relatively and simultaneously. The proper size of farm to win the goal under the given circumstances for a given crop is one of the element-quantities destined to combine with the other elements under the given conditions and is to be found in connection with the kinds and quantities of the other elements.

(3) C. L. Holmes insists that the proper combination of the production elements cannot be determined unless a factor concerning farm management is at first fixed, and introduces the "proprietorship" into consideration, the reasons being that "it is impossible that the proper proportionate combination between the technical factors of production is reached by pushing each of them successively to the margin." But by the investigation above described it is evident that there cxist in general one or more combinations of the production elements each to give $\mathrm{p} /(\mathrm{lc}+\mathrm{t}+\mathrm{r}) \max , \mathrm{p} /(\mathrm{l} \mathrm{c}+\mathrm{t}) \max$ or $\mathrm{p} / \mathrm{rl} \max$ for all production elements at the same time, all being generally possible to bc ascertaincd, and that such combinations are got by pushing each of technical factors of production successively to the limit. As to his "proprietorship," it limits the quantities of the production elements to be combined but it is nothing but one factor to linit them, just the same as the relation of managerial ability on $M$, and moreover the proper amounts of them may not always be limited by it.

(4) Many investigators deal with $\mathrm{P} \max , \mathrm{p} \max , \mathrm{Np} \max ,(\mathrm{p}-\mathrm{r})$ $\max , \mathrm{Gp} \max , \mathrm{P} / \mathrm{L} \max , \mathrm{p} / \mathrm{L} \max , \mathrm{Np} / \mathrm{L} \max ,(\mathrm{p}-\mathrm{r}) / \mathrm{L} \max$ and $\mathrm{Gp} / \mathrm{L}$ max. But there are few or none dealing with $\mathrm{p} /(\mathrm{lc}+\mathrm{t}+\mathrm{r}) \max$ or $\mathrm{Np} /(\mathrm{lc}+\mathrm{t}+\mathrm{r}) \max , \mathrm{p} /(\mathrm{lc}+\mathrm{t}) \max$ or $\mathrm{Gp} /(\mathrm{lc}+\mathrm{t}) \max$ and $\mathrm{p} / \mathrm{rl}$ max or $(\mathrm{p}-\mathrm{rl}) / \mathrm{r} l$ max , especially $\{(\mathrm{l} \mathrm{c}+\mathrm{t}+\mathrm{r})-\mathrm{p}\} /(\mathrm{l} \mathrm{c}+\mathrm{t}+\mathrm{r}) \min ,\{(\mathrm{l} c+\mathrm{t}+\mathrm{r})-\mathrm{p}\}$ min, $\{(\mathrm{lc}+\mathrm{t})-\mathrm{p}\} /(\mathrm{l} \mathrm{c}+\mathrm{t}) \min ,\{(\mathrm{l} \mathrm{c}+\mathrm{t})-\mathrm{p}\} \min ,(\mathrm{rl}-\mathrm{p}) / \mathrm{r} l$ min and $(\mathrm{r} l-\mathrm{p})$ 
min when the profit will not be gained temporarily. And there is none who deals with $M A X$ cases. This state of matter seems to be due to the fact that the former investigators in this line studied in the main the relations between the additional expenses, in money or in substance, and the increments of returns instead of those between the total expenses and the total returns. A graphical method dealing with the relations between the total expenses and the total returns has been investigated by Hidetoshi Isobe. But his method seems to be impossible to penetrate into the problem how much quantities of the production elements should be technicaliy combined to win the goal desired under the given economical circumstances, while the last problem is the chief subject in this investigation. The graphical method as proposed here will throw a light for the future in this line.

(5) All investigators on the economics seem to have the common idea that on comparing the combinations of the production elements generally there is no means but by the sums of the prices of the elements, because there is no means to add the numerals of different units. H. C. Taylor has discussed the intensities of culture substantially, but the circle of application, where the idea of the "intensity of culture" holds good in concrete sense, is limited and moreover his "composite units made up of laborers and capital goods" is an abstract one, not practicable, so far as his explanation goes. Thus all investigators dealing with the combinations of the production elements tend to put the importance on the prices of the production elements, ignoring the numerals of their substantial quantities, to the effect that all data on the decreasing returns are chiefly taken for the relations between the products and the prices of the elements. The curves obtained by these data being all affected by the prices and thus being unstable, their active uses for the practical purposes are unavoidably limited, in spite of great efforts paid for. Am dst such state of affairs, this investigation proposes the method of

(i) comparing the combinations of all production elements measurable, economic or not, by their substantial quantities, not by their costs, and finding the combinations most desirable under the circumstances directly in the substantial amounts of the production elements, on the footing of the technically invariable relations between the amounts of the products and those of the production elements, which exist among the crop and the production elements under a certain process of technic ; 
(ii) finding the reasonable combinations economically most suitable for the circumstances, by the aid and on the basis of the said stable technical relations among the crop and the production elements which are not affected by the prices.

(6) The method introduced in this cssay proposes the general solution of the problems on the proper combination of the production elements from the stand-point of the law of decreasing returns. The special or rather actual cases will fairly be treated $c n$ the principle. As to the subdivision of $\mathrm{L}$, this investigation conventionally adopts that which is considered as the practically most convenient one. Other ways of subdivision, which may suit the circumstances, can be treated similarly. As to the goals to win, there may be several others not treated here, for which similar treatments will be applicablc. As to $t$, the proper corrections for each individual case will be effected without so much difficulty. In case the curve is discontinuous, treat those parts separately, where it is continuous, and select the most suitable one by comparing the results.

Thus, I believe, the size of farm observed through the law of decreasing returns will make the economists give up the common iciea, that the combinations of the production elements having the different kinds of units can be compared through their costs only, and make the investigators' full technical records in this line indispensable to solve the problems on the proper combinaticns of the prcduction elements not only in agriculture but in all scrts of picduction inciustries.

\section{LITERATURE}

I. Holmes, C. I., Economics of organization and management, 1926.

2. TAYLOR, II. C., Outlines of agricultural economics, 1923.

3. ISOHE, Hinetosit, Manifold meanings of the so called "law of diminishing returns" and a consideration on it (in Japanese) Nogyo Keizai Kenkyu, Vol. 4, p. 683, 1929.

4. Spillmann, W. J. and Emil I.aNG, The law of diminishing returns, 1924 (?)

5. CAR VER, T. N., The distribution of wealth, I919. 


\section{(A)}

Product Curve solid surface when.

$\mathrm{L}$, to obtain $\mathrm{P}$ proportional to.l, is proportional to 1 .
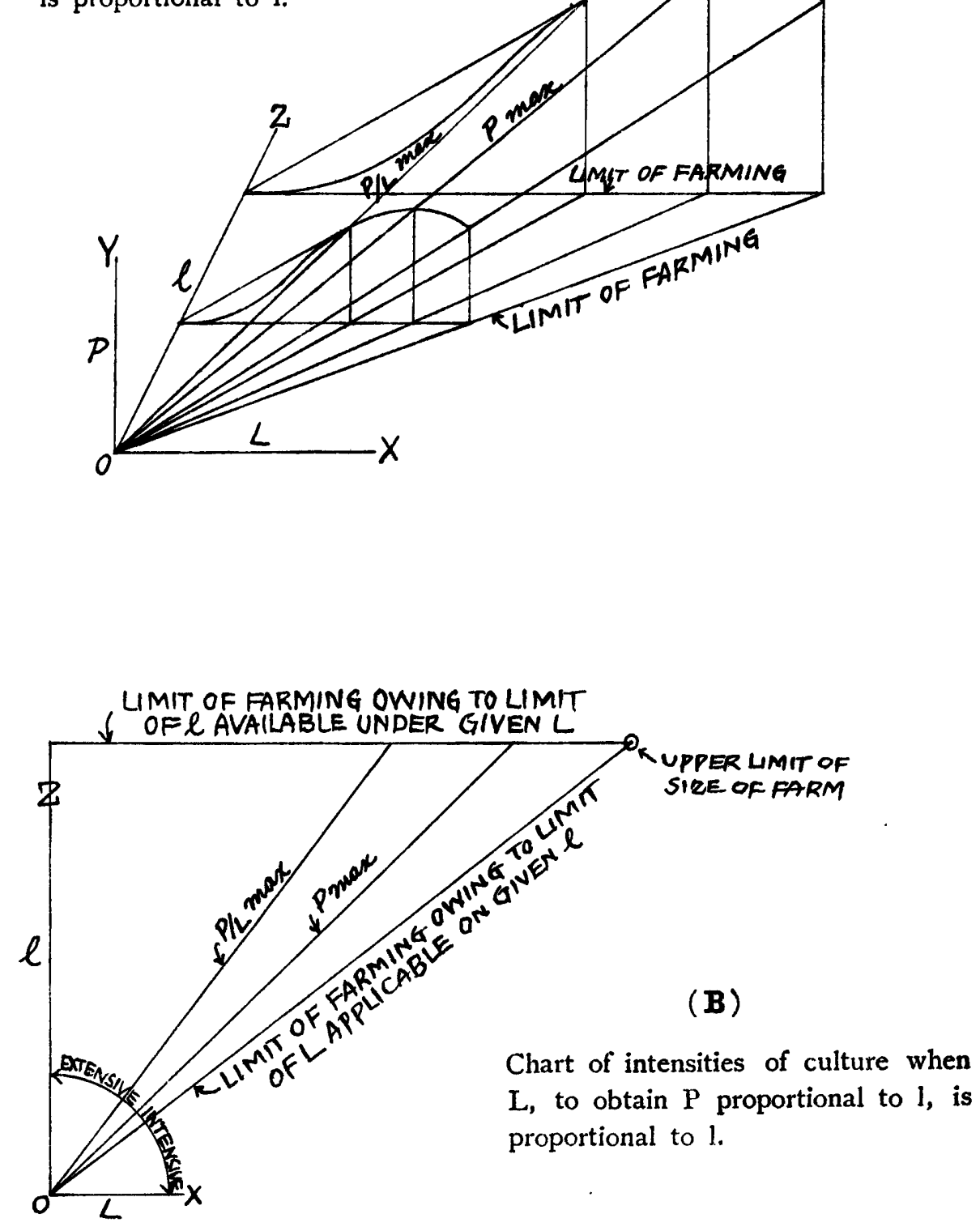
(A)

Product Curve solid surface when $\mathrm{L}$ to obtain $\mathrm{P}$ proportional to 1 increases, as 1 increases, not in proportion with 1.
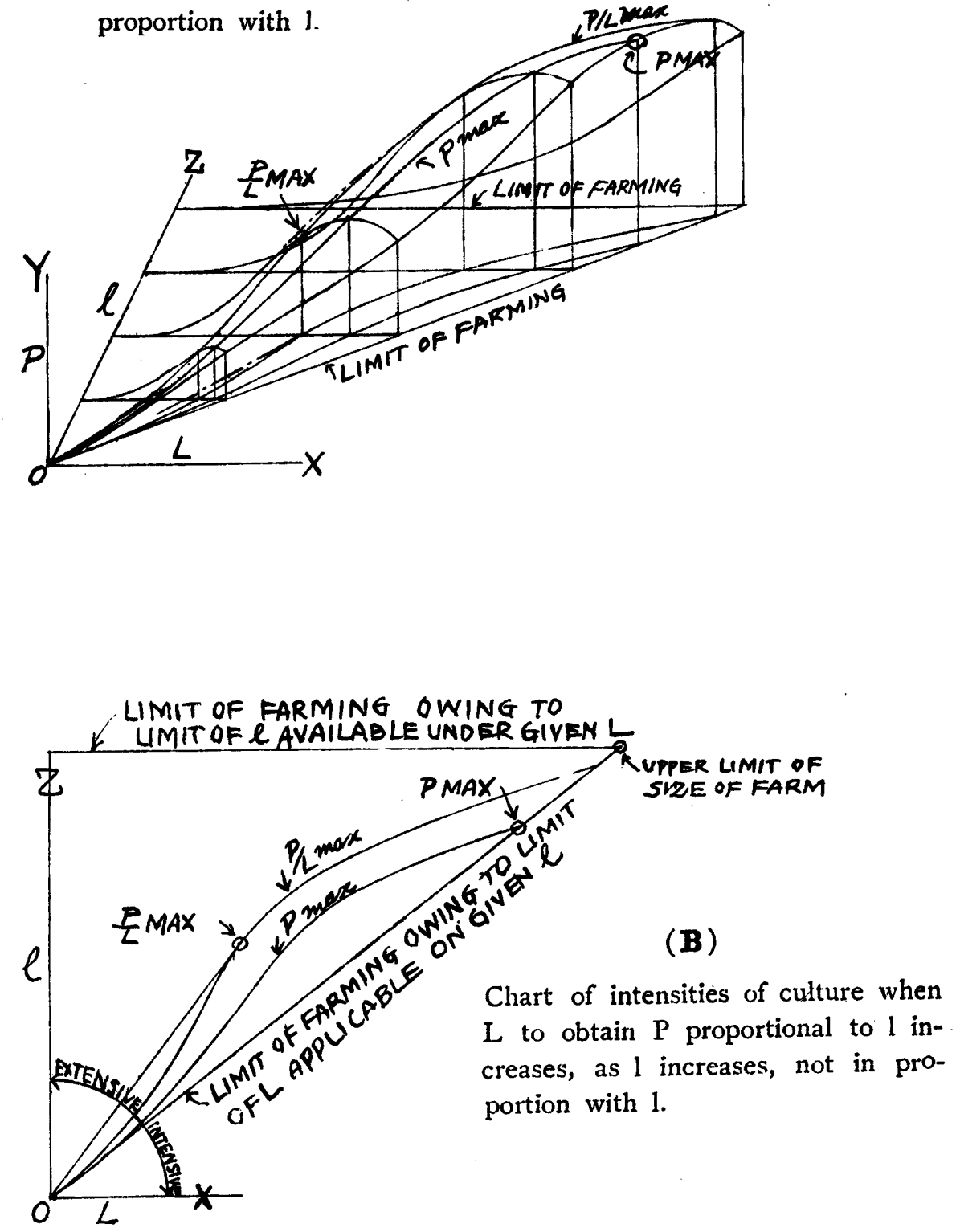
Curves of prices of products in two senses, $I$ is given and $\mathrm{L}$ is given, when $\mathrm{L}$, to obtain $\mathrm{p}$ proportional to $\mathrm{I}$, is proportional to I. (Fixed tenancy).

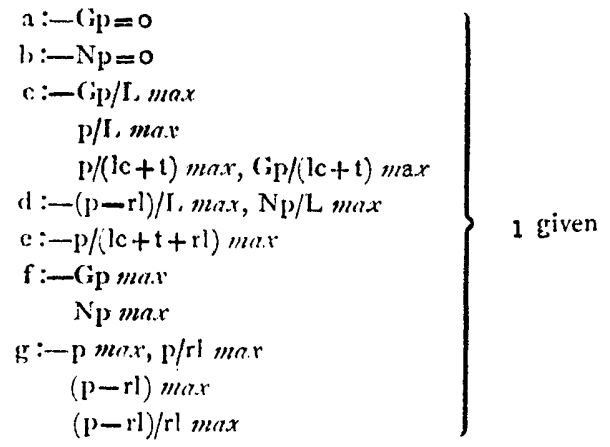

$$
\begin{aligned}
& x^{\prime}:-(i p=0 \\
& \mathrm{l}^{\prime}:-\mathrm{Np}=\mathrm{O} \\
& \mathrm{c}^{\prime}:-\mathrm{p} \max , \mathrm{p} /(\mathrm{l} \mathrm{c}+\mathrm{t}) \text { max } \\
& \text { (ip) } \max x \\
& \mathrm{Gp} /(\mathrm{lc}+\mathrm{t}) \max \\
& \begin{array}{ll}
\mathrm{d}^{\prime}:-(\mathrm{p}-\mathrm{rl}) \text { max, } \mathrm{Np} \text { ma.r } \\
\mathrm{e}^{\prime}:-\mathrm{p}(\mathrm{lc}+\mathrm{t}+\mathrm{rl}) \text { man. }
\end{array} \quad \text { Lgiven } \\
& f^{\prime}:-(\mathrm{ip} / \mathrm{l} \text { ma.r, } \\
& \mathrm{Np} / 1 \text { mar } \\
& \mathrm{g}^{\prime}:-\mathrm{p} / \mathrm{l} m a \mathrm{r}, \mathrm{p} / \mathrm{rl} m \boldsymbol{\mathrm { r }} \mathrm{x} \\
& (\mathrm{p}-\mathrm{rl}) / \mathrm{l} \max \\
& (\mathrm{p}-\mathrm{rl}) / \mathrm{rl} \max \text {. }
\end{aligned}
$$

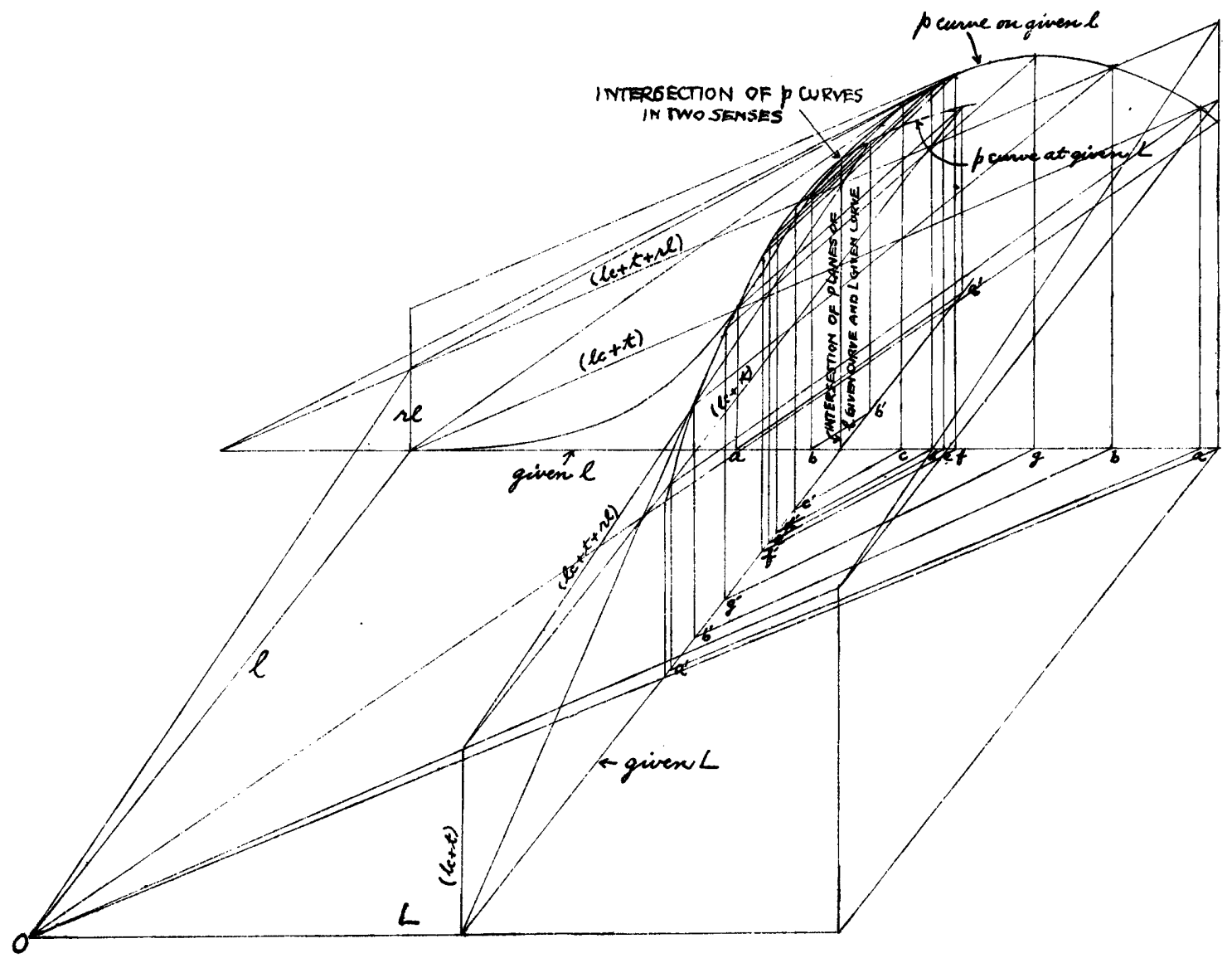




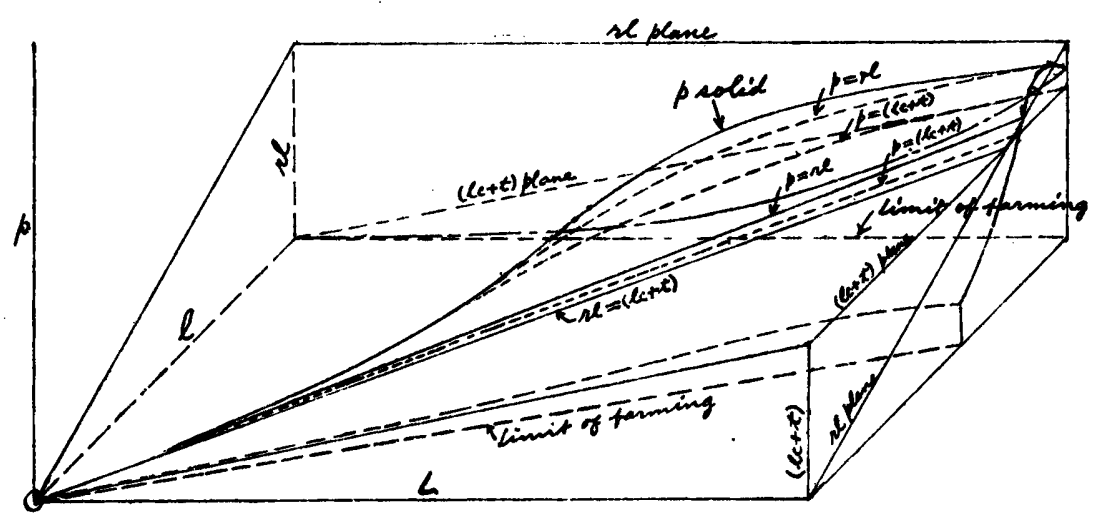

(A)

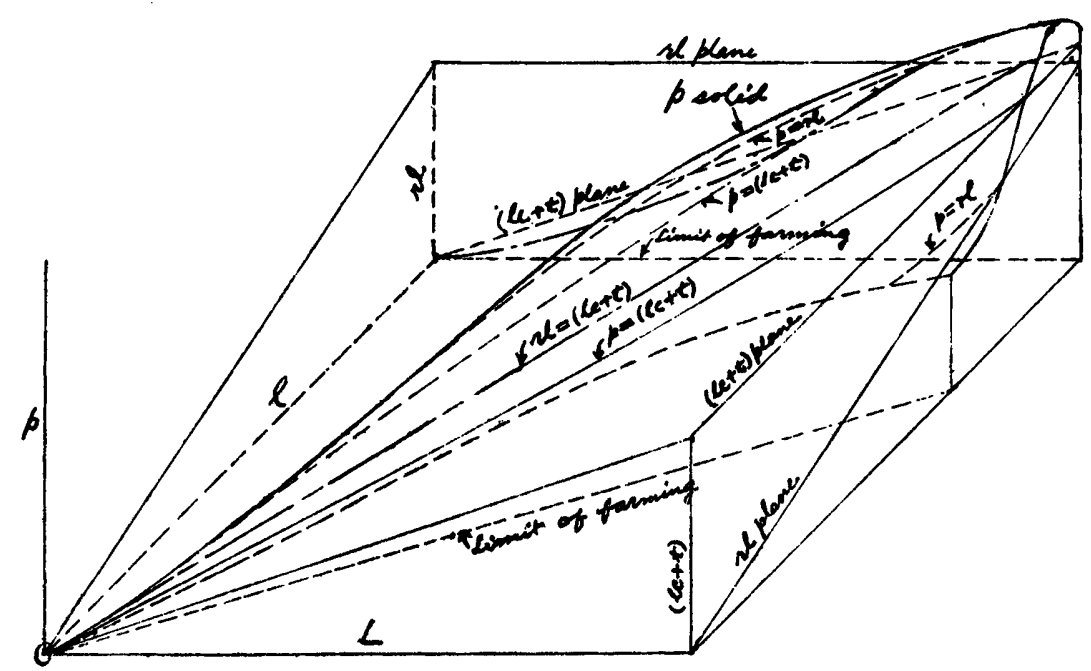

(B) 


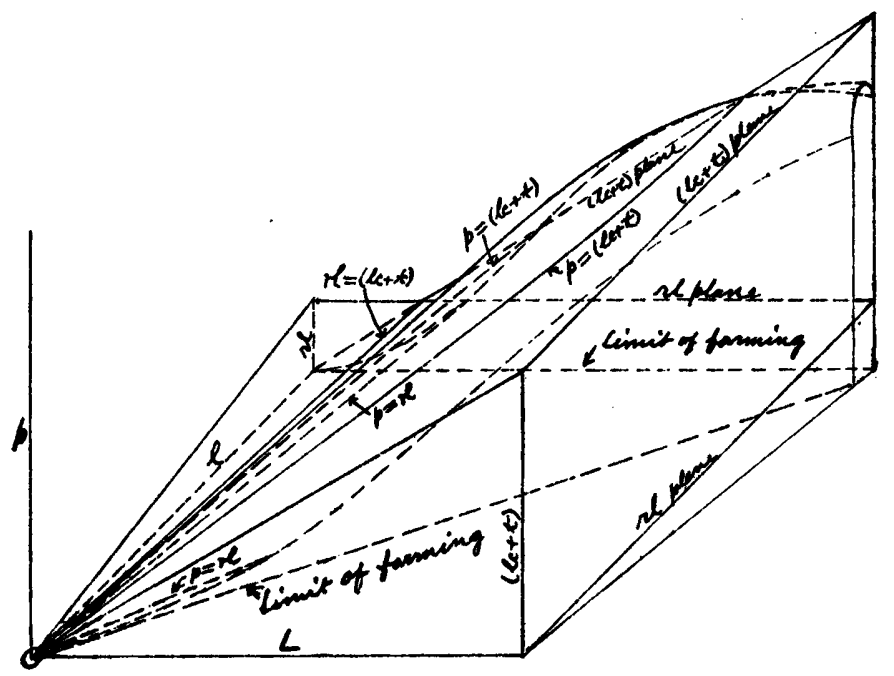

(A)

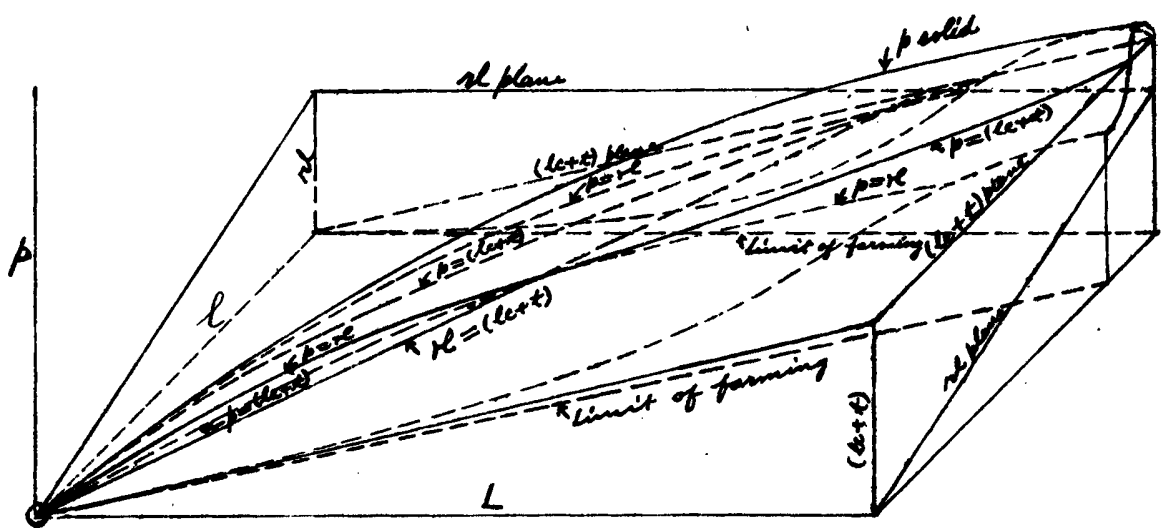

(B) 
UPPERMOST SIZE OF FARM

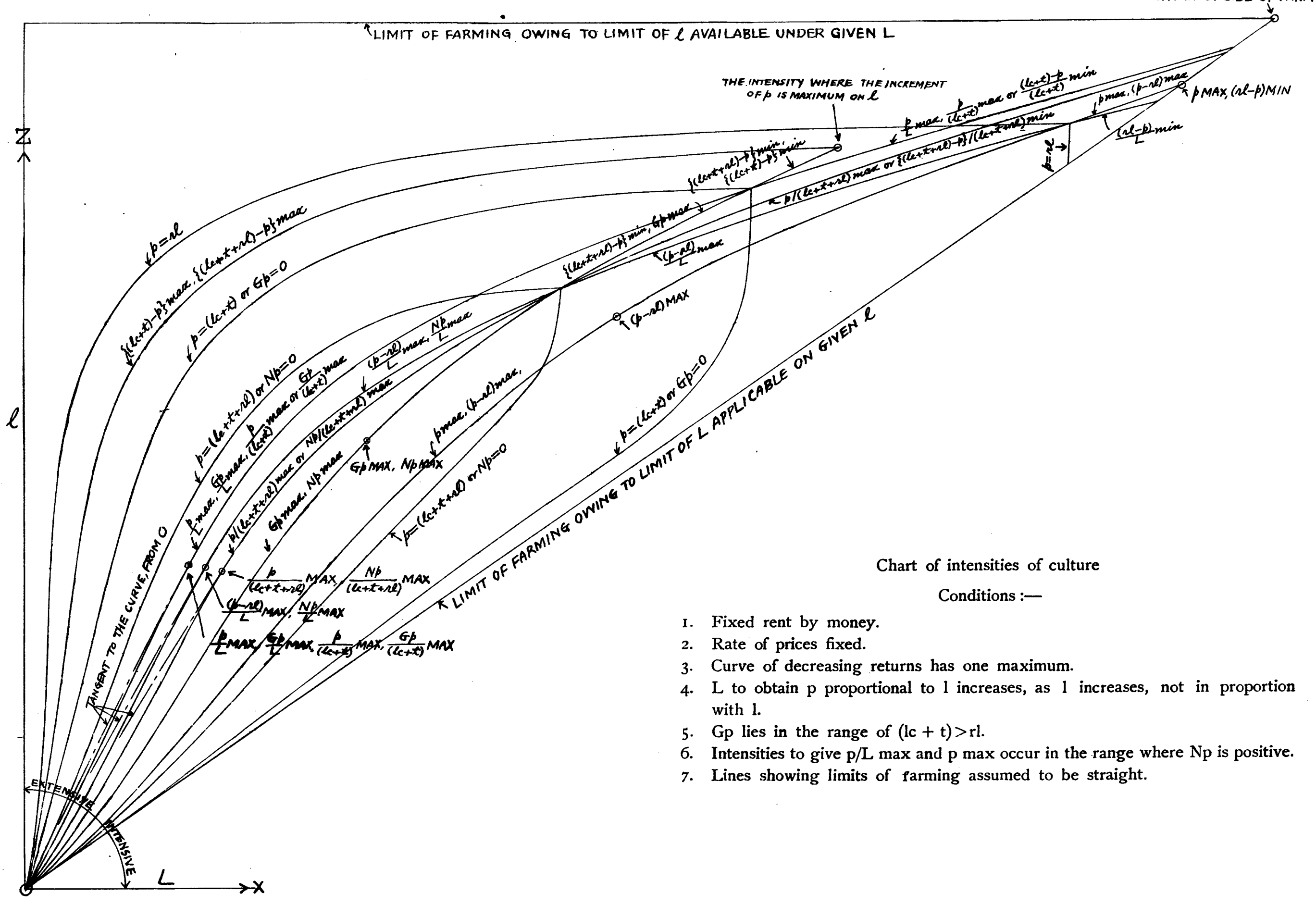




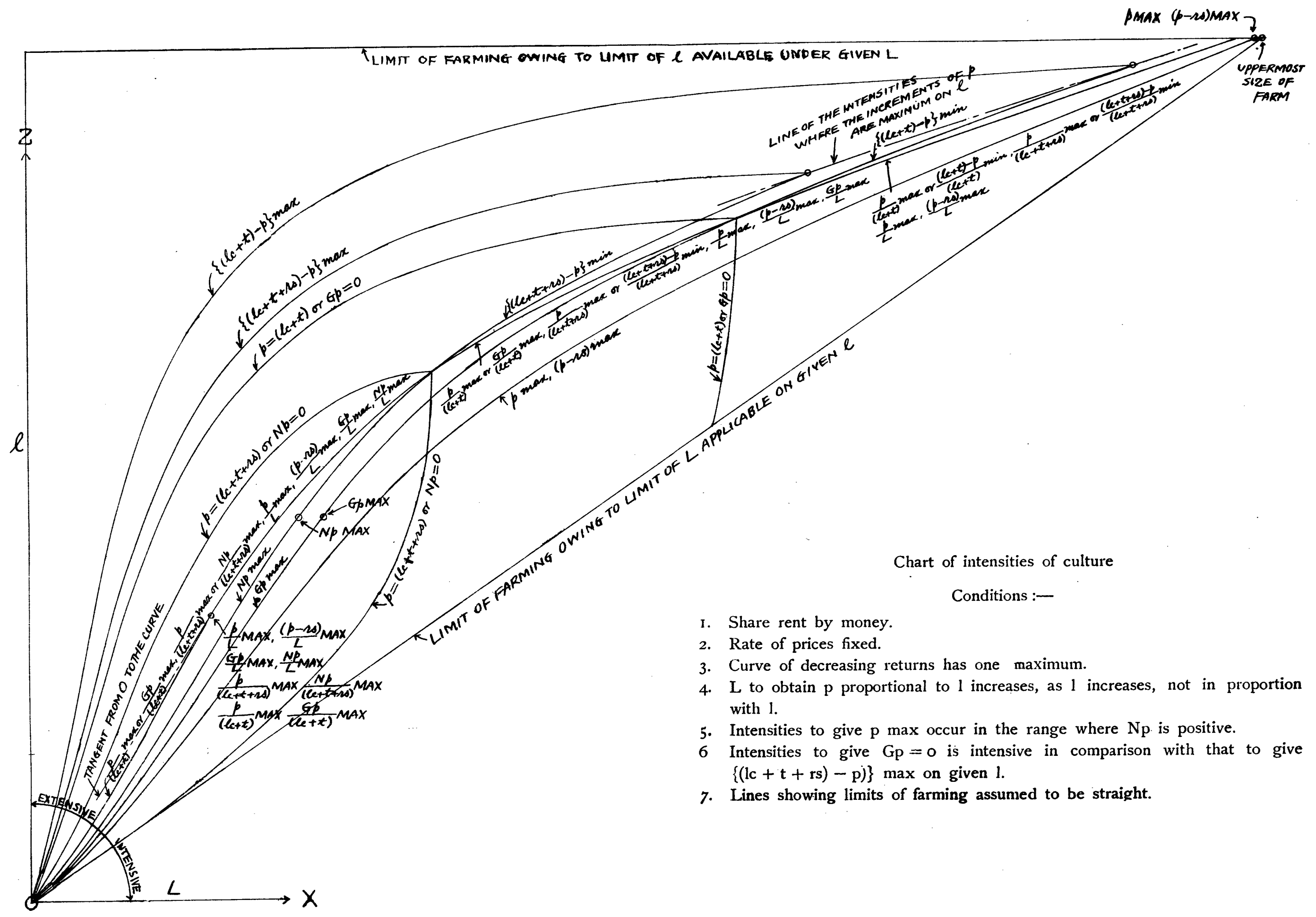


Table showing how to find the proper combination of the production Elements

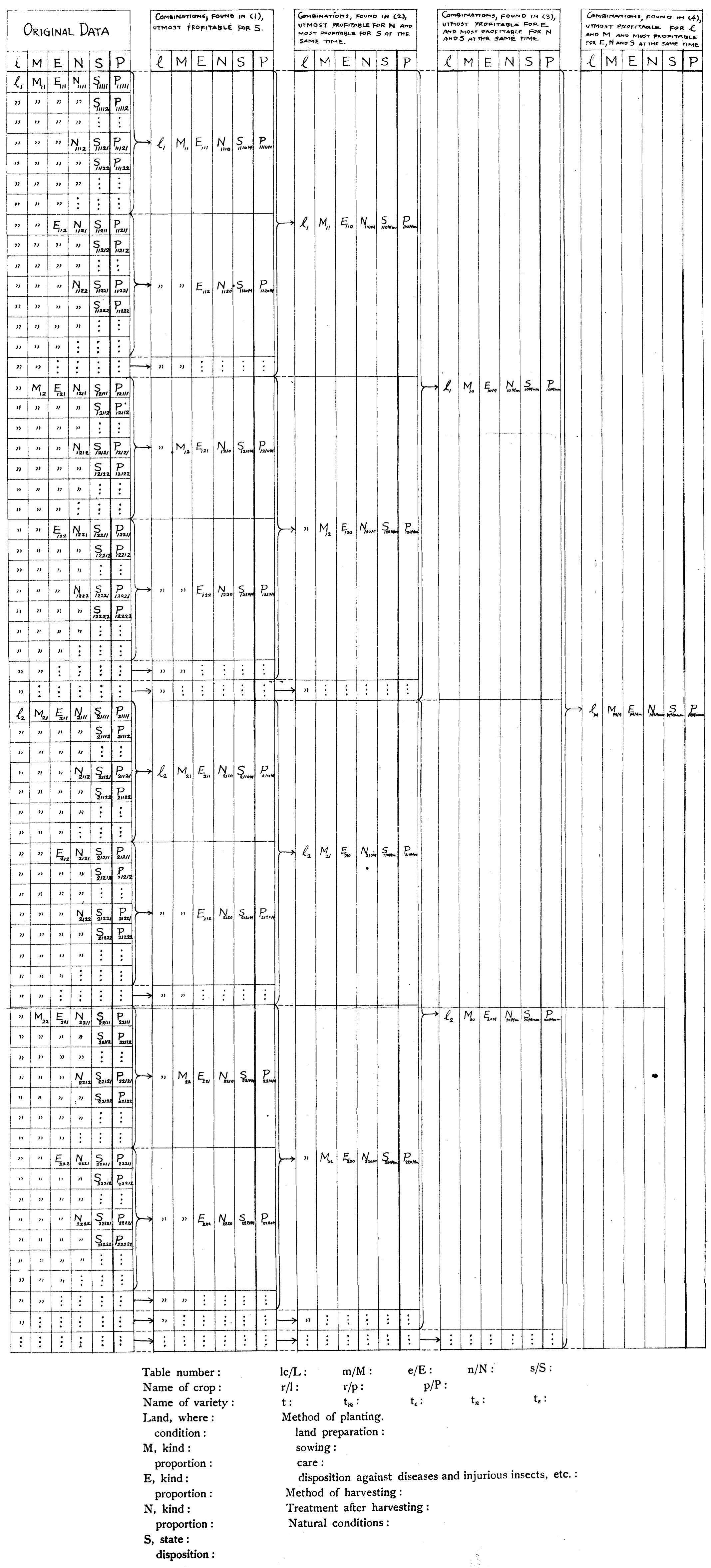

